DUCE, Mauricio. “Una aproximación empírica al uso y prácticas de la prueba pericial en el proceso penal Chileno a la luz de su impacto en los errores del sistema".

Polít. crim. Vol. 13, No 25 (Julio 2018) Art. 2, pp. 42-103.

[http://www.politicacriminal.cl/Vol_13/n_25/Vol13N25A2.pdf]

\title{
Una aproximación empírica al uso y prácticas de la prueba pericial en el proceso penal chileno a la luz de su impacto en los errores del sistema
}

\section{An empirical approach to the use and practices of expert evidence in the Chilean criminal procedure in light of its impact on wrongful decisions of the system}

\author{
Mauricio Duce J. * \\ Magíster en Ciencias Jurídicas Universidad de Stanford, Profesor Titular Facultad de \\ Derecho Universidad Diego Portales \\ mauricio.duce@udp.cl
}

\section{Resumen}

El trabajo presenta los resultados de una investigación cuyo objetivo central es ofrecer una aproximación con base empírica acerca de las prácticas y usos que en nuestro sistema de justicia penal tiene la prueba pericial (con foco en la Región Metropolitana), ello a la luz de su impacto en la producción de decisiones erradas. Los hallazgos dan cuenta que se desarrollan diversas prácticas que han sido descritas en el ámbito comparado como riesgosas desde el punto de vista de aumentar la probabilidad de condenas erróneas, como el uso de prueba de baja confiabilidad y un escaso control de calidad de la misma por litigantes y jueces en distintas instancias procesales. El texto finaliza identificando algunas líneas de trabajo futuro destinadas a minimizar riesgos, las que incluyen: desarrollo de programas de capacitación especializados para los actores del sistema legal, fortalecimiento de especialidades forenses y del trabajo de las comunidades de profesionales expertos y propuestas de reforma legal destinadas a mejorar el control en el uso de esta prueba.

\section{Palabras claves}

Peritos; prueba pericial; condenas erróneas; sistema de justicia criminal.

\begin{abstract}
The paper presents the results of a research oriented to offer an empirically based approach about the practices and uses of expert evidence in our criminal justice system (with focus on the Metropolitan Region), in the light of its impact on wrongful decisions. The findings show several practices that have been described at a comparative level as dangerous in

\footnotetext{
${ }^{*}$ Este trabajo ha sido elaborado en el marco del proyecto Fondecyt Regular $\mathrm{N}^{\circ} 1150073$ "Errores de la justicia penal: investigación empírica y dogmática sobre sus causas en nuestro país y recomendaciones para evitarlos"; Investigador Responsable: Mauricio Duce. El autor agradece el valioso apoyo realizado por los ayudantes del proyecto en sus distintas etapas: Eduardo Alcaíno y Ricardo Lillo. También se agradece el trabajo de los alumnos de la Facultad de Derecho de la Universidad Diego Portales que colaboraron con la transcripción de las entrevistas. Finalmente, agradezco los comentarios y sugerencias realizadas por mis colegas de la Facultad de Derecho de la Universidad Diego Portales en la discusión de un borrador preliminar y de los evaluadores anónimos que revisaron el texto para la Revista Política Criminal.
} 
terms of increasing the likelihood of wrongful convictions, such as, use of evidence of low reliability and scarce control of its quality by the parties and judges en different procedural stages. The paper concludes with the identification of some lines of future work oriented toward minimizing the risks. Those includes: development of specialized training programs to legal actors of the system, strengthening of forensic specialties and the work of professional expert community and proposals of legal reform oriented to improve controls in the use of this evidence.

\section{Key words}

Expert witnesses; expert evidence; wrongful convictions; criminal justice system

\section{Introducción}

La evidencia disponible en el ámbito comparado da cuenta que el uso de la prueba pericial ${ }^{1}$ constituye uno de los factores más relevantes entre aquellos que aumentarían las probabilidades de los sistemas de justicia penal de cometer un error en las decisiones que adoptan. $^{2}$

En este contexto, el trabajo presenta los resultados de una investigación cuyo objetivo central es el de ofrecer una aproximación con base empírica acerca del uso y las prácticas que se desarrollan en nuestro sistema de justicia penal en relación a la prueba pericial (con foco en la Región Metropolitana), complementando así la escasa evidencia existente en

\footnotetext{
${ }^{1}$ Aún cuando me parece se trata de un tema relativamente pacífico en la literatura procesal penal, esclarezco que para los efectos de este trabajo entenderé por prueba pericial aquella que consiste en la presentación de una opinión o conclusión emanada de un experto o perito que ha sido requerida de manera explícita por el sistema de justicia penal y que recae sobre una materia que se encuentra fuera del conocimiento común u ordinario de los encargados de tomar la decisión del caso. Por perito, a su vez, entiendo a la persona que producto de su conocimiento especial o experiencia- está en condiciones de aportar conclusiones o entregar opiniones sobre temas que están fuera de la esfera de conocimiento de los jueces y que el sistema de justicia requiere para resolver los casos que conoce. En la doctrina comparada puede verse, entre otros: ROXIN, Claus, Derecho Procesal Penal, $25^{a}$ Edición, Trad.: CÓRDOBA, Gabriela; PASTOR, Daniel, Buenos Aires: Editores del Puerto, 2003, pp. 238-240; MAIER, Julio, Derecho Procesal Penal, Tomo III Parte General. Actos Procesales, Buenos Aires: Editores del Puerto, 2011, pp. 147-150. En Chile, entre otros: DUCE, Mauricio, La Prueba Pericial, Buenos Aires: Ediciones Didot, 2013, pp. 29-36.

${ }^{2}$ Bajo la noción de errores del sistema se pueden abarcar una gran gama de situaciones. La más evidente es la condena de un inocente (lo que se conoce como falso positivo y en su contracara la absolución de un culpable o falso negativo). Además, la literatura comparada ha venido señalado la necesidad de extender esta noción a casos que dan cuenta de errores del sistema entendidos de una manera más amplia, por ejemplo, cuando aún sin llegar a una condena se lleva adelante un proceso en contra de una persona producto de decisiones equivocadas de los diversos actores del sistema y que con la información disponible en ese momento pudieron haber sido corregidas. En este sentido, como lo plantea Forst, si bien muchos de estos casos no obedecen al mismo problema que aquellos de las condenas de inocentes, especialmente tratándose de las personas que han sufrido privaciones de libertad sin sentencia, las causas que los generan son similares y sus efectos igualmente devastadores. FORST, Brian, "Wrongful Convictions in a World of Miscarriages of Justice", en: HUFF, Ronald; KILliAS, Martin (Eds.), Wrongful Conviction and Miscarriages of Justice: Causes and Remedies in North American and European Criminal Justice Systems, New York: Routledge, 2013, pp. 1543, p.17.
} 
DUCE, Mauricio. “Una aproximación empírica al uso y prácticas de la prueba pericial en el proceso penal Chileno a la luz de su impacto en los errores del sistema".

nuestro medio sobre la materia. El marco de fondo de la investigación es identificar aquellas prácticas que según la experiencia comparada tendrían incidencia en generar decisiones erradas por parte de nuestros fiscales y tribunales de justicia. Se pretende desarrollar, entonces, una descripción que permita detectar problemas concretos que se presentarían en nuestra realidad cotidiana. Ello permitirá luego elaborar recomendaciones de mejora para el futuro tendientes a minimizar el riesgo de decisiones que puedan afectar de manera significativa a las víctimas de las mismas y a la sociedad en su conjunto.

Para estos efectos, el trabajo se basa en una investigación de corte empírico cualitativo basado centralmente en la opinión de un número importante de informantes expertos de nuestro sistema procesal penal. Se trata de opiniones obtenidas por medio de entrevistas semi-estructuradas efectuadas a un total de 52 actores del sistema de justicia penal de la Región Metropolitana, incluyendo a abogados privados (6), defensores penales públicos (8), fiscales del Ministerio Público (13), jueces de garantía (9), jueces de tribunales orales en lo penal (9) y peritos (7). Dichas entrevistas fueron realizadas entre los meses de mayo de 2015 y noviembre de $2016 .^{3}$

Esta metodología, usada de manera principal en esta investigación, permite otorgar mucha fortaleza a hallazgos vinculados a la descripción de prácticas en las que estos observadores expertos son testigos calificados, especialmente cuando surgen patrones comunes y ellos son descritos por actores que cumplen roles institucionales diversos. En cambio, tiene algunos límites en relación con áreas en dónde se relatan percepciones u opiniones y no su experiencia directa. Por lo mismo, se ha hecho un esfuerzo de complementar la investigación en estas materias con la recopilación de otras fuentes que contienen datos relevantes. La primera está constituida por las estadísticas y datos provenientes de las instituciones del sistema, algunos publicados en diversos textos o sitios web de acceso general y otros obtenidos gracias a requerimientos de información específicos realizados por medio de solicitudes de transparencia en el curso del desarrollo de la investigación. La segunda, proviene de los hallazgos obtenidos en dos estudios empíricos exploratorios realizados sobre la base de revisión y análisis sentencias dictadas por Tribunales Orales en lo Penal (en adelante TOP) de la ciudad de Santiago. Ambos elaborados por tesistas de

\footnotetext{
3 En el anexo de este trabajo se aportarán mayores detalles acerca de las características del universo entrevistado y contenidos de la entrevista, pero adelanto que se trató de un $42,3 \%$ de mujeres y un $57,7 \%$ de hombres. También adelanto el tipo de peritos que entrevisté. Tres fueron expertos en el área de la medicina legal (tanatología y sexología forense), tres de la psicología forense y uno en el área de auditoría forense. Los peritos de las dos primeras áreas fueron escogidos debido a la importancia que tiene la prueba pericial en los delitos sexuales y contra la vida, áreas en las que se puso énfasis en la realización de las investigaciones complementarias que este proyecto apoyó. El último perito, en cambio, correspondió a una materia que permitió contrastar realidades en una disciplina diferente. Todos los peritos fueron seleccionados debido a su alta experiencia en el sistema de justicia penal. Para un estudio de esta naturaleza, el total de entrevistados y las diversas categorías de los mismos satisfacen con creces las exigencias metodológicas de este tipo de investigación empírica, donde su foco no está tanto el número de entrevistados sino en su calidad de observadores expertos de la realidad que se pretende indagar. Todos los entrevistados serán citados en género masculino y con un número asignado por rol que desempeñan y la fecha de la entrevista, todo esto con el propósito de salvaguardar su anonimato. Cuando se reproduzcan los contenidos de las entrevistas se lo hará en el lenguaje textual formulado por cada entrevistado de manera de no afectar el sentido de lo que quiso expresar, aún cuando en algunas ocasiones eso lleve a un uso de lenguaje coloquial producto del nivel de confianza adquirido en el desarrollo de la entrevista.
} 
Polít. crim. Vol. 13, № 25 (Julio 2018) Art. 2, pp. 42-103.

[http://www.politicacriminal.cl/Vol_13/n_25/Vol13N25A2.pdf]

magíster cuyo trabajo contó con el apoyo de este proyecto en su desarrollo. El primero incluyó la revisión de todas las sentencias dictadas en el año 2015 por tres TOP de la ciudad de Santiago en materia de delitos sexuales (en adelante "estudio sentencias TOP delitos sexuales"). ${ }^{4}$ El segundo, está constituido por una base de datos en donde se sistematizan las sentencias dictadas por dos TOP de la ciudad de Santiago en el año 2016 en materia de delitos contra la vida e integridad física de las personas (en adelante "base de datos sentencias TOP delitos CVIF"). ${ }^{5}$

Estimo importante enfatizar que, a pesar de la orientación empírica del trabajo, no pretendo entregar una imagen estadísticamente representativa de lo que ocurre en el país y ni siquiera de la Región Metropolitana. Mi propósito es más modesto. Se intenta incrementar en contenido y calidad la información disponible a la fecha en la materia con el objeto de aproximarnos de manera sucesiva a un mejor conocimiento de la realidad nacional. Por lo mismo, con las entrevistas no se busca generalizar las prácticas en cada una de las instituciones a los que pertenecen los entrevistados, sino extraer una imagen con base empírica que permite construir una hipótesis de trabajo fundada. También espero contribuir en otras direcciones, como lo es sensibilizar a nuestra comunidad jurídica sobre estos problemas y así generar el interés por desarrollar nuevas investigaciones en el área que complementen y mejoren los resultados de la presente. Finalmente, espero aportar algunos elementos preliminares para la formulación de propuestas de mejoramiento en aquellas materias que he detectado el sistema presenta mayor debilidad o vulnerabilidad.

Para el cumplimiento de sus objetivos, el trabajo se divide en tres secciones además de esta introducción. En la primera, mi objetivo es dar una visión muy general de los problemas identificados en la literatura comparada acerca de las áreas específicas en donde la prueba pericial incrementa los riesgos de decisiones erróneas del sistema, lo cual servirá de base para la comprensión de los problemas identificados en la realidad nacional. La segunda sección presenta los principales hallazgos obtenidos en la investigación divididos en dos partes. La primera pretende entregar una visión panorámica, basada centralmente en las estadísticas oficiales de las instituciones del sistema, de la cantidad y tipo de prueba pericial

\footnotetext{
${ }^{4}$ Se trató del análisis de 53 sentencias dictadas por el primer, tercer y sétimo tribunales orales en lo penal de Santiago. Ellas corresponden al total de juicios orales por delitos sexuales conocidos por dichos tribunales en el año 2015. Como forma de control de la información, el estudio también implicó la revisión de los registros de audios correspondientes cinco de esos juicios. En lo sucesivo citaré los resultados de esta investigación que no ha sido publicada cómo: SANTIBAÑEZ, Martina, Uso de la prueba pericial en juicio oral de connotación sexual, Santiago: Trabajo final para titulación del Magíster en Derecho Penal y Procesal Penal, Universidad Diego Portales, 2016, pp. 84. Este trabajo no ha sido publicado, pero fue aprobado en el mes de septiembre de 2016 con nota final 6,3 (documento electrónico en poder del autor).

${ }^{5}$ Se trata de una base de 51 sentencias dictadas por el tercer y cuarto tribunales orales en lo penal de Santiago. Ellas correspondieron al total de juicios orales por delitos contra la vida e integridad física conocidos por dichos tribunales el año 2016 y en el que se presentó prueba pericial de algún tipo. Se trata de un trabajo llevado adelante por Juan Ignacio Vásquez, alumno del programa de Magíster de Derecho Penal y Procesal Penal 2016-2017 de la Facultad de Derecho de la Universidad Diego Portales. La base de datos ha sido generada como insumo para la posterior elaboración de su trabajo final de titulación y ha contado con el apoyo del proyecto Fondecyt que financia la presente investigación con el explícito propósito de ser utilizada como una fuente complementaria a este trabajo. Los datos están disponibles en formato electrónico en poder del autor de este trabajo. Se citarán en lo sucesivo sólo en el texto principal.
} 
DUCE, Mauricio. “Una aproximación empírica al uso y prácticas de la prueba pericial en el proceso penal Chileno a la luz de su impacto en los errores del sistema".

que se produce en nuestro país. La segunda identifica y explica los principales hallazgos a partir de las entrevistas realizadas y de otras fuentes complementarias. La última sección del trabajo contiene -a modo de conclusión- algunas sugerencias desarrolladas de manera preliminar para abordar los principales problemas detectados en la investigación.

\section{La prueba pericial y sus riesgos en la producción de errores en el sistema de justicia penal en la experiencia comparada}

Los estudios disponibles en el ámbito comparado sobre condena de inocentes suelen enfatizar que el uso inadecuado de prueba pericial constituye uno de los principales factores que explican los errores del sistema. El país donde más se ha investigado este tema desde una perspectiva empírica es Estados Unidos. Allí, las investigaciones muestran de manera consistente que el uso impropio de esta evidencia constituye uno de los factores de mayor relevancia en ese sentido. ${ }^{6}$ Más allá de este caso, el debate en países provenientes de regiones y tradiciones jurídicas diversas en la materia da cuenta que se trata de un fenómeno bastante general en la justicia criminal contemporánea, por ejemplo, en países como Inglaterra y Gales ${ }^{7}$, Canadá $^{8}$, Alemania ${ }^{9}$ y China. ${ }^{10}$

\footnotetext{
${ }^{6}$ De acuerdo a los datos provenientes del Innocence Project se trata de un factor presente en el $46 \%$ de los casos de personas condenadas en las que se acreditó con posterioridad su inocencia, tan solo por debajo de los reconocimientos oculares errados que sería el aspecto de mayor incidencia. http://www.innocenceproject.org/causes/unvalidated-or-improper-forensic-science/ [Visitado el 02.02.2017]. De acuerdo National Registry of Exonerations (Registro Nacional de Exoneraciones o NRE) Se trataría del cuarto factor en orden de frecuencia estadística, estando presente en un $24 \%$ de los casos, después de acusaciones falsas, mala conducta de agentes de persecución penal y los reconocimientos oculares errados. Véase http://www.law.umich.edu/special/exoneration/Pages/ExonerationsContribFactorsByCrime.aspx [Visitado el 02.02.2017].

${ }^{7}$ Aún cuando en estos países no se cuenta con iniciativas que hayan sistematizado casos de manera similar a la que se ha realizado en los Estados Unidos que permitan dimensionar la escala probable o magnitud estadística del problema, se trata de un tema que ha sido fuertemente discutido por la doctrina e incluso ha generado diversas investigaciones y propuestas de reforma legal por organismos oficiales. Una visión general puede verse en NAUGHTON, Michael, The Innocent and the Criminal Justice System. A Sociological Analysis of Miscarriages of Justice, United Kingdom: Palgrave Macmillan, 2013, pp. 95-105

${ }^{8} \mathrm{El}$ impacto de la prueba pericial en la producción de condenas erróneas en Canadá ha sido tan alto que desde la propia persecución penal se ha abordado como uno de los problemas más relevantes en dos informes realizados por grupos de trabajo de fiscales que han elaborado sendos reportes (2004 y 2011) con el objetivo de prevenirlas. Véase: FPT Heads of Prosecutions Committee Working Group, Report on the Prevention of Miscarriages of Justice, Canadá: Department of Justice, 2004, pp. 115-132; FPT Heads of Prosecutions Committee, The Path to Justice: Preventing Wrongful Convictions, Canadá: FPT Heads of Prosecutions Committee, 2011, pp. 133-159.

${ }^{9}$ La preocupación por este tema ha sido recogida en la doctrina hace más de cincuenta años en este país. En esta dirección, Hirschberg analiza varios casos de condenas erróneas producidos en Alemania que ubica bajo el concepto de "valoración no crítica de los dictámenes periciales", señalando que numerosas sentencias erróneas tienen su principal causa en "...esa fe ciega de los tribunales en el perito, sobretodo en el dictaminador oficial, y en la deficiente instrucción de la mayoría de los jueces y defensores..." Véase: HIRSCHBERG, Max, La Sentencia Errónea en el Proceso Penal, Trad.: BANZHAF, Tomas A., Buenos Aires: Ediciones Jurídicas Europa-América, 1969, pp. 69-92.

10 Jiahong ha llamado recientemente la atención acerca de cómo el incorrecto uso e interpretación de la evidencia científica en dicho país ha sido la causa de condenas erróneas en una serie de casos que analiza en su texto. JIAHONG, He, Back from the Dead: Criminal Justice and Wrongful Convictions in China, Honolulu: University of Hawaii Press, 2016, pp. 31-51.
} 
Polít. crim. Vol. 13, № 25 (Julio 2018) Art. 2, pp. 42-103.

[http://www.politicacriminal.cl/Vol_13/n_25/Vol13N25A2.pdf]

La evidencia comparada ha permitido identificar una serie de problemas en el uso de la prueba pericial que explicarían los riesgos de producir condenas a inocentes. Además, hoy día también existe una literatura importante que da cuenta de algunas dificultades específicas que presenta la evaluación de esta prueba que aumentan sus riesgos. Me detengo muy brevemente en estas dos cuestiones ya que ellas permitirán luego comprender los alcances de los hallazgos de la investigación empírica de la realidad nacional.

\subsection{Principales problemas en el uso de la prueba pericial}

De acuerdo a la evidencia consolidada en el ámbito comparado, cuatro serían los principales problemas en el uso de prueba pericial que aumentan la probabilidad de una condena errónea. El primero estaría constituido por la tendencia de los sistemas de justicia penal de utilizar pruebas periciales de muy baja confiabilidad. Esto se produce generalmente como consecuencia del uso de opiniones expertas fundadas en disciplinas de escaso rigor metodológico o científico o lo que la literatura anglosajona identifica como Junk Science o ciencia basura. ${ }^{11}$ Así, los sistemas de justicia penal parecen recurrir con frecuencia a prueba pericial que es presentada con un aura de rigor científico o metodológico, que realmente no posee y que lleva a los juzgadores a cometer errores en la decisión final. ${ }^{12}$ Sobre este problema existe múltiple evidencia en países como Estados Unidos, ${ }^{13}$ Canadá, ${ }^{14}$ Australia, ${ }^{15}$ e Inglaterra y Gales. ${ }^{16}$

${ }^{11}$ THOMAS, Sabra, "Addressing Wrongful Convictions: An Examination of Texas's New Junk Science Writ and other Measures for Protecting the Innocent", Houston Law Review, n 52 (2015), pp. 1037- 1068, p. 1039. Thomas explica como este término se popularizó en los Estados Unidos a través de un trabajo publicado por Peter Huber el año 1991. En este describió a la ciencia basura como "la imagen del espejo de la ciencia real, con mucho de la misma forma, pero nada de la misma sustancia" (traducción del autor).

${ }^{12}$ Sobre esta materia, un aporte central desde la comunidad científica ha venido del trabajo desarrollado por la Academia Nacional de Ciencias (National Academy of Sciences o NAS) de los Estados Unidos. En el año 2009 el National Research Council de la institución publicó un informe en el que se identificaron serias deficiencias en el trabajo forense en áreas de común uso en los tribunales penales. Dentro de ellas, el análisis de marcas de mordeduras, los análisis microscópicos de pelos, las marcas de huellas de zapatos, la comparación de voces y el uso huellas digitales. El informe establece que se trata de disciplinas que no tienen grados de confiabilidad mínimos, debido al escaso soporte de investigación científica sobre el que se fundan y que permita validar las premisas básicas y las técnicas sobre las cuáles se construyen. National Research Council, Strengthening Forensic Science in the United States: A Path Forward, Washington: The National Academies Press, 2009, pp. 1-33. Disponible en: https://www.ncjrs.gov/pdffiles1/nij/grants/228091.pdf [Visitado el 02.02.2017]. Una visión actualizada del estado del arte de la discusión científica en varias de las materias identificadas en el reporta de la NAS y desde la perspectiva del impacto del uso de la ciencias forenses en las condenas de inocentes puede verse en KOEN, Wendy y BOWERS, Michael, Forensic science reform: protecting the innocent, London: Elsevier, 2017 (el texto contiene análisis en áreas cómo los análisis microscópicos de pelo, incendios, análisis de marcas de mordidas, identificación de armas de fuego, ADN, análisis de sangre, análisis de patrones de manchas de sangre, reconstrucciones de escenas del crimen y análisis de huelas digitales).

${ }^{13}$ Dentro de la múltiple evidencia disponible en este punto sugiero revisar: GARRET, Brandon, Convicting the Innocent: Where Criminal Prosecutions Go Wrong, United States: Harvard University Press, 2011, p. 90.

${ }^{14} \mathrm{ROACH}$, Kent, "Wrongful Convictions: Adversarial and Inquisitorial Themes", North Carolina Journal of International Law and Commercial Regulation, vol. 35, $\mathrm{n}^{\circ} 2$ (2010), pp. 387-446, p. 399.

${ }^{15}$ FRECKELTON, Ian; GOODMAN-DELAHUNTY, Jane; HORAN, Jacqueline, y McKIMMIE, Blake, Expert Evidence and Criminal Jury Trials, Oxford: Oxford University Press, 2016, pp. 31-33. 
DUCE, Mauricio. “Una aproximación empírica al uso y prácticas de la prueba pericial en el proceso penal Chileno a la luz de su impacto en los errores del sistema".

Un segundo problema identificado en la literatura comparada es lo que Garret y Naufeld describen para el contexto de los Estados Unidos como testimonio pericial inválido. ${ }^{17}$ Con este término se refieren a que los peritos, incluso aquellos pertenecientes a disciplinas que no presentan problemas de confiabilidad importante, tienen la tendencia en juicio a realizar afirmaciones y entregar conclusiones que no cuentan con apoyo empírico en su respectiva disciplina. Es decir, el problema se da en la manera en que los expertos reportan e interpretan los resultados obtenidos en sus operaciones al momento de entregar sus testimonios en las audiencias de juicio. ${ }^{18}$ El problema descrito por Garret y Naufeld parece ser un patrón común también en la experiencia comparada, según se puede apreciar en la revisión de casos en países tan diversos como Inglaterra ${ }^{19}$, Canadá, ${ }^{20}$ o China. ${ }^{21}$

Un tercer problema está vinculado al mal comportamiento de los expertos que trabajan para los sistemas de justicia penal. Este problema en realidad cubre dos tipos de comportamientos bastante diferentes. Por una parte, se encuentran las conductas de los peritos deliberadamente orientados a causar un error, lo que incluiría cuestiones como: no dar a conocer al acusado evidencia favorable a su caso; fabricar evidencia forense en su contra; y, presentar la opinión forense de manera de asistir indebidamente al trabajo de las policías o los fiscales. ${ }^{22}$ La evidencia comparada mostraría que no se trataría sólo un

${ }^{16}$ La Law Commission de Inglaterra y Gales ha elaborado el año 2011 una propuesta de reforma legal destinada a elevar los estándares de admisibilidad. Esta, se estructura sobre la base de considerar que un problema frecuente en estos países, y que explica las condenas de inocentes, ha sido el uso de evidencia no confiable por parte de la persecución penal. The Law Commission, Expert Evidence in Criminal Proceedings in England and Wales, London: Stationary Office, Law Com. $\mathrm{N}^{\circ} 325,2011, \mathrm{p} .1$. Disponible en:

https://www.gov.uk/government/uploads/system/uploads/attachment_data/file/229043/0829.pdf [Visitado el 02.02.2017].

${ }^{17}$ GARRET, Brandon; NAUFELD, Peter, "Invalid Forensic Testimony and Wrongful Convictions", Virginia Law Review, vol. 95, $\mathrm{n}^{\circ} 1$ (2009), pp. 1-97, pp. 7-8.

${ }^{18}$ Por ejemplo, en el estudio de estos autores, que recae sobre los casos del Innocent Project, se determina que en el $27 \%$ de los casos en que se presentaron analistas de ADN, una tecnología ampliamente validada en la ciencia, hubo declaraciones inválidas en la audiencia de parte de los expertos que comparecieron. Véase: GARRET / NAUFELD, Invalid Forensic Tesimony, cit. nota ${ }^{\circ} 17$, p. 15. La magnitud del problema les permite identificar que no sólo se trata de un comportamiento común de los peritos en juicio sino una práctica prevalente en los Estados Unidos. GARRET / NAUFELD, Invalid Forensic Tesimony, cit. nota n ${ }^{\circ} 17$, p. 14.

${ }^{19}$ Uno de los casos más conocidos en Inglaterra sobre este tema es el de Sally Clark, quien fuera condenada el año 1999 como autora del homicidio de dos hijos lactantes (Christopher de dos meses en el año 1996 y Harry, también de dos meses, en el año 1998) y luego fue exonerada debido al escaso rigor estadístico de la prueba científica utilizada en su contra. Análisis del caso y sus consecuencias posteriores puede verse en NAUGHTON, The Innocent, cit. nota $\mathrm{n}^{\circ}$, pp. 102-105.

${ }^{20}$ En este país el ejemplo más llamativo ha sido el de los testimonios presentados por el pediatra patólogo forense Dr. Charles Smith en diversos casos. Los problemas detectados en su trabajo como jefe del área en la Provincia de Ontario generaron una investigación oficial cuyo reporte del año 2008 muestra serias falencias en las declaraciones de Smith en 20 de 45 casos revisados, 12 de los cuales resultaron en la condena de los acusados. El informe llama la atención sobre la necesidad de monitorear con más cuidado las declaraciones de los expertos en juicio y poner más atención crítica al lenguaje utilizado por los expertos al expresar sus hallazgos. Información general puede verse en: ROACH, "Wrongful Convictions", cit. nota n 14, pp. 72-73.

21 Buena parte de los casos descritos por Jiahong precisamente se vinculan a errores que suponen afirmaciones de los expertos sin soporte empírico en su disciplina o extendiendo los resultados a hipótesis no aplicables. JIAHONG, Back from the Dead, cit. nota ${ }^{\circ} 10$, pp. 31-42.

${ }^{22}$ NAUGHTON, The Innocent, cit. nota ${ }^{\circ} 7$, p. 65. En el último de estos tres comportamientos inadecuados de los peritos, el asistir indebidamente a la policía o fiscales, se producen intersecciones con el segundo de los problemas descritos, es decir, el de prestar testimonio inválido a juicio. 
Polít. crim. Vol. 13, № 25 (Julio 2018) Art. 2, pp. 42-103.

[http://www.politicacriminal.cl/Vol_13/n_25/Vol13N25A2.pdf]

problema de algunas "manzanas podridas" sino algo un poco más sistémico y, por lo mismo, más extendido. Esto me lleva a un segundo grupo de conductas. Diversos estudios indican que los analistas forenses podrían verse expuestos de manera inadvertida a sesgos importantes por su trabajo para la policía o los fiscales, ${ }^{23}$ producto de fenómenos psicológicos como los "sesgos cognitivos". ${ }^{24}$ Por otra parte, como destaca Edmond, los sesgos de los expertos no sólo se producen de manera consciente, sino que también en muchas ocasiones producto de exponerlos a información irrelevante o prejudicial que no es requerida para elaborar su opinión. Estos sesgos cognitivos inconscientes son igualmente dañinos que los otros, ya que llevan a los peritos a declarar en forma no deliberada cuestiones que están fuera de su disciplina y que podrían influir de manera relevante en la decisión del tribunal. ${ }^{25}$

Un cuarto y último problema en el uso de prueba pericial proviene de las investigaciones realizadas en casos de errores del sistema que no han concluido con la condena de inocentes. Se trata del uso y evaluación tardía de la evidencia experta en las investigaciones penales, en particular por la tardanza en su realización. Por ejemplo, al someter a análisis las evidencias físicas encontradas en los sitios del suceso o en el curso de la investigación. Aparentemente, el problema de fondo estaría en la concepción que habría de las agencias de persecución penal sobre el rol de esta prueba. Así, se comprendería a la prueba pericial como una forma de asegurar una condena de una persona cuya culpabilidad ya creen establecida más que como una herramienta al servicio de la investigación, lo que generaría pocos incentivos para su uso temprano. ${ }^{26}$

\subsection{Dificultades adicionales: la valoración de la prueba pericial}

Los riesgos descritos se ven potenciados en un contexto en el cual la valoración de la prueba pericial presenta desafíos importantes. En efecto, existe una preocupación relevante en la doctrina y jurisprudencia comparada, que cuenta además con respaldo empírico, acerca del riesgo de que jueces y jurados sobrevaloren a la prueba pericial. ${ }^{27} \mathrm{La}$

\footnotetext{
${ }^{23}$ GARRET, Convicting the Innocent, cit. nota $\mathrm{n}^{\circ}$ 13, pp. 92-93. En esta misma línea haciendo un análisis general sobre las influencias y sesgos que desarrollan profesionales forenses que trabajan en laboratorios, véase: SAKS, Michael; SPELLMAN, Barbara, The Psychological Foundations of Evidence Law, New York: New York University Press, 2016, pp. 209-210.

${ }^{24}$ Garret explica que la investigación psicológica muestra que los sesgos cognitivos se producen debido a que nuestras creencias, deseos y esperanzas influyen en las cosas que percibimos, como razonamos y nos comportamos. Esto se traduciría, entre otras cosas, en identificar con fines nobles a nuestro comportamiento. Por ejemplo, cuando la policía cree que atrapa a un culpable está haciendo justicia más allá de la forma con que lo haya hecho. GARRET, Convicting the Innocent, cit. nota ${ }^{\circ} 13$, pp. 266-267. Un análisis de diversas barreras cognitivas para el trabajo policial pude verse en: HARRIS, David, Failed Evidence: Why Law Enforcement Resists Science, New York: New York University Press, 2012, pp. 78-98.

25 EDMOND, Gary, "Expert Evidence in Report and Courts", Australian Journal of Forensic Sciences, vol. $45, \mathrm{n}^{\circ} 3$ (2013), pp. 248-262, pp. 256-257.

${ }^{26}$ GOULD, Jon; CARRANO, Julia; LEO, Richard; HAIL-JARES, Katie, "Innocent Defendants: Divergent Cases Outcomes and What They Teach Us", en: ZALMAN, Marvin; CARRANO, Julia (edit.), Wrongful Conviction and Criminal Justice Reform, New York: Routledge, 2014, pp.73-89, pp. 77-78.

27 El riesgo de sobre evaluación de la prueba pericial sería una de las bases que explicaría, según algunos, el tratamiento especial que tiene la admisibilidad de esta prueba en países como los Estados Unidos.
} 
DUCE, Mauricio. “Una aproximación empírica al uso y prácticas de la prueba pericial en el proceso penal Chileno a la luz de su impacto en los errores del sistema".

preocupación consiste, entonces, que en la práctica se le otorgue un peso más decisivo a la prueba pericial sobre el resto de la evidencia aún cuando no lo merezca. Eso se produciría, entre otros factores, por el aura especial que tiene las opiniones al provenir de expertos o por las dificultades que en ciertas materias se pueden producir para comprender adecuadamente los alcances de esta evidencia. ${ }^{28}$ Por lo mismo, el riesgo es que ella pueda influir indebidamente en decisiones de condenas más allá del valor real que debiera otorgársele. $^{29}$

Un segundo fenómeno, para completar el cuadro que intento describir, se vincula a otro hallazgo en el que pareciera existir consenso en la literatura comparada. De acuerdo a ella, los abogados litigantes tienen baja capacidad para someter a un control intenso de la calidad del trabajo de los peritos y sus declaraciones por vía de la ejecución de contraexamenes. ${ }^{30}$ Por ejemplo, el estudio de Garret y Naulfeld del año 2009 concluye que los defensores raramente cuestionan el testimonio inválido presentado por peritos en juicio y en muy pocas ocasiones realizan contraexámenes exitosos a esos expertos. También encuentran que los defensores presentas fallas al momento de hacerse cargo de esa prueba en los alegatos de apertura y, además, que sólo en un porcentaje menor (19 de 137 casos) presentan expertos que pudieran cuestionar a los de la fiscalía, lo que hace que en la práctica la presentación de prueba pericial sea de un lado solamente. ${ }^{31}$

SCHAUER, Frederick; SPELLMAN, Barbara, "Is Expert Evidence Really Different?", Notre Dame Law Review, vol. 89 (2013), pp. 1-26, pp. 3-4.

${ }^{28}$ En esta dirección Appazov da cuenta que las preocupaciones por este problema pueden incluso encontrarse en la literatura especializada desde mediados del siglo XIX y se traducen en una delegación de facto de las facultades de establecimiento de los hechos en los expertos. APPAZOV, Artur, Expert Evidence and International Criminal Justice, Suiza: Springer, 2016, pp. 21-22.

${ }^{29}$ Así, por ejemplo, un estudio empírico reciente sobre el comportamiento de los jurados muestra que la credibilidad de un peritaje se construye tanto considerando el contenido de la pericia como en las características del experto. Además, que en la ponderación de ambas cuestiones existe mucho margen para considerar elementos que no son los más confiables y relevantes, lo que abre riesgos importantes de llegar a decisiones equivocadas basadas en una incorrecta valoración de esta prueba. FRECKELTON et al., Expert Evidence, cit. nota $\mathrm{n}^{\circ} 15$, pp. 202-203. Por otra parte, existe también evidencia que muestra que los jueces profesionales no presentan diferencias significativas de comprensión de la evidencia que los jurados y, por lo mismo, que lo hacen tan bien o mal como ellos. Véase: SAKS / SPELLMAN, The Psychological Foundations, cit. nota $\mathrm{n}^{\circ} 23$, p. 217.

30 Citando diversos estudios sobre la capacidad real de cuestionar prueba pericial por medio de contraexámenes, Edmond concluye: "Más que un vehículo o motor capaz de exponer las debilidades y descubrir la verdad, los efectos de los contraexámenes son inconsistentes y a menudo mundanos." EDMOND, "Expert Evidence", cit. nota n 25, p. 184.

${ }^{31}$ GARRET / NAUFELD, Invalid Forensic Tesimony, cit. nota $n^{\circ}$ 17, pp. 89-90. En el estudio de Garret del año 2011 se repiten hallazgos similares. Por ejemplo, en un 50\% del total de casos en donde se prestó un testimonio inválido de parte del perito los defensores ni siquiera realizaron una pregunta en el área en donde hubo testimonio erróneo. Esto lo lleva a concluir que no se puede depender exclusivamente del proceso adversarial como forma de impedir los errores generados por el uso de la prueba pericial. GARRET, Convicting the Innocent, cit. nota $\mathrm{n}^{\circ} 13$, pp. 113-114. En una dirección similar el reporte de la Academia Nacional de Ciencias de los Estados Unidos ha concluido que debido a las serias falencias que presentan jueces y abogados para lidiar con la presentación y evaluación de evidencia forense, los controles del sistema legal no son suficientes para corregir todos los problemas. National Research Council, Strengthening Forensic cit. nota $n^{\circ} 12$, p. 53. En Australia, una reciente investigación empírica sobre juicios orales llevados ante jurados concluye, respecto a las prácticas de los abogados en casos de presentación de evidencia de ADN, que: "El hecho que expertos de la fiscalía presentando perfiles de ADN sean raramente cuestionados con éxito por defensores hábiles en los contraexámenes sirve para reforzar la percepción que este tipo de 
Polít. crim. Vol. 13, No 25 (Julio 2018) Art. 2, pp. 42-103.

[http://www.politicacriminal.cl/Vol_13/n_25/Vol13N25A2.pdf]

Por otra parte, también existe bastante información que muestra los límites que tiene la presentación de peritajes de refutación como mecanismo de control de la prueba pericial de incriminación. ${ }^{32}$

La suma de ambos fenómenos descritos, mayor peso en la práctica de este tipo de prueba y menor capacidad de control de su calidad por parte de los abogados y actores del sistema legal, generan el riesgo de resolver erróneamente si se ha presentado prueba pericial poco confiable, si los peritos prestan testimonio inválido, o si se comportan derechamente mal.

Teniendo presente estos aportes provenientes de la literatura y experiencia comparada propongo que revisemos a continuación la realidad nacional.

\section{Prueba pericial en el proceso penal chileno: una descripción de su uso y prácticas}

Como se adelantó en la introducción, el presente capítulo está destinado a presentar los principales hallazgos obtenidos durante esta investigación. En la primera parte entregaré una visión panorámica acerca del uso de prueba pericial en la justicia penal en nuestro país, fundamentalmente a partir de los datos estadísticos disponibles. En la segunda describiré los principales hallazgos acerca de las prácticas problemáticas detectadas partir de las entrevistas efectuadas, apoyados con la información proveniente de otras fuentes complementarias cuando corresponda.

\subsection{Una visión panorámica acerca del uso de la prueba pericial en Chile a partir de las estadísticas institucionales}

Uno de los factores que asoma en el ámbito comparado como una constante, en relación al uso de la prueba pericial en los procesos penales, es su uso cada más masivo. Por lo mismo, una primera cuestión que me interesó indagar es la cantidad y tipo de prueba pericial que producen las principales instituciones públicas que trabajan en el sistema. ${ }^{33}$ Para estos efectos recurrí a las estadísticas oficiales publicadas por estos organismos o, en caso de no encontrar dichos datos, realicé solicitudes de acceso a la información pública bajo el procedimiento establecido por la denominada Ley de Transparencia. Esto me permitió

expertizaje es inviolable." FRECKELTON et al., Expert Evidence, cit. nota $n^{\circ} 15$, p. 198. (Traducción del autor).

${ }^{32}$ Estos límites tienen que ver con las dificultades que normalmente enfrentan las defensas para conseguir en ciertas áreas expertos de calidad dispuestos a dar testimonios que contradigan a otros expertos; con sesgos en los jueces al valorar a estos expertos; y, finalmente, con las dificultades que tiene cuestionar efectivamente evidencia experta de dudosa calidad cuando ella se inserta a una narrativa coherente y más compleja como la que suelen presentar los fiscales en juicio. EDMOND, Gary, "Actual Innocents? Legal Limitations and Their Implications for Forensic Science and Medicine", Australian Journal of Forensic Sciences, vol. 43, n 2-3 (2011), pp. 177-212, pp.184-186.

${ }^{33}$ Solicité información a las tres instituciones que se esperaría produzcan mayor cantidad de prueba pericial: las policías (Carabineros e Investigaciones), el Servicio Médico Legal y el Instituto de Salud Pública. A ellos agregué el trabajo realizado en la materia por la Defensoría Penal Pública que destina fondos propios para producir prueba pericial por fuera de las agencias estatales anteriores. 
DUCE, Mauricio. “Una aproximación empírica al uso y prácticas de la prueba pericial en el proceso penal Chileno a la luz de su impacto en los errores del sistema".

contar con datos acerca del número de peritajes producidos entre los años 2013 a 2015 y en la mayoría de los casos su tipo específico. Cabe destacar que es frecuente que opiniones expertas provengan de funcionarios públicos que trabajan en reparticiones no especializadas del sistema (vgr. los servicios de salud pública) o derechamente de instituciones privadas, las cuáles no son consideradas en estos datos y tienen el efecto de incrementar el número de peritajes que consigno de manera muy significativa. ${ }^{34}$ Por otra parte, es necesario recordar que el hecho de que se haya encargado un peritaje en el proceso judicial no significa que luego se haya necesariamente transformado en prueba en juicio oral. Por el contrario, me parece pacífico asumir que sólo un porcentaje menor del total de peritajes encargados a las respectivas instituciones se transforma en prueba en un juicio oral ordinario o simplificado. ${ }^{35}$

Aclarado el contexto, parto por mostrar la información obtenida de Carabineros de Chile (en adelante Carabineros) y la Policía de Investigaciones de Chile (en adelante PDI). La tabla $n^{\circ} 1$ presenta los resultados de los peritajes realizados por ambas instituciones entre los años 2013 a 2015.

Tabla $n^{\circ} 1$

Peritajes producidos por instituciones policiales años 2013-2015

\begin{tabular}{|l|r|r|r|}
\hline Institución & Año 2013 & Año 2014 & Año 2015 \\
\hline PDI & 32.859 & 35.401 & 36.132 \\
\hline Carabineros & 23.395 & 23.898 & 25.728 \\
\hline Total & $\mathbf{5 6 . 2 5 4}$ & $\mathbf{5 9 . 2 9 9}$ & $\mathbf{6 1 . 8 6 0}$ \\
\hline
\end{tabular}

La tabla muestra diversas cuestiones. La primera es que la PDI produce una mayor cantidad de peritajes que Carabineros (alrededor de un 30\% en el período). Lo segundo es que ellas dan cuenta cómo efectivamente se ha ido produciendo un aumento en el número total de pericias practicadas por ambas instituciones, en un contexto en el que en el mismo período al ingreso de casos al sistema de justicia penal se ha mantenido estable e incluso con una pequeña baja. ${ }^{37}$ Esto indicaría que efectivamente el sistema está haciendo un esfuerzo por

\footnotetext{
${ }^{34}$ El propio Código Procesal Penal regula en sus artículos 198 a 199 bis que los peritajes en el área de los exámenes médicos en delitos sexuales, exámenes médicos generales y autopsias y exámenes y pruebas de ADN pueden ser llevados adelante por el Servicio Médico Legal o por hospitales, clínicas, establecimientos de salud y semejantes sean públicos o privados.

35 Hay al menos dos factores que explican esto. El primero es que en muchos de los casos en los que se solicita un peritaje no concluyen con sentencia sino por una salida previa. En segundo lugar, muchos de los peritajes solicitados en casos que sí son objeto de algún tipo de juicio y concluyen con sentencia no son presentados como prueba en los mismos. No existen datos disponibles que indiquen la magnitud estadística exacta de ambos efectos, pero considerando la dinámica de funcionamiento del sistema es muy probable que ellos representen el mayor número de prueba pericial requerida por los actores del sistema.

${ }^{36}$ Fuente: elaboración propia sobre datos proporcionados por PDI y Carabineros de Chile. Información entregada por comunicación electrónica gracias a requerimientos de acceso a información pública disponibles en formato digital en poder del autor. La información de la PDI fue enviada con fecha 11 de agosto de 2016 y la de Carabineros de Chile 6 de septiembre de 2016.

${ }^{37}$ En efecto, de acuerdo con las cifras proporcionadas por el Ministerio Público, el total de delitos ingresados el año 2013 fue de 1.343.570 y el año 2015 de 1.332.238. Ministerio Público de Chile, Boletín Estadístico Anual 2013, Santiago: Ministerio Público de Chile, 2014, p. 4, en:
} 
Polít. crim. Vol. 13, No 25 (Julio 2018) Art. 2, pp. 42-103.

[http://www.politicacriminal.cl/Vol_13/n_25/Vol13N25A2.pdf]

mejorar la calidad probatoria a partir de un mayor uso de este tipo de pruebas. Como ya señalé, debe tenerse presente que estos totales no significan que se trate luego de prueba pericial presentada efectivamente a juicio.

Me parece interesante mirar los datos de manera desagregada para comprender mejor qué es lo que existe al interior de los totales. Lamentablemente, se trata de información que pude obtener sólo de Carabineros. La tabla $n^{\circ} 2$ presenta los resultados del año 2015 divididos en las 16 categorías en que me fueron acompañados. Luego, agrego una columna que muestra el porcentaje que ese número representa dentro del total de peritajes de ese mismo año. Los porcentajes son similares a las de los años 2013 y 2014 por lo que no incorporo dichos datos en la tabla para hacerla más sencilla en su lectura.

Tabla $\mathrm{n}^{\circ} 2$

Peritajes producidos por Carabineros de Chile año $2015^{38}$

\begin{tabular}{|l|c|c|}
\hline Tipo peritaje & $\mathbf{N}^{\circ}$ año 2015 & \% del total \\
\hline Química forense & 3.442 & $13,3 \%$ \\
\hline Genética forense & 506 & $1,9 \%$ \\
\hline Informática forense & 835 & $3,2 \%$ \\
\hline Antropológico & 0 & $0 \%$ \\
\hline Balístico & 6.401 & $24,8 \%$ \\
\hline Documental & 1.887 & $7,3 \%$ \\
\hline Huellas & 2.773 & $10,7 \%$ \\
\hline Incendio & 472 & $1,8 \%$ \\
\hline Médico criminalístico & 62 & $0,2 \%$ \\
\hline Propiedad intelectual & 1.365 & $5,3 \%$ \\
\hline Psicológico & 0 & $0 \%$ \\
\hline Reconstitución de escena & 63 & $0,2 \%$ \\
\hline Sitio suceso & 4.678 & $18,1 \%$ \\
\hline Otros & 2.357 & $9,1 \%$ \\
\hline Entomología & 28 & $0,1 \%$ \\
\hline Biología & 859 & $3,3 \%$ \\
\hline Total & $\mathbf{2 5 . 7 2 8}$ & $\mathbf{1 0 0 \%}$ \\
\hline
\end{tabular}

Se observa una gran dispersión entre las distintas categorías en donde destaca como principal los peritajes balísticos. Llama la atención que un porcentaje no despreciable de ellos parecen estar dedicados a realizar actividades de investigación de orden técnico, pero que no necesariamente luego se transforman en una prueba pericial que pueda ser utilizada en esa calidad en un proceso. En esta categoría se encuentran, por ejemplo, los sitio del

http://www.fiscaliadechile.cl/Fiscalia/estadisticas/index.do?d1=0 [Visitado el 02.02.2017]; Ministerio Público de Chile, Boletín Estadístico Anual Enero-Diciembre 2015, Santiago: Ministerio Público de Chile, 2016, p. 8, en: http://www.fiscaliadechile.cl/Fiscalia/estadisticas/index.do?d1=0 [Visitado el 02.02.2017].

${ }^{38}$ Fuente: elaboración propia sobre datos proporcionados por Carabineros de Chile. Información entregada el 6 de septiembre de 2016 por comunicación electrónica gracias a requerimiento de acceso a información pública disponibles en formato digital en poder del autor. 
DUCE, Mauricio. “Una aproximación empírica al uso y prácticas de la prueba pericial en el proceso penal Chileno a la luz de su impacto en los errores del sistema".

suceso que representan el $18,18 \%$ del total. Por otra parte, también llama la atención la importante presencia estadística de los peritajes de huellas $(10,77 \%)$ que, como señalé, han sido objeto de cuestionamientos en el ámbito comparado. ${ }^{39}$ Por su parte, los peritajes provenientes de áreas científicas en su conjunto no superarían el 20\% del total (incluyendo química, genética, medicina, biología). En la contracara, se puede apreciar que peritajes médico criminalísticos $(0,2 \%)$ y psicológicos $(0 \%)$ son marginales, por lo que su realización queda entregada preferentemente al trabajo de otras instituciones del sistema.

La segunda institución a la que se le requirió información fue al Servicio Médico Legal (en adelante SML). Por el rol especializado que cumplen para el sistema de justicia penal, lo esperable sería que esta institución sea la principal proveedora de conocimiento experto. La tabla $n^{\circ} 3$ resume la cantidad de peritajes elaborados desagregados por las ocho categorías en que fue enviada la información entre los años 2013 a 2015 con el porcentaje del tipo de peritaje dentro del año respectivo.

Tabla $\mathrm{n}^{\circ} 3$

Peritajes producidos por el Servicio Médico Legal años 2013-2015

\begin{tabular}{|l|c|c|c|}
\hline Tipo peritaje & Año 2013 (\%) & Año 2014 (\%) & Año 2015 (\%) \\
\hline Laboratorios & $190.503(79,7 \%)$ & $196.042(80,7 \%)$ & $194.319(81,5 \%)$ \\
\hline Lesionología forense & $21.317(8,9 \%)$ & $20.552(8,4 \%)$ & $18.730(7,8 \%)$ \\
\hline Psiquiátrico adulto & $2.733(1,1 \%)$ & $2.529(1,0 \%)$ & $2.239(0,9 \%)$ \\
\hline Psiquiátrico infantil & $343(0,1 \%)$ & $293(0,1 \%)$ & $241(0,1 \%)$ \\
\hline Psicológico adulto & $2.913(1,2 \%)$ & $3.267(1,3 \%)$ & $3.370(1,4 \%)$ \\
\hline Psicológico infantil & $793(0,3 \%)$ & $848(0,3 \%)$ & $949(0,4 \%)$ \\
\hline Sexológico & $8.144(3,4 \%)$ & $6.763(2,7 \%)$ & $6.182(2,6 \%)$ \\
\hline Tanatológico & $12.220(5,1 \%)$ & $12.435(5,1 \%)$ & $12.576(5,2 \%)$ \\
\hline \multicolumn{1}{|c|}{ Total (100\%) } & $\mathbf{2 3 8 . 9 6 6}$ & $\mathbf{2 4 2 . 7 2 9}$ & $\mathbf{2 3 8 . 2 4 6}$ \\
\hline
\end{tabular}

Como era de esperarse, los datos muestran que el total de peritajes producidos por el SML es superior al de ambas policías en su conjunto, llegando a cerca de cuatro veces más en cada año. Con todo, a diferencia de las policías, el número total de pericias se mantiene estable e incluso con una pequeña baja entre los años 2013 a 2015, lo que sería consistente con los datos de ingreso del sistema ya revisados y podría indicar que con los recursos disponibles a esa fecha la institución había alcanzado un cierto tope en su capacidad de producir peritajes. A pesar de eso, se aprecian disminuciones por sobre la tendencia general en los peritajes de lesiones y sexológicos. En cambio, se produce un aumento en los psicológicos. Eso es consistente como veremos un poco más adelante respecto al peso que tendría este tipo de peritajes en los delitos sexuales.

\footnotetext{
${ }^{39}$ National Research Council, Strengthening Forensic, cit. nota $\mathrm{n}^{\circ} 12$, pp. 1-33 y BRIGHT-BIRNBAUM, Kathleen, "The fingerprint expert: do you really have one?", en KOEN, Wendy y BOWERS, Michael, Forensic science reform: protecting the innocent, London: Elsevier, 2017, pp. 338-361.

${ }^{40}$ Fuente: elaboración propia sobre datos proporcionados el SML Información entregada el 24 de agosto de 2016 por vía de comunicación electrónica gracias a requerimientos de acceso a información pública disponibles en formato digital en poder del autor.
} 
Polít. crim. Vol. 13, No 25 (Julio 2018) Art. 2, pp. 42-103.

[http://www.politicacriminal.cl/Vol_13/n_25/Vol13N25A2.pdf]

Respecto al tipo de pericias, se puede observar que las realizadas por laboratorios representan la gran mayoría. Así, el año 2015 representaron el 81,56\% de los peritajes. Se trata de la categoría que por lejos es mayoritaria y, por lo mismo, resulta conveniente mirar cómo se integra. La tabla $\mathrm{n}^{\circ} 4$ desagrega estos peritajes en las cinco categorías que organiza el SML para el año 2015.

Tabla $n^{\circ} 4$

Peritajes de laboratorios producidos por el Servicio Médico Legal año $2015^{41}$

\begin{tabular}{|l|c|c|}
\hline Tipo de peritaje & Año 2015 & \% año 2015 \\
\hline Alcoholemia & 136.732 & $70,36 \%$ \\
\hline Toxicología & 28.587 & $14,71 \%$ \\
\hline Bioquímica & 6.322 & $3,25 \%$ \\
\hline Genética & 21.311 & $10,96 \%$ \\
\hline Histología & 1.367 & $0,70 \%$ \\
\hline Total & $\mathbf{1 9 4 . 3 1 9}$ & $\mathbf{1 0 0 \%}$ \\
\hline
\end{tabular}

Dentro de los peritajes producidos por laboratorios, la gran mayoría (más del 70\%) son las alcoholemias. Con porcentajes mucho más bajos aparecen los exámenes toxicológicos y genéticos.

Junto con los datos anteriores, solicité también información al Instituto de Salud Pública (en adelante ISP) encargado de analizar las muestras de drogas incautadas en las investigaciones penales. La tabla $\mathrm{n}^{\circ} 5$ resume los resultados de las muestras informadas por dicha institución a las instituciones del sistema de justicia penal entre los años 2013 a 2015.

Tabla $\mathrm{n}^{\circ} 5$

Peritajes producidos por el Instituto de Salud Pública años 2013-2015 ${ }^{42}$

\begin{tabular}{|c|c|}
\hline Año & Número \\
\hline 2013 & 44.870 \\
\hline 2014 & 27.204 \\
\hline 2015 & 27.737 \\
\hline
\end{tabular}

La observación más relevante de estos es la baja significativa de muestras informadas entre el año 2013 y el 2014 ya que luego la cifra se mantiene estable el 2015 en relación al año anterior. Según los datos del Ministerio Público el total de delitos ingresados por ley de

\footnotetext{
${ }^{41}$ Fuente: elaboración propia sobre datos proporcionados el SML. Información entregada el 24 de agosto de 2016 por vía de comunicación electrónica gracias a requerimientos de acceso a información pública disponibles en formato digital en poder del autor.

42 Fuente: elaboración propia sobre datos proporcionados el ISP. Información entregada por comunicación electrónica el 20 de julio de 2016 gracias a requerimientos de acceso a información pública disponibles en formato digital en poder del autor. La información registra el número como "muestras informadas" no como peritajes.
} 
DUCE, Mauricio. “Una aproximación empírica al uso y prácticas de la prueba pericial en el proceso penal Chileno a la luz de su impacto en los errores del sistema".

drogas entre los años 2013 a 2015 se habría incrementado pasando de 18.429 a $23.827^{43}$ y eso debiera llevar naturalmente al aumento del trabajo del ISP y no a una disminución. No tengo una explicación precisa de este comportamiento contradictorio. Con todo, lo más probable es que ello obedecería a un cambio de políticas producida en el período acerca del tipo de muestras serían objeto de análisis. ${ }^{44}$

Asumiendo que los peritajes e informes producidos por las instituciones anteriormente expuestas debieran, por regla general, estar al servicio de los requerimientos de la persecución penal, también me pareció de interés indagar el trabajo de la Defensoría Penal Pública (en adelante DPP) en esta materia. Esta institución cuenta desde sus inicios con un presupuesto especial asignado precisamente a la producción de peritajes. La tabla $n^{\circ} 6$ resume la cantidad de peritajes y el presupuesto invertido por la institución en el período 2013 a 2015.

Tabla $n^{\circ} 6$

Peritajes producidos a solicitud de DPP y presupuesto invertido en ellos años 2013-2015 45

\begin{tabular}{|l|c|c|}
\hline Año & $\mathbf{N}^{\circ}$ peritajes & Presupuesto (en M\$) \\
\hline 2013 & 8.030 & $\$ 849.599$ \\
\hline 2014 & 9.061 & $\$ 1.022 .360$ \\
\hline 2015 & 11.319 & $\$ 1.247 .341$ \\
\hline
\end{tabular}

Se puede observar en el período un importante aumento de cerca de $41 \%$ de los peritajes realizados y de más de $46 \%$ del presupuesto. Esto daría cuenta de un enorme esfuerzo institucional en la materia, aún cuando se trataría de un número muy inferior en comparación con el total de peritajes sumados de las instituciones anteriormente revisadas. La tabla $\mathrm{n}^{\circ} 7$ contiene el datos desagregado en once categorías que utiliza la DPP en el período, se agrega el porcentaje dentro del total de cada año.

Tabla $\mathrm{n}^{\circ} 7$

Tipos de peritajes producidos a solicitud de DPP años 2013-2015

\footnotetext{
${ }^{43}$ Ministerio Público de Chile, Boletín 2013, cit. nota n 37, p. 4; Ministerio Público de Chile, Boletín 2015, cit. nota $\mathrm{n}^{\circ} 37$, p. 8.

${ }^{44}$ Esta explicación surge de conversaciones con diversos actores del sistema que he tenido fuera de las entrevistas. El cambio de política consistiría en no enviar muestras en casos que las drogas incautadas no superaran un cierto pesaje mínimo. Ello habría tenido un impacto en una disminución drástica en un escenario previo en que toda droga incautada, no importando su cantidad, generaba una muestra para su examen por esta institución.

${ }^{45}$ Fuente: elaboración propia sobre datos publicados por la DPP en sus cuentas anuales 2013, 2014 , y 2015. Defensoría Penal Pública, Memoria 2013, Santiago: Defensoría Penal Pública, 2013, pp. 62, 240, en: http://www.dpp.cl/resources/upload/files/documento/3a11ed0c600a87c84d4b07eaffc937c3.pdf [Visitado el 02.02.2017]; Defensoría Penal Pública, Memoria 2014, Santiago: Defensoría Penal Pública, 2014, pp. 72-74, 235, en:

http://www.dpp.cl/resources/upload/files/documento/3a11ed0c600a87c84d4b07eaffc937c3.pdf [Visitado el 02.02.2017]; Defensoría Penal Pública, Memoria 2015, Santiago: Defensoría Penal Pública, 2015, pp. 68-70, 258, en:

http://www.dpp.cl/resources/upload/files/documento/c3b8389eb0ae9ec02148e4225368f58b.pdf [Visitado el 02.02.2017].
} 
Polít. crim. Vol. 13, № 25 (Julio 2018) Art. 2, pp. 42-103.

[http://www.politicacriminal.cl/Vol_13/n_25/Vol13N25A2.pdf]

\begin{tabular}{|l|c|c|c|}
\hline Tipo de peritaje & Año 2013 (\%) & Añ 2014 (\%) & Año 2015 (\%) \\
\hline Antropológico & $23(0,2 \%)$ & $17(0,1 \%)$ & $36(0,3 \%)$ \\
\hline Asistente social & $4.473(55,7 \%)$ & $5.314(58,6 \%)$ & $6.791(60,0 \%)$ \\
\hline Balístico & $17(0,2 \%)$ & $15(0,1 \%)$ & $25(0,2 \%)$ \\
\hline Investigación criminalística & $563(7,0 \%)$ & $629(6,9 \%)$ & $743(6,5 \%)$ \\
\hline Investigación accidentes & $51(0,6 \%)$ & $37(0,4 \%)$ & $48(0,4 \%)$ \\
\hline Médico legista & $70(0,8 \%)$ & $56(0,6 \%)$ & $70(0,6 \%)$ \\
\hline Psicológico & $1.980(24,6 \%)$ & $2.247(24,8 \%)$ & $2.669(23,5 \%)$ \\
\hline Psiquiátrico & $466(5,8 \%)$ & $338(3,7 \%)$ & $478(4,2 \%)$ \\
\hline Toxicológico & $222(2,7 \%)$ & $255(2,8 \%)$ & $309(2,7 \%)$ \\
\hline Urólogo & $9(0,1 \%)$ & $1(0,0 \%)$ & $1(0,0 \%)$ \\
\hline Otros & $156(1,9 \%)$ & $102(1,1 \%)$ & $149(1,3 \%)$ \\
\hline Total & $\mathbf{8 . 0 3 0}$ & $\mathbf{9 . 0 6 1}$ & $\mathbf{1 1 . 3 1 9 ( 1 0 0 \% )}$ \\
\hline
\end{tabular}

La tabla permite apreciar que por lejos la actividad que representa el mayor porcentaje de trabajo es la realizada por asistentes sociales (casi 60\% el año 2015) y, además, se ha ido incrementando en el período. Si a ello se le suman otras categorías, como la de investigación criminalística, tenemos que cerca de dos tercios del total podrían corresponder a actividades técnicas de investigación y no necesariamente a operaciones que se vayan a traducir en prueba pericial en el juicio oral. Es decir, se produciría un fenómeno similar pero intensificado al identificado tratándose de las policías. En cambio, dentro de las categorías donde se puede asumir razonablemente que estos sí producirán prueba pericial, claramente destaca el área psicológica con porcentajes entre $23 \%$ y $24 \%$ del total en el período. Esto volvería a ratificar la importancia que ha ido adquiriendo este tipo de prueba también en otras instituciones.

El estudio empírico exploratorio de estudio sentencias TOP delitos sexuales, descrito anteriormente, ayuda a poner estos datos en el contexto del uso concreto de la prueba pericial en juicios orales. De acuerdo a los datos que entrega el estudio, ${ }^{47}$ en un $87 \%$ de ellos se presenta prueba pericial. Se trataría de 128 pericias presentadas cuya gran mayoría sería del Ministerio Público. En efecto, se trataría de 115 peritajes emanados de esa parte, cuyo promedio por juicio sería de 2,5 por caso. ${ }^{48}$ La tabla $n^{\circ} 8$ contiene de manera resumida las principales categorías de peritajes identificados en este estudio. He simplificado la tabla original agrupando algunos de ellos en una categoría de otros.

\footnotetext{
${ }^{46}$ Fuente: elaboración propia sobre datos publicados por la DPP en sus cuentas anuales 2013, 2014, y 2015.

${ }^{47}$ Como señalé en la introducción, el estudio abarcó las sentencias dictadas por el primer, tercer y séptimo tribunal oral en lo penal de Santiago, identificando 53 juicios por delitos sexuales en los mismos en el año 2015. En un $62,2 \%$ se trató de casos por abuso sexual, en 9,4\% de violación y 28,3\% incluyó ambos delitos. SANTIBAÑEZ, Uso de la Prueba Pericial, cit. nota ${ }^{\circ} 4$, p. 27.

48 SANTIBAÑEZ, Uso de la Prueba Pericial, cit. nota $\mathrm{n}^{\circ}$ 4, pp. 30-31. La defensa habría presentado 12 peritajes, equivalente a un 26,6\% del total de casos en donde hubo prueba pericial del Ministerio Público, y la parte querellante sólo uno en un universo de 13 casos en los que hubo querellante.
} 
DUCE, Mauricio. “Una aproximación empírica al uso y prácticas de la prueba pericial en el proceso penal Chileno a la luz de su impacto en los errores del sistema".

Tabla $\mathrm{n}^{\circ} 8$

Tipos de peritajes presentados en juicios por delitos sexuales ${ }^{49}$

\begin{tabular}{|c|c|c|}
\hline Tipo peritaje & $\mathbf{N}^{\circ}$ & $\%$ \\
\hline Psicológico & 62 & $48,4 \%$ \\
\hline Sexológico & 26 & $20,3 \%$ \\
\hline Psiquiátrico & 9 & $7,03 \%$ \\
\hline Bioquímico & 8 & $6,25 \%$ \\
\hline Químico & 7 & $5,46 \%$ \\
\hline Asistente social & 5 & $3,98 \%$ \\
\hline Informático & 3 & $2,34 \%$ \\
\hline $\operatorname{Otros}^{50}$ & 8 & $6,25 \%$ \\
\hline Total & 128 & $100 \%$ \\
\hline
\end{tabular}

Como se puede apreciar, la gran mayoría de peritajes son de carácter psicológico y psiquiátrico, los que considerados en su conjunto representan más de un $55 \%$ del total. Su agrupación como una sola categoría es posible de hacer ya que el estudio identifica que la gran mayoría de ambos tipos de peritajes, independiente del profesional que lo realice, recaen en dos cuestiones: peritajes de credibilidad y de daño (o ambos a la vez). ${ }^{51}$ Muy por debajo se encuentran los peritajes sexológicos y el resto de las categorías aparece con porcentajes bastante marginales. Cabe señalar que un porcentaje mayoritario de los peritajes presentados recaerían sobre materias, por ejemplo los denominados peritajes de credibilidad $^{52}$, cuya confiabilidad científica es objeto de enorme discusión en la comunidad científica y legal comparada. ${ }^{53}$

La base de datos sentencias TOP delitos CVIF muestra resultados similares. Allí se presentaron 136 peritajes en un total de 51 juicios, es decir, un promedio de 2,66 peritos por caso. De ellos 129 fueron presentadas por el Ministerio Público y siete por la defensa (en seis juicios). En esta base de datos las principales pericias presentadas estarían concentradas en peritajes médico legales, tales como la constatación de lesiones $(17,6 \%)$ y

\footnotetext{
${ }^{49}$ Fuente: elaboración propia sobre datos de Martina Santibáñez. SANTIBAÑEZ, Uso de la Prueba Pericial, cit. nota $\mathrm{n}^{\circ} 4$, p. 35 .

50 Incluye dos peritajes en donde no se puedo especificar con claridad, dos planimétricos y uno farmacológico, sexológico/psiquiátrico, neurológico y sonidista.

51 En efecto, los datos recopilados indican que 46 peritajes psicológicos corresponden a alguna de estas tipologías. SANTIBAÑEZ, Uso de la Prueba Pericial, cit. nota ${ }^{\circ}$ 4, pp. 39, 40, 44.

${ }^{52}$ Se trata de peritajes basados en el método conocido como Statement Validity Assessment (SVA). La base teórica central detrás del método está constituida por la conocida como "Hipótesis Unduestch" según la cual una declaración derivada de la memoria de una experiencia real difiere en contenido, calidad y expresión de una declaración basada en la invención o fantasía. Para quienes quieran conocer con más detalle sobre la historia, contenidos y pasos del SVA recomiendo, VRIJ, Aldert, Detecting Lies and Deceit, West Sussex: Wiley, 2008, pp. 201-259; MACURÁN, Greter, La Prueba Pericial Psicológica en los Delitos de Abuso Sexual Infantil, Santiago: Editorial Jurídica de Chile, 2011, pp. 61-70; MAFFIOLETTI, Francisco (ed.) et al, "Evaluación Pericial Psicológica de Credibilidad de Testimonio: Documento de Trabajo Insterinstitucional", en: Revista Jurídica del Ministerio Público, n ${ }^{\circ} 34,2008$, pp. 215-253.

53 VRIJ, Detecting Lies, cit. nota n ${ }^{\circ} 56$, pp. 250-254.
} 
Polít. crim. Vol. 13, Nº 25 (Julio 2018) Art. 2, pp. 42-103.

[http://www.politicacriminal.cl/Vol_13/n_25/Vol13N25A2.pdf]

las autopsias (16,9\%). Luego vendrían otros peritajes técnicos como son los bioquímicos y químicos $(12,5 \%)$ y los exámenes balísticos y sobre armas $(11,7 \%)$. Una última categoría relevante estaría compuesta por peritajes en disciplinas variadas como son los planimétricos $(7,3 \%)$ y los informes de causas basales de accidentes producidas por el SIAT de Carabineros $(4,4 \%)$. El resto se distribuye peritajes de disciplinas variadas con porcentajes menores (incluyen análisis de salud mental, criminalístico, sitio del suceso, análisis de huella dactilar, entre otros).

En definitiva, para ir cerrando esta sección, me parece que estos datos tienden a mostrar que efectivamente la realización de distintos exámenes e investigaciones destinados a obtener información, que puede traducirse en prueba pericial en los juicios, es bastante intensa en el período objeto de estudio. También se puede apreciar que el principal usuario de estos sería el Ministerio Público, consistente con su rol de ente a cargo de la investigación penal y con el peso de probar en juicio las acusaciones que formula. En la contracara, se puede apreciar un enorme esfuerzo institucional de parte de la Defensoría Penal Pública por incrementar el número y presupuesto para la elaboración de peritajes, pero todavía con cifras muy lejanas al total del resto de las instituciones.

En cuanto al tipo de peritajes, varias observaciones. Lo primero que me llama la atención que exista una importante cantidad de recursos destinados a la realización de actividades técnicas de investigación que difícilmente podrían traducirse en informes periciales (sitios del suceso, asistentes sociales, entre otros). Además, la presencia importante de exámenes en áreas en donde existe crítica desde el punto de vista de su fiabilidad científica (huellas, peritajes de credibilidad, etc.). Finalmente, la importancia que están adquiriendo en el sistema las pericias psicológicas, especialmente en los delitos sexuales. Volveré con más detalle sobre estos hallazgos en las secciones que siguen.

\subsection{Principales hallazgos de la investigación empírica acerca de las prácticas en materia de prueba pericial en el proceso penal de la Región Metropolitana}

En esta segunda parte del capítulo me dedicaré a revisar los principales hallazgos obtenidos en las entrevistas y complementados con información proveniente de las otras fuentes de apoyo que he recopilado. Para estos efectos, dividiré la presentación en seis temas principales que a continuación expongo.

\subsubsection{Aspectos problemáticos en relación a la calidad de los peritajes que utiliza el sistema}

Un primer aspecto a indagar en la investigación se refirió a las percepciones de los actores del sistema acerca de la calidad de la prueba pericial que habitualmente se utiliza. Como se mencionó previamente, la experiencia comparada indica que, en la medida que la prueba pericial que se valore no tenga niveles de confiabilidad relevante, se aumenta el riesgo de tomar una decisión errada. Para facilitar la presentación de los hallazgos divido estos en dos temas principales: la identificación de las áreas que son percibidas como más problemáticas y las que en cambio producen peritajes de mayor calidad, y luego, las principales razones esgrimidas para justificar los problemas de calidad identificados. 
DUCE, Mauricio. “Una aproximación empírica al uso y prácticas de la prueba pericial en el proceso penal Chileno a la luz de su impacto en los errores del sistema”.

Las opiniones de los actores del sistema legal en este punto presentaron matices ${ }^{54}$, no obstante lo cual me parece que la percepción más extendida, con distintos niveles de intensidad, es que existen problemas de calidad de la prueba pericial que se utiliza regularmente. Los entrevistados reconocen que en algunas materias los peritajes cuentan con razonable confiabilidad, pero que hay otras áreas específicas en dónde la calidad es muy problemática. ${ }^{55} \mathrm{La}$ descripción de las áreas varía en las distintas entrevistas, pero al analizarlas en conjunto se consolidan algunos hallazgos de mucha relevancia. Así, existe una tendencia en afirmar que los peritajes que corresponden a disciplinas técnicas (que algunos entrevistados identifican como "ciencias duras" o peritajes más objetivos o realizados en laboratorios) serían de razonable calidad. En cambio, los peritajes aportados por disciplinas menos técnicas (que algunos entrevistados identifican como "ciencias blandas" o que introducen elementos de subjetividad importantes en la interpretación de resultados) tendrían problemas significativos. ${ }^{56}$ La distinción entre estos dos "mundos" de prueba pericial no es muy certera y presenta varios problemas en relación a cuál es el criterio que los distintos entrevistados usan para poner una y otra prueba dentro de cada

\footnotetext{
${ }^{54}$ Dejo fuera por ahora a las opiniones de los peritos entrevistados ya que ellos en general sólo hacen referencia a su disciplina en específico, por lo que analizaré por separado sus opiniones cuando me refiera a sus respectivas áreas de trabajo. Con todo, señalo desde ya que todos ellos manifiestan una posición bastante crítica con la calidad del trabajo pericial que se realiza en sus áreas de desempeño.

${ }^{55}$ Agrupo en esta categoría general una gran cantidad de opiniones aún cuando ellas se presentan con algunos matices. Entre fiscales véase: Entrevista Fiscal $n^{\circ} 2,9$ de junio de 2015; Entrevista Fiscal $n^{\circ} 5,4$ de septiembre de 2015; Entrevista Fiscal n ${ }^{\circ}$ 7, 2 de octubre de 2015; Entrevista Fiscal n ${ }^{\circ}$ 9, 4 de enero de 2016; Entrevista Fiscal ${ }^{\circ}$ 10, 6 de enero de 2016; Entrevista Fiscal ${ }^{\circ}$ 12, 12 de enero de 2016; y, Entrevista Fiscal $\mathrm{n}^{\circ}$ 13, 29 de enero de 2016. Entre los defensores penales públicos véase: Entrevista Defensor $\mathrm{n}^{\circ} 1,11$ de junio de 2015; Entrevista Defensor n ${ }^{\circ}$ 2, 17 de junio de 2015; y, Entrevista Defensor n ${ }^{\circ}$ 5, 4 de septiembre de 2015. Entre los jueces de garantía véase: Entrevista Juez de Garantía n ${ }^{\circ}$ 5, 15 de julio de 2015; Entrevista Juez de Garantía $n^{\circ}$ 6, 3 de septiembre de 2015; y, Entrevista Juez de Garantía n 7, 14 de septiembre de 2016. Entre los jueces de tribunal oral en lo penal véase: Entrevista Juez TOP n ${ }^{\circ} 1,9$ de junio de 2015; Entrevista Juez TOP $n^{\circ}$ 4, 6 de julio de 2015; Entrevista Juez TOP ${ }^{\circ} 5,8$ de julio de 2015; Entrevista Juez TOP ${ }^{\circ} 6,14$ de julio de 2015; Entrevista Juez TOP n ${ }^{\circ}$ 7, 5 de octubre de 2015; Entrevista Juez TOP n ${ }^{\circ}$ 8, 22 de diciembre de 2015; y, Entrevista Juez TOP n ${ }^{\circ}$ 9, 19 de agosto de 2016. Entre los abogados privados véase: Entrevista Abogado n $^{\circ}$ 1, 4 de mayo de 2015; Entrevista Abogado n 3, 2 de julio de 2015; y, Entrevista Abogado n 4 , 22 de julio de 2015. Con una visión más crítica señalando que el problema es bastante generalizado, véase Entrevista Defensor ${ }^{\circ}$ 6, 1 de abril de 2016; Entrevista Defensor $n^{\circ}$ 7, 19 de abril de 2016; Entrevista Defensor $\mathrm{n}^{\circ}$ 8, 11 de mayo de 2016; Entrevista Juez de Garantía ${ }^{\circ} 1,7$ de mayo de 2015; Entrevista Juez de

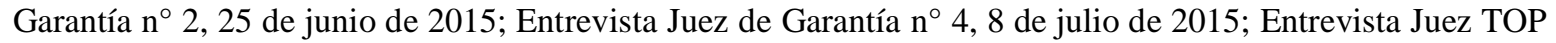
$\mathrm{n}^{\circ}$ 2, 15 de junio de 2015; Entrevista Juez TOP n ${ }^{\circ}$ 3, 2 de julio de 2015; Entrevista Abogado n ${ }^{\circ}$ 5, 25 de agosto de 2016; y, Entrevista Abogado n 6, 25 de agosto de 2016.

${ }^{56}$ Resume muy bien esta lógica las palabras de un juez de tribunal oral quien al responder sobre si nota diferencias de calidad entre los peritajes señaló: "En general las pericias más duras, las más científicas, tienen aparentemente una calidad superior y las pericias más blandas son las complejas, por ejemplo, todo lo que tiene que ver con el análisis de lesiones", Entrevista Juez TOP n ${ }^{\circ} 6,14$ de julio de 2015. Ideas similares son expresadas por varios entrevistados en lenguajes que cambian. Por ejemplo, un fiscal señaló: "En las ciencias blandas, como psiquiatría y psicología, ahí se problematiza todo, desde encontrarlos, que sean peritos, con títulos. Son muy escasos. Mientras más dura la ciencia mejora el perito." Entrevista Fiscal n 2, 9 de junio de 2015. En un lenguaje diferente un juez de tribunal oral indicó que "Hay que distinguir entre las pericias de orden psiquiátrico y psicológicas, de las que recaen en cuestiones puramente técnicas, como peritajes balísticos, ADN, alcoholemia. Esas son bastante buenas, están bien tratadas." Entrevista Juez TOP n ${ }^{\circ} 5,8$ de julio de 2015.
} 
Polít. crim. Vol. 13, № 25 (Julio 2018) Art. 2, pp. 42-103.

[http://www.politicacriminal.cl/Vol_13/n_25/Vol13N25A2.pdf]

categoría. Con todo, a pesar de este problema decidí dejar manifestada esta división ya que es representativa de la forma en que un grupo grandes de entrevistados se refería al tema.

En lo que sigue intentaré profundizar las áreas del trabajo pericial en dónde los actores entrevistados consideran se producen mayores riesgos. Como ya señalaba, en un cierto marco de heterogeneidad, un número importante de los entrevistados correspondientes a los distintos roles del sistema coincide respecto a que los peritajes que presentan mayores problemas de confiabilidad serían los psicológicos y psiquiátricos. Si bien estos peritajes se utilizan en diversas materias y en ellas varios entrevistados identifican son igualmente problemáticos, ${ }^{57}$ pareciera que donde existe la mayor conciencia de su baja calidad es en el contexto de su uso en los delitos sexuales. ${ }^{58}$ Sobre esto, vale la pena recordar que en el estudio de sentencias TOP delitos sexuales se identificó que más del 55\% de los peritajes presentados en los juicios orales ordinarios llevados adelante en esa materia correspondían a estas especialidades, pero con una clara preeminencia de los de carácter psicológico. Por lo mismo, estamos en presencia de un tipo de prueba pericial de uso muy significativo en el sistema. ${ }^{59}$ Por otra parte, se trata de un área de producción de prueba pericial en nuestro país en el que también se ha generado una crítica importante de parte de un sector de la comunidad de especialistas desde hace algún tiempo. ${ }^{60}$

Una buena porción de los entrevistados específicamente destaca que dentro del total de peritajes psicológicos el que consideran más problemático es el denominado "peritaje de credibilidad". 61 Se trata de una prueba usada frecuentemente en casos en los que hay niños

\footnotetext{
${ }^{57}$ Por ejemplo, Entrevista Fiscal $n^{\circ} 2,9$ de mayo de 2015; Entrevista Juez de Garantía n ${ }^{\circ} 2,25$ de junio de 2015; y, Entrevista Juez TOP n ${ }^{\circ} 5,8$ de julio de 2015.

${ }^{58}$ Entre otros: Entrevista Fiscal $n^{\circ} 5,4$ de septiembre de 2015; Entrevista Fiscal $n^{\circ} 6,11$ de septiembre de 2015; Entrevista Juez de Garantía n ${ }^{\circ}$ 1, 7 de mayo de 2015; Entrevista Juez de Garantía n ${ }^{\circ} 4,8$ de julio de 2015; Entrevista Juez TOP $\mathrm{n}^{\circ}$ 1, 9 de junio de 2015; Entrevista Juez TOP $\mathrm{n}^{\circ} 2$, 15 de junio de 2015; Entrevista Juez TOP $n^{\circ}$ 4, 6 de julio de 2015; Entrevista Defensor $n^{\circ} 2,17$ de junio de 2015; Entrevista Defensor $n^{\circ} 5,4$ de septiembre de 2015; Entrevista Defensor $n^{\circ} 6,1$ de abril de 2016; Entrevista Defensor $n^{\circ}$ 7, 19 de abril de 2016; y, Entrevista Abogado n² 2, 2 de junio de 2015.

59 Además, debe tenerse presente que si bien los delitos sexuales representan sólo el 1,44\% del total de ingresos del Ministerio Público el año 2015, su presencia se eleva de manera significativa en los juicios orales. Así, el año 2015 cerca de un $9 \%$ (8,96\%) del total de juicios realizados fue en un delito sexual (1.259). Véase Ministerio Público, Boletín Estadístico 2015, p. 8 (tabla 3) y 42 (tabla 9), respectivamente.

${ }^{60}$ Así, por ejemplo, un estudio publicado el año 2005 identificó problemas serios de falta de formación especializada de los "expertos" que realizan los peritajes psicológicos; falta de investigación en el área de la psicología forense en el país; falta de homogeneidad en los procedimientos de evaluación; no uso de instrumentos de confiables y, en cambio, el uso de otros instrumentos con poca validación; agregándose también, defectos en la elaboración de informes. CONDEMARÍN, Patricia; MACURÁN, Greter, Peritajes Psicológicos sobre los Delitos Sexuales, Santiago: Editorial Jurídica de Chile, 2005, pp. 70-74. Investigaciones posteriores han evidenciado avances en la materia, pero también han manifestado preocupación por la persistencia en el tiempo de varios de estos problemas. MACURÁN, La Prueba Pericial, cit. nota $n^{\circ}$ 56, pp. 113-128; QUIJADA, Diego, “Aportes al Debido Proceso Penal en Evaluación Pericial Psicológica y Psiquiátrica a Imputados en Delitos Sexuales: ¿Existe Relación de Coherencia entre Solicitud y Respuesta Pericial?", en: FUENTES, Claudio (Comp.), Diez Años de la Reforma Procesal Penal en Chile, Santiago: Ediciones Universidad Diego Portales, 2011, pp. 457-499.

${ }^{61}$ Entrevista Fiscal $\mathrm{n}^{\circ}$ 6, 11 de septiembre de 2016; Entrevista Fiscal $\mathrm{n}^{\circ}$ 7, 2 de octubre de 2015 (quien focaliza la crítica cuando son realizados por instituciones diversas al SML); Entrevista Fiscal $\mathrm{n}^{\circ} 10,6$ de enero de 2016; Entrevista Fiscal $n^{\circ}$ 12, 12 de enero de 2016; Entrevista Fiscal $n^{\circ} 13,29$ de enero de 2016;
} 
DUCE, Mauricio. “Una aproximación empírica al uso y prácticas de la prueba pericial en el proceso penal Chileno a la luz de su impacto en los errores del sistema”.

y niñas víctimas de delitos sexuales. ${ }^{62}$ Así, por ejemplo, un fiscal manifestó su punto de vista refiriéndose a este tipo de peritajes de la siguiente forma: “...no les tengo mucha fe, siempre estructuralmente fallan en algo. A veces son valoradas por los jueces, pero otras no". ${ }^{63}$ Más lacónicamente un juez de tribunal oral señaló “...son malísimos, tanto los del SML como los privados." 64 Otro juez oral al explicar sus aprehensiones con estas pericias señaló "Por ejemplo, en los abusos sexuales hay una psicóloga que tiene respuesta para todo y siempre son creíbles y todo lo justifican. Uno le pregunta qué fue lo que dijo el niño, el relato es tan escueto que todo pasa a la imaginación". ${ }^{65}$

Estas apreciaciones negativas sobre la calidad de los peritajes psicológicos en general y, en específico, tratándose de los utilizados en delitos sexuales como los de credibilidad, son compartidas por los peritos psicólogos entrevistados en el área, lo que le entrega mayor fuerza al hallazgo. ${ }^{66}$ Se trató de tres peritos con amplia experiencia profesional y académica y que han cumplido roles en el sistema por encargo de las distintas partes que intervienen en él. Así, por ejemplo, un perito concluyendo su punto de vista sobre la situación de las pericias psicológicas en el sistema señaló: "El producto del peritaje está estrechamente vinculado con la formación del perito y las condiciones que le han sido otorgadas para hacer este trabajo. El promedio del peritaje, entendiendo que hay excelentes peritos, es muy deficitario". ${ }^{67}$ Otro perito concluye que la práctica en el área "Por regla general, es poco rigurosa", al explicar esta afirmación señala: "La mayoría de los peritos tiene escasa experiencia profesional, no se dedican a estudiar el tema, no emplean pruebas exactas, sino que, especulan acerca del estado psicológico de una persona, sus conclusiones se basan en impresiones subjetivas." Luego concluye: "Entonces hay un tema de falta de formación y método". ${ }^{68}$ En una línea similar se pronuncia el tercer experto del área. ${ }^{69}$

Entrevista Juez de Garantía n ${ }^{\circ}$ 5, 15 de julio de 2015; Entrevista Juez de Garantía n ${ }^{\circ} 8,4$ de enero de 2016; Entrevista Juez TOP $n^{\circ}$ 1, 9 de junio de 2015; Entrevista Juez TOP n ${ }^{\circ}$ 2, 15 de junio de 2015; Entrevista Juez TOP $n^{\circ}$ 4, 6 de julio de 2015; Entrevista Juez TOP n ${ }^{\circ} 7,5$ de octubre de 2015; Entrevista Juez TOP n ${ }^{\circ} 8,22$ de diciembre de 2015; Entrevista Defensor $n^{\circ} 1,11$ de junio de 2015; Entrevista Defensor $n^{\circ} 3,2$ de julio de 2015; Entrevista Defensor n ${ }^{\circ}$ 4, 2 de julio de 2015; y, Entrevista Defensor n ${ }^{\circ} 5,4$ de septiembre de 2015.

${ }^{62}$ Una explicación de su amplio uso en el sistema es entregada por un fiscal que señaló: "Se ha hecho un abuso de las pericias de credibilidad del relato, hay casos en que no son necesarias y se presentan de todas formas, lo que ha provocado que hoy se exijan en todo tipo de delitos sexuales". Entrevista Fiscal n 12,12 de enero de 2016. En la misma dirección Entrevista Fiscal n 13, 29 de enero de 2016. Según otro fiscal con especialidad en el área sexual, este abuso sumado a los problemas de calidad de estas pericias estaría llevando a experimentar ir a juicio sin ellas. Entrevista Fiscal $n^{\circ} 6,11$ de septiembre de 2015.

${ }^{63}$ Entrevista Fiscal $n^{\circ} 10,6$ de enero de 2016.

${ }^{64}$ Entrevista Juez TOP $\mathrm{n}^{\circ}$ 4, 6 de julio de 2015.

${ }^{65}$ Entrevista Juez TOP n ${ }^{\circ} 2,15$ de junio de 2015.

${ }^{66}$ Como he señalado en la sección previa se trata también de un método que también es objeto de fuerte cuestionamiento en la literatura científica comparada. Así, Vrij haciendo una revisión exhaustiva de los estudios disponibles acerca del SVA, ha señalado que, si bien este método aumenta las posibilidades de detectar versiones verdaderas y mentirosas por sobre la probabilidad estadística, lo que la transforma en una herramienta muy útil para las investigaciones penales, no es suficientemente precisa y confiable para ser admitida a juicio como evidencia científica. Véase: VRIJ, Detecting Lies, cit. nota n 56, pp. 251-254.

${ }^{67}$ Entrevista Perito ${ }^{\circ}$ 4, 4 de agosto de 2016.

${ }^{68}$ Entrevista Perito ${ }^{\circ} 2,19$ de julio de 2016.

${ }^{69}$ En su opinión la práctica nacional en la confección de peritajes psicológicos "es poco rigurosa", destacando el poco tiempo que algunos peritos dedican a confeccionar sus informes y en otros casos problemas de método utilizado y formación de los peritos que los practican. Entrevista Perito n ${ }^{\circ} 1,18$ de julio de 2016. 
Polit. crim. Vol. 13, No 25 (Julio 2018) Art. 2, pp. 42-103.
[http://www.politicacriminal.cl/Vol_13/n_25/Vol13N25A2.pdf]

Cómo se puede apreciar, en la opinión de todos los peritos hay bastante consenso acerca de los problemas de calidad existente en su área de trabajo. Una explicación a esto se daría por el vínculo que los tres hacen entre la calidad del peritaje y las carencias en el nivel de conocimiento y especialización de los peritos. Se trata de un punto que por su relevancia analizaré por separado un poco más adelante.

Un segundo grupo de peritajes en los que varios entrevistados identificaron problemas de calidad, aún cuando con menor frecuencia que los anteriores, son los exámenes médico forenses comúnmente conocidos como "peritajes sexológicos". ${ }^{70}$ Estos tienen por propósito realizar exámenes físicos a las potenciales víctimas para detectar signos que certifiquen la existencia de lesiones compatibles con agresiones sexuales. ${ }^{71}$ En palabras de un fiscal: "Todo lo que es peritaje sexológico he tenido muchos problemas. Yo creo que hay un problema de falta de dotación y vocación..."72 Otro, en cambio, pone el acento en la evolución que habría tenido el área y señaló que "En el ámbito de los delitos sexuales todo es muy dispar. Yo diría que la calidad del SML incluso en los exámenes sexológicos ha decaído. No sé si por rotación o disminución de funcionarios, pero ha decaído." 73 Como se puede apreciar, ambas opiniones también realizan una conexión entre la calidad de las pericias y quienes la realizan.

Estas opiniones son coincidentes con la de los tres peritos entrevistados con experiencia en el área de la medicina legal. ${ }^{74}$ Los tres han sido o desempeñan actualmente funciones en el SML y, por lo mismo, tienen una visión muy cercana de la realidad de la institución. Con distintos niveles de crítica, todos coinciden que hay problemas, en algunos casos importantes, con la calidad de las pericias en el área médico legal. Una distinción fundamental para entender esto es que una parte de ellas son realizadas por el SML, en tanto otras por los distintos servicios de salud pública que atienden a las víctimas. En este último caso la situación sería la más problemática debido a la falta de formación y

\footnotetext{
${ }^{70}$ Entrevista Fiscal $n^{\circ}$ 5, 4 de septiembre de 2015; Entrevista Fiscal $\mathrm{n}^{\circ}$ 6, 11 de septiembre de 2016; Entrevista Fiscal $n^{\circ}$ 9, 4 de enero de 2016; Entrevista Juez de Garantía n ${ }^{\circ}$ 1, 7 de mayo de 2016; y, Entrevista Juez TOP ${ }^{\circ} 2,15$ de junio de 2015.

${ }^{71}$ Disponible en: http://www.sml.cl/labor-forense.html [Visitado el 02.02.2017].

${ }^{72}$ Entrevista Fiscal n ${ }^{\circ}$ 9, 4 de enero de 2016.

${ }^{73}$ Entrevista Fiscal $n^{\circ} 5,4$ de septiembre de 2015.

74 Además, se trata de una percepción también coincidente con los resultados de algunas investigaciones periodísticas disponibles en el área. Por ejemplo, CIPER Chile publicó un reportaje en octubre de 2013 sobre los procesos con niños víctimas de delitos sexuales en los que se mostraban falencias importantes en los peritajes producidos por el SML y otras agencias, derivadas de problemas de falta de especialización de sus expertos en ciertas materias, sobrecarga de trabajo con impacto en la calidad de los resultados, falta de procesos de formación institucionales de los peritos, entre otras. VILLARRUBIA, Gustavo: FIGUEROA, Juan Pablo, "La Dolorosa Ruta Judicial que Recorren los Niños Abusados Sexualmente", en: CIPER Chile, 2010, en: http://ciperchile.cl/2013/10/28/la-dolorosa-ruta-judicial-que-recorren-los-ninos-abusados-sexualmente/

[Visitado el 02.02.2017]. En otro reportaje más reciente (julio 2016) focalizado en el delito de violación, se describe como en los servicios de salud pública se recibe habitualmente a víctimas de estos delitos por médicos sin ninguna capacitación sobre elaboración de peritajes sexológicos. DOMEYKO, Antonia, "La Denuncia: el Duro Camino de una Violación”, en: Revista Ya, n 1714, 2016, pp. 38-41, p. 40.
} 
DUCE, Mauricio. “Una aproximación empírica al uso y prácticas de la prueba pericial en el proceso penal Chileno a la luz de su impacto en los errores del sistema".

especialización de quienes los practican. ${ }^{75}$ En el SML las opiniones presentan matices. El perito más crítico señaló: "En mi área es mala...El gran problema no es el dinero, ni los recursos, ni la tecnología. Su problema es metodológico, hacen todo a la chilena" ${ }^{76}$ Otro experto presentó una versión con matices: "Hay una variabilidad grande dependiendo de cada perito. Hay algunos de calidad que hacen buenas pericias e informes siendo en mi opinión confiables. Pero hay otros de menos calidad, que trabajan a la rápida y son menos confiables". ${ }^{77}$ Finalmente, el tercer perito señala que los problemas de calidad de los peritajes sexológicos en específico se explican en parte por las dificultades por contar con peritos especializados en un área en que "Los peritajes son muy interpretables..." y "La subjetividad del que lo hace tiene un rol". ${ }^{78}$ Nuevamente, como se puede apreciar, el nivel de formación y especialización de los expertos aparece como una variable relevante explicativa de los problemas de calidad que se identifican.

Fuera de estas áreas, los entrevistados identifican algunos problemas, pero con frecuencias mucho más bajas de mención en temas, como, por ejemplo, las pericias contables. ${ }^{79}$ Debido a la baja frecuencia con la que son mencionadas estas otras áreas no me detengo en su análisis.

En la contracara, una de las áreas en donde los entrevistados identificaron mayores fortalezas en términos de calidad de los peritajes, fue en el trabajo de los laboratorios de distintas instituciones auxiliares. ${ }^{80}$ En este contexto, me pareció interesante indagar en algunos indicadores objetivos de funcionamiento del sistema que pudieran justificar esta percepción y que ella no sea producto simplemente de un sesgo favorable hacia la cientificidad de lo que luce como "técnico". A nivel internacional los principales desarrollos en esta materia han estado ligados al establecimiento de sistemas de acreditación de laboratorios forenses que permiten verificar si efectivamente los procesos de trabajo en lo mismo responden a estándares de calidad, lo que asegura la confiabilidad de sus resultados. ${ }^{81}$ En esta dirección, se presentaron solicitudes de acceso a información

\footnotetext{
${ }^{75}$ Entrevista Perito ${ }^{\circ} 7,18$ de noviembre de 2016, quien en todo caso señala que en su experiencia es cada vez es menos frecuente en la Región Metropolitana que las distintas redes del sistema de salud pública hagan estos peritajes. Más bien se prefieren derivar los casos al SML.

${ }^{76}$ Entrevista Perito n ${ }^{\circ}$ 3, 20 de julio de 2016.

${ }^{77}$ Entrevista Perito ${ }^{\circ}$ 6, 8 de noviembre de 2016.

${ }^{78}$ Entrevista Perito ${ }^{\circ} 7,18$ de noviembre de 2016.

${ }^{79}$ Entrevista Juez TOP $\mathrm{n}^{\circ} 7,5$ de octubre de 2015, quien en todo caso reconoce que hay una falta de preparación de los propios jueces para comprender y aprovechar mejor a este tipo de peritajes. Se trató también de un área en donde se entrevistó a un experto con amplia experiencia en la materia. Su conclusión sobre el punto fue que "Los peritajes en mi área son mediocres y de bajo nivel, aun cuando siempre hay excepciones." Al explicar esto se señalan problemas de formación, experiencia y uso de metodología. Entrevista Perito ${ }^{\circ}$ 5, 15 de septiembre de 2016.

${ }^{80}$ Entre otros, Entrevista Fiscal n ${ }^{\circ}$ 5, 4 de septiembre de 2015; Entrevista Defensor $n^{\circ} 1,11$ de junio de 2015 ; Entrevista Defensor $n^{\circ}$ 2, 17 de junio de 2015; Entrevista Juez TOP n ${ }^{\circ}$ 6, 14 de julio de 2015; y, Entrevista Abogado $n^{\circ} 1,4$ de mayo de 2015.

${ }^{81}$ El documento base en la actualidad ha sido desarrollado por la Organización Internacional de Acreditación de Instituciones que operan de acuerdo con las normas ISO/IEC 17011, también conocida como ILAC: http://ilac.org/about-ilac/ [Visitado el 02.02.2017]. Esta institución publicó en agosto de 2014 el estándar ILAC G19-2014, una guía para las unidades forenses que tienen responsabilidad en el examen y testeo de muestras de tipo forense (laboratorios básicamente) para asegurar la aplicación de las normas ISO/IEC 17025
} 
Polít. crim. Vol. 13, № 25 (Julio 2018) Art. 2, pp. 42-103.

[http://www.politicacriminal.cl/Vol_13/n_25/Vol13N25A2.pdf]

pública al SML, el ISP y Carabineros y la PDI requiriendo antecedentes sobre las acreditaciones de sus laboratorios. Las respuestas recibidas dan cuenta que se trata de un tema en el que se ha avanzado parcialmente en nuestro país. El $\mathrm{SML}^{82}$ y la $\mathrm{PDI}^{83}$ han iniciado procesos de acreditación de sus respectivos laboratorios aún cuando no necesariamente las certificaciones más especializadas disponibles para el trabajo de laboratorios forenses. En tanto el ISP $^{84}$ y Carabineros ${ }^{85}$ informan que no cuenta con acreditación ISO 17025. Como se ve, el estado de avance de los procesos de acreditación de los laboratorios forenses nacionales en el área todavía está en una etapa muy preliminar y, por lo mismo, la percepción positiva de los actores en la materia debiera ser leída con "beneficio de inventario".

\section{b) Algunos problemas específicos de calidad}

Saliendo de las áreas más conflictivas, me interesó identificar qué problemas concretos perciben los actores más allá de la falta especialización de los peritos, tema sobre la cual profundizaré en la próxima sección. Una explicación que se repitió con frecuencia entre los entrevistados fue la de señalar que la falta de calidad de los peritajes sería un problema derivado de defectos de tipo metodológico en su confección. Se trata de un tema destacado tanto por jueces de garantía ${ }^{86}$ como de juicio oral ${ }^{87}$, defensores penales públicos ${ }^{88}$,

y ISO/IEC 17020, disponible en: http://ilac.org/latest_ilac news/ilac-g19082014-published/ [Visitado el 02.02.2017].

${ }^{82}$ El laboratorio de Genética Forense efectivamente ha obtenido acreditación ISO 17025 desde el año 2012 y que se encuentra vigente hasta 2019 pero referida al área de genética para filiación de poco impacto en materia penal. Por otra parte, también ha recibido acreditación ISO 9001 (referida a gestión de calidad en general y no de manera específica al trabajo de laboratorios forenses como la norma ISO 17025) desde el 30 de noviembre de 2015 con vigencia hasta la misma fecha de 2018 para la realización de diversos procesos periciales en distintas sedes a lo largo del país. La información ha sido proporcionada por el SML a través de Ordinario 3777 de 28 de febrero de 2017 (documento en formato electrónico en poder del autor).

${ }^{83}$ Al 13 de marzo de 2017, vencido los plazos legales, no se recibió respuesta al requerimiento de acceso de información pública de parte de la PDI. Con todo, en la página web institucional se informa que la institución se encuentra en proceso de acreditación de los ensayos de cuatro Secciones según la norma ISO 17025:2005. Además, que en forma próxima comenzará el proceso de ampliación de alcance de la certificación, en conjunto a la implementación de la norma ISO 17025:2005 en los Laboratorios de Criminalística Regionales. http://www.investigaciones.cl/criminalistica2/portada/index.htm [Visitado el 02.02.2017].

${ }^{84}$ Sin embargo señala cumplir con protocolos de calidad de la propia institución recomendados por la United Nations Office on Drug and Crime (UNODC). Información enviada por el ISP, Respuesta Folio AO005T0001268 de 9 de febrero de 2017 (documento en formato electrónico en poder del autor). En una solicitud posterior se me entregó información más específica acerca del tipo de protocolos en donde se identifican seis disponibles. Información enviada por el ISP, Respuesta Folio AO005T0001337 de 9 de marzo de 2017 (documento en formato electrónico en poder del autor)

${ }^{85}$ Sin embargo, señalan que el Laboratorio de Genética Forense del Departamento y de la Sección Regional de Antofagasta cuentan desde el 20 de julio de 2016 con certificación de control de calidad del Grupo Iberoamericano de trabajo de análisis de ADN (GITAD). Información enviada por Carabineros de Chile, RSIP n 36051 de 28 de febrero de 2017 (documento en formato electrónico en poder del autor).

${ }^{86}$ Entrevista Juez de Garantía n ${ }^{\circ}$ 1, 7 de mayo de 2015; Entrevista Juez de garantía n ${ }^{\circ} 2,25$ de junio de 2015; y, Entrevista Juez de Garantía n ${ }^{\circ}$ 5, 15 de julio de 2015.

${ }^{87}$ Entrevista Juez TOP n ${ }^{\circ} 1,9$ de junio de 2015; Entrevista Juez TOP n ${ }^{\circ}$ 3, 2 de julio de 2015; Entrevista Juez Top $n^{\circ}$ 6, 14 de julio de 2015; y, Entrevista Juez Top n ${ }^{\circ}$, 5 de octubre de 2015. 
DUCE, Mauricio. “Una aproximación empírica al uso y prácticas de la prueba pericial en el proceso penal Chileno a la luz de su impacto en los errores del sistema".

abogados $\operatorname{privados}^{89}$ y peritos entrevistados. ${ }^{90}$ Sólo tratándose de los fiscales esta explicación no aparece con fuerza.

Por el tipo de problema, la opinión de los actores, salvo los peritos, podría tener poco peso ya que se refiera a una cuestión que está fuera de la especialidad de los profesionales del área legal. Con todo, lo interesante de estas distintas opiniones es apreciar algunas diferencias en el tipo de problema metodológico que se identifica. Un primer grupo de cuestionamientos, el mayoritario en las entrevistas, señala que los defectos en esta materia están en la poca o nula explicación que realizan los peritos en sus informes escritos o en las declaraciones que presentan en juicio acerca de los métodos utilizados para arribar a las conclusiones que exponen. En esta versión, por lo tanto, el problema no necesariamente está en el uso de métodos errados o poco fiables, sino más bien en la falta de justificación de los mismos, tema respecto al cual los actores del sistema legal son testigos directos y su opinión tiene un peso importante que le da relevancia al hallazgo. Un defensor explica este problema señalando: "Los peritajes tienen un problema, pues no reflejan la metodología usada. No se reproduce el razonamiento. Es bien patente en materia de delitos sexuales: 'de los 19 criterios encontramos 11', pero no te dicen cuáles eran esos. No se señala el método". ${ }^{91}$ Más brevemente un juez de garantía indica: “...los informes tienden a ser formales, sin ninguna metodología, nunca...".92 Un juez oral, refiriéndose a las declaraciones en juicio señala que “...no ponen énfasis en la metodología y si hablan algo de metodología es muy lacónico. Los intervinientes tampoco lo exigen”. ${ }^{93}$

Debo enfatizar que la falta de explicación y justificación de la metodología no es un problema puramente formal. Como revisaré a propósito de la valoración que hacen los jueces, se trata de un aspecto clave para poder controlar la calidad de la información que se introduce a juicio. Por lo mismo, al identificarse prácticas de este tipo, ello da cuenta de que nuestro sistema se expone al riesgo de tomar decisiones erradas debido a que no tiene información básica que es requerida para valorar adecuadamente el peso de las opiniones de los peritos. Aún más grave sería, cómo se desprende de la declaración del juez de tribunal oral, si es que tampoco los intervinientes estuviesen manifiestando mucha preocupación por eso.

Vinculado al tema en análisis, durante la investigación se indagó sobre la calidad de los peritajes tratándose del contenido de los informes escritos. Como es sabido, la prueba pericial en nuestro sistema procesal penal acusatorio es una evidencia compleja que está integrada por dos elementos: el informe escrito y la posterior declaración del perito en

\footnotetext{
${ }^{88}$ Entrevista Defensor $n^{\circ} 1,11$ de junio de 2015; Entrevista Defensor $n^{\circ} 3,2$ de julio de 2015; Entrevista Defensor $^{\circ}$ 4, 2 de julio de 2015; y, Entrevista Defensor $n^{\circ}$ 5, 4 de septiembre de 2015.

${ }^{89}$ Entrevista Abogado ${ }^{\circ} 3,2$ de julio de 2015.

${ }^{90}$ Entrevista Perito $n^{\circ} 1,18$ de julio de 2016; Entrevista Perito $n^{\circ} 2,19$ de julio de 2016; Entrevista Perito $n^{\circ}$ 3, 20 de julio de 2016; Entrevista Perito $\mathrm{n}^{\circ}$ 4, 4 de agosto de 2016; y, Entrevista perito $\mathrm{n}^{\circ}$ 5, 15 de septiembre de 2016.

${ }^{91}$ Entrevista Defensor $n^{\circ}$ 3, 2 de julio de 2015.

${ }^{92}$ Entrevista Juez de Garantía n ${ }^{\circ}$ 2, 25 de junio de 2016.

${ }^{93}$ Entrevista Juez TOP n ${ }^{\circ} 6,14$ de julio de 2015.
} 
Polít. crim. Vol. 13, No 25 (Julio 2018) Art. 2, pp. 42-103.

[http://www.politicacriminal.cl/Vol_13/n_25/Vol13N25A2.pdf]

juicio. ${ }^{94}$ De esta forma, lo que se intentó fue obtener información acerca de cómo los actores del sistema de justicia criminal valoran este primer componente que es clave para su toma de decisiones y preparación de los casos. ${ }^{95}$

Un primer hallazgo, fue que un grupo minoritario de los entrevistados compuesto en su gran mayoría fiscales, consideraron que los informes periciales escritos no presentaban problemas de calidad, sino más bien cumplían en forma adecuada con lo que ellos necesitaban. ${ }^{96}$ La opinión prevalente de los actores, con excepción de los jueces de tribunal oral que por sus funciones por regla general no tienen acceso a este documento, en cambio, identificó distintos problemas de calidad en los informes escritos. Dentro de estos, uno que se repite con frecuencia y que ya ha sido objeto de mención es la falta de explicación de la metodología o, visto desde otra perspectiva, el énfasis en las conclusiones sin justificación adecuada de cómo se llegó a ellas. ${ }^{97}$

Surgen también algunos nuevos problemas. El principal, que complementa al anterior, es la falta de información o el carácter incompleto de los informes. ${ }^{98}$ Un perito del área de la medicina legal describe la situación señalando que "Hay mucho informe incompleto que escribe lo básico o menos que lo básico. El problema es que no hay nadie que pesquise eso, no tenemos buenos controles de calidad y tampoco afuera nuestros usuarios parecen darse cuenta de la diferencia de un buen o mal informe". ${ }^{99}$ Lo interesante de esta opinión no es sólo el hecho central, sino la explicación de las causas que podrían contribuir a esta situación, las que no sólo estarían en el propio perito sino en el entorno de incentivos que tiene para hacer un trabajo riguroso en la materia.

${ }^{94}$ Se trata de un aspecto bastante reconocido por nuestra doctrina, la que normalmente identifica estas dos dimensiones al conceptualizar la prueba pericial en nuestro país. Puede verse, entre otros, CAROCCA, Alex, El Nuevo Sistema Procesal Penal Chileno, 4ta Edición, Santiago: Thomson Reuters, 2008, p. 162; MATURANA, Cristián; MONTERO, Raúl, Derecho Procesal Penal, Tomo II, Santiago: AbeledoPerrot, 2010, pp. 1030-1031.

95 Sobre las funciones que cumple el informe escrito en los sistemas acusatorios véase: DUCE, La Prueba Pericial, cit. nota $\mathrm{n}^{\circ} 1$, pp. 148-155.

${ }^{96}$ Entrevista Fiscal $n^{\circ} 2,9$ de junio de 2015; Entrevista Fiscal $n^{\circ} 5,4$ de septiembre de 2015; Entrevista Fiscal $\mathrm{n}^{\circ}$ 7, 2 de octubre de 2015; Entrevista Fiscal $n^{\circ}$ 9, 4 de enero de 2016; Entrevista Fiscal $\mathrm{n}^{\circ} 10,6$ de enero de 2016; Entrevista Fiscal n ${ }^{\circ}$ 13, 29 de enero de 2016; y, Entrevista Defensor $n^{\circ}$ 8, 11 de mayo de 2016.

${ }^{97}$ En esta línea, entre otros, Entrevista Defensor n ${ }^{\circ}$ 7, 19 de abril de 2016 (quien señala: "no se plasma en peritajes el proceso para llegar a la conclusión”); Entrevista Juez de Garantía n 5, 15 de julio de 2015 (quien indica: "No son muy completos en cuanto a la forma que se llega a la conclusión..."); Entrevista Abogado ${ }^{\circ}$ 1, 4 de mayo de 2015 (quien indica: "En general mi impresión es que no siempre se informa sobre los métodos utilizados, cuál es la metodología específica de un determinado caso...”); Entrevista Abogado $n^{\circ} 2,2$ de junio de 2015 (quien señala como problema que “...no encuentro el hilo conductor que me lleve a esa conclusión”); Entrevista Perito n 3, 20 de julio de 2016.

${ }^{98}$ Entrevista Fiscal n ${ }^{\circ}$ 6, 11 de septiembre de 2015 (quien focaliza esta crítica respecto de ciertas categorías de peritos); Entrevista Fiscal $n^{\circ}$ 11, 7 de enero de 2016 (quien hace la crítica en casos más complejos en donde los peritajes normalmente se "quedan cortos" en relación a los hechos y esto obliga a solicitar muchas ampliaciones); Entrevista Defensor ${ }^{\circ}$ 6, 1 de abril de 2016; Entrevista Abogado $\mathrm{n}^{\circ}$ 2, 2 de junio de 2015; Entrevista Abogado $n^{\circ}$ 5, 25 de agosto de 2016; Entrevista Abogado n ${ }^{\circ}$ 6, 25 de agosto de 2016; Entrevista Perito $\mathrm{n}^{\circ}$ 1, 18 de julio de 2016; Entrevista Perito ${ }^{\circ}$ 5, 15 de septiembre de 2016; y, Entrevista Perito $n^{\circ} 6,8$ de noviembre de 2016.

${ }^{99}$ Entrevista Perito ${ }^{\circ}$ 6, 8 de noviembre de 2016. 
DUCE, Mauricio. “Una aproximación empírica al uso y prácticas de la prueba pericial en el proceso penal Chileno a la luz de su impacto en los errores del sistema".

Un elemento que se repite al indagar en qué sentido serían incompletos los informes, además del problema de falta de explicación de la metodología y justificación de conclusiones ya visto, es que normalmente no se incluiría el material básico de complemento, como por ejemplo, transcripción de entrevistas, resultados de test, dibujos, etc. ${ }^{100}$ Otra información que se repite y podría explicar este problema, aun cuando constituye uno adicional, es la excesiva estandarización de muchos informes, que obedecen a formatos tipos $\mathrm{y}$, por tanto, incapaces de recoger algunas particularidades de los casos específicos. $^{101}$

Se suma a los problemas anteriores un conjunto de opiniones críticas acerca de la claridad en la redacción de los informes y del exceso de lenguaje técnico que dificulta su comprensión por parte de los actores legales del sistema. ${ }^{102}$ Finalmente, también se mencionan, con menor intensidad, problemas de coherencia interna y contradicciones en los informes. ${ }^{103}$

Un problema diferente obtenido como resultado de la investigación en materia de calidad se presentaría a nivel de cuestionamiento sobre la pertinencia o confiabilidad del método usado para llegar a las conclusiones que se presentan. Se trata, como puede intuirse, de un tipo de problema de extrema gravedad. Si un peritaje llega a conclusiones que no tienen un soporte metodológico, ellas podrían llevar fácilmente al sistema de justicia penal a cometer errores en la decisión de los casos.

Si bien existen cuestionamientos de este tipo de parte de los actores legales del sistema entrevistados ${ }^{104}$, quienes con más fuerza se pronuncian sobre este punto son los propios peritos en sus respectivas áreas de trabajo. Esto, en mi opinión, le da un importante peso al hallazgo ya que se trata de información de expertos en las disciplinas respectivas que tienen conocimiento profundo de las exigencias metodológicas de las mismas. Las entrevistas a los expertos en las diversas áreas tienden a reproducir algunos patrones de problemas

${ }^{100}$ Entrevista Abogado ${ }^{\circ}$ 5, 25 de agosto de 2016; Entrevista Abogado n ${ }^{\circ}$ 6, 25 de agosto de 2016; y, Entrevista Perito ${ }^{\circ} 1,18$ de julio de 2016.

${ }^{101}$ Entrevista Fiscal n ${ }^{\circ}$ 1, 7 de mayo de 2015; Entrevista Juez de Garantía n ${ }^{\circ}$ 9, 28 de julio de 2016; Entrevista Abogado n ${ }^{\circ} 2,2$ de junio de 2015; y, Entrevista Perito n ${ }^{\circ}$ 3, 20 de julio de 2016.

${ }_{102}$ Entrevista Defensor $n^{\circ}$ 6, 1 de abril de 2016; Entrevista Defensor n ${ }^{\circ}$ 7, 19 de abril de 2016; Entrevista Juez de Garantía $n^{\circ}$ 2, 25 de junio de 2015; Entrevista Perito ${ }^{\circ}$ 5, 15 de septiembre de 2016; y, Entrevista Perito ${ }^{\circ}$ 7, 18 de noviembre de 2016 (quien focaliza el problema en la construcción de conclusiones).

${ }^{103}$ Entrevista Perito n ${ }^{\circ}$ 2, 19 de julio de 2016; Entrevista Perito n ${ }^{\circ} 4,4$ de agosto de 2016; y, Entrevista Perito $\mathrm{n}^{\circ} 5,15$ de septiembre de 2016.

${ }^{104}$ Un juez oral señaló de manera general que "Sobre la metodología veo que hay mucha debilidad" (Entrevista Juez TOP $\mathrm{n}^{\circ}$ 7, 5 de octubre de 2015). Focalizado en los problemas de peritajes psicológicos en delitos sexuales un defensor señaló “...hay defectos metodológicos importantes...de verdad que es un método que no está determinado, se mezcla lo que se ha aprendió por la experiencia o el método que se ha acordado en un congreso X. A mí me parece que hay problemas de rigor científico importantes."(Entrevista Defensor $\mathrm{n}^{\circ} 5,4$ de septiembre de 2015). Otro juez oral, refiriéndose también a los peritajes psicológicos en delitos sexuales indicó "Me da la impresión que ellos hacen una evaluación con una metodología que ni siquiera se preguntan si es adecuada o no. Me da la impresión que es más una opinión subjetiva acerca de la impresión que causó una persona, más que el resultado psicológico derivado de una metodología validada científicamente." (Entrevista Juez TOP ${ }^{\circ} 1,9$ de junio de 2015). Un ejemplo a nivel de abogados puede verse en Entrevista Abogado n 3, 2 de julio de 2015. 
Polít. crim. Vol. 13, № 25 (Julio 2018) Art. 2, pp. 42-103.

[http://www.politicacriminal.cl/Vol_13/n_25/Vol13N25A2.pdf]

metodológicos. Dentro de ellos se señalan dos principales: la falta de estandarización en el uso de métodos y pruebas, que en su contracara significa en algunos casos la falta de desarrollo de protocolos claros de actuación ${ }^{105}$ y las inconsistencias en los informes, entre las que las más graves serían entre el método empleado para elaborar el peritaje y las conclusiones a las que finalmente se arriba. ${ }^{106}$

\subsubsection{Especialidad de los peritos:}

Un segundo gran tema objeto de investigación fue establecer si existían problemas a nivel de formación y especialidad de los peritos. Se trata de una cuestión básica para determinar la confiabilidad de los resultados obtenidos en un peritaje. Recordemos que los peritos son personas que -producto de su conocimiento especial o experiencia- están en condiciones de aportar conclusiones o entregar opiniones sobre temas que están fuera de la esfera de conocimiento de los jueces y que el sistema de justicia requiere para resolver los casos que conoce. Por lo mismo, el elemento central que justifica la existencia de esta prueba es precisamente que quien comparece en calidad de perito efectivamente tenga formación o experiencia. Por cierto, ese sólo elemento no asegura la calidad de un peritaje como revisamos en la sección previa, pero sí pareciera ser una condición absolutamente necesaria para ello.

Como ya fue mencionado en la sección anterior, varios entrevistados identificaron que buena parte de los defectos de calidad de los peritajes que se ocupan en nuestro país emanan de problemas importantes en el nivel de formación y especialidad de quienes comparecen habitualmente como peritos en el sistema de justicia penal. Este es un tópico que se repite entre actores legales del sistema. ${ }^{107}$ Con todo, me interesa detenerme con un poco más de detalle en la visión que manifestaron los peritos entrevistados sobre este punto. Ella resulta particularmente relevante ya que proviene desde el conocimiento disciplinar experto que poseen y, por lo mismo, son una muy buena aproximación al mejor conocimiento de la realidad nacional. Por otra parte, de acuerdo a los entrevistados, en esta materia existiría un consenso de que se trataría de una de las áreas más deficitarias en nuestro sistema. En efecto, hay coincidencia en las tres áreas de conocimiento experto en la que realicé entrevistas (psicología forense, medicina legal y auditoría forense) que se trata de un problema de gravedad. Analizo brevemente cada una de ellas.

En el área de la psicología forense los tres peritos entrevistados concuerdan se trata de un área crítica. Uno de ellos describe el problema de la siguiente forma: "El principal problema es la resistencia a la ciencia, lo codifico así porque no se puede decir que en Chile

\footnotetext{
${ }^{105}$ Entrevista Perito $n^{\circ} 1,18$ de julio de 2016; Entrevista Perito $n^{\circ} 2,19$ de julio de 2016; Entrevista Perito $n^{\circ}$ 3, 20 de julio de 2016; y, Entrevista Perito ${ }^{\circ}$ 5, 15 de septiembre de 2016.

${ }^{106}$ Entrevista Perito n ${ }^{\circ} 2,19$ de julio de 2016 y Entrevista Perito n ${ }^{\circ}$ 4, 4 de agosto de 2016.

107 Con distintos matices los entrevistados identifican que hay problemas importantes en esta materia. Entrevista Fiscal $n^{\circ}$ 6, 11 de septiembre de 2016; Entrevista Fiscal $n^{\circ}$ 8, 28 de diciembre de 2015; Entrevista Fiscal $n^{\circ}$ 13, 29 de enero de 2016; Entrevista Juez de Garantía n ${ }^{\circ}$ 2,25 de junio de 2015; Entrevista Juez TOP $\mathrm{n}^{\circ}$ 1, 9 de junio de 2015; Entrevista Juez TOP n ${ }^{\circ} 2,15$ de junio de 2015; Entrevista Juez TOP ${ }^{\circ} 5,8$ de julio de 2015; Entrevista Juez TOP n ${ }^{\circ}$ 6, 14 de julio de 2015; Entrevista Abogado n ${ }^{\circ} 5$, 25 de agosto de 2016; y, Entrevista Abogado n 6, 25 de agosto de 2016.
} 
DUCE, Mauricio. “Una aproximación empírica al uso y prácticas de la prueba pericial en el proceso penal Chileno a la luz de su impacto en los errores del sistema".

no se conozca cual es la metodología correcta para este tipo de evaluaciones, pero como no hay formación específica, fiscalización, ni seguimiento, la práctica termina siendo un mix de cosas que no son el método pero tienen algo de él" luego agrega: "Falta formación específica, que en estos casos implica supervisión, programas que lo hagan...”, concluye el análisis explicando la trayectoria de los peritos que trabajan en instituciones como los Proyecto de Diagnóstico Ambulatorio (DAM): "Hay alta rotación...Jóvenes se titulan, hacen la práctica y se quedan ahí, sin tener alguna experiencia clínica hacen este tipo de evaluaciones. Cuando logran tener experiencia se van y así vuelve a pasar". ${ }^{108}$ Con un lenguaje algo distinto otro perito concluye casi lo mismo al señalar que "El problema es que las solicitudes de evaluación de psicológica son muchísimas y hay pocos psicólogos formados en el medio nacional para hacer esto. Muchas demandas las satisfacen personal de los DAM, que pertenecen a organismos colaboradores del SENAME...." Luego explica el problema que se genera por los bajos montos destinados a financiar estas operaciones periciales en dichas instituciones, lo que lleva a una contratación con las siguientes características:

[...] jóvenes recién salidos de la universidad, que no necesariamente tienen estudios de postgrado, quizás sólo tienen experiencia clínica y ese conocimiento lo importan de manera equivocada, no hay fiscalización de esos equipos, hay mucha rotación de personal, relaciones contractuales a honorarios, lo que viene a ser muchas veces el primer peldaño de un psicólogo que luego renuncia y busca otro trabajo ${ }^{109}$

Cabe señalar que esta información es consistente con diversos artículos periodísticos en los que se han venido haciendo críticas al trabajo de los peritos en el área. ${ }^{110}$ Debe destacarse el área de la psicología forense si bien relativamente nueva en nuestro país ya cuenta con programas de especialización a nivel de magíster en diversas universidades nacionales. ${ }^{111}$

En el área de la medicina legal también existe acuerdo entre los tres entrevistados sobre la falta de especialización como un problema crítico. Un perito describe el nivel de especialidad señalando:

\footnotetext{
${ }^{108}$ Entrevista Perito ${ }^{\circ} 1,18$ de julio de 2016.

109 Entrevista Perito $\mathrm{n}^{\circ}$ 4, 4 de agosto de 2016. Incluso el tercer experto del área cuantifica el problema señalando que "El 70\% de los peritos psicólogos y psiquiatras carecen de formación teórica adecuada. Entonces hay un problema de formación y de método.” Entrevista Perito n 2, 19 de julio de 2016.

110 Por ejemplo, JARA, Matías; ALBERT, Carolina, "Tribunales de Familia: las Graves Deficiencias del Sistema de Peritos, en: CIPER Chile, 2016, en: http://ciperchile.cl/2016/08/30/tribunales-de-familia-lasgraves-deficiencias-del-sistema-de-peritos/ [Visitado el 02.02.2017]. El foco del reportaje es analizar el funcionamiento de la prueba pericial en los Tribunales de Familia. Ahí se muestra cómo la demanda generada por esta jurisdicción ha producido una sobrecarga laboral en el SML y los DAM que les impide atender la demanda adecuadamente.

${ }^{111}$ Uno de los programas más antiguos es el de la Universidad Diego Portales que cuenta con un Magíster en Psicología Jurídica y Forense que se encuentra en su XI versión. En http://postgrados.udp.cl/magisterpsicologia-juridica-forense/ [visitado el 07.06.2017]. La Universidad de la Frontera también cuenta con un programa de Magíster en Psicología Jurídica y Forense acreditado por cinco años (2014-2019). En http://postgrado.ufro.cl/index.php/magister/9-sin-categoria/95-magister-especialidad-en-psicologia-juridica-y-

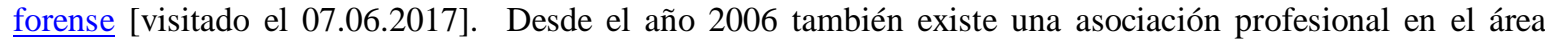
(Asociación Psicología Jurídica).
} 
Polít. crim. Vol. 13, № 25 (Julio 2018) Art. 2, pp. 42-103.

[http://www.politicacriminal.cl/Vol_13/n_25/Vol13N25A2.pdf]

Mediocre. De partida, hablando dentro de los peritos del SML, la mínima cantidad tiene una especialidad formal. La mayor parte se forma en el camino, sin ninguna capacitación. En provincia es peor, en Santiago como se concentran gran número de casos y con varios médicos que tratamos de capacitar a los que llegan, hay más posibilidad de elevar el nivel de los peritos. En provincia eso no pasa, a veces el médico es el único...llegan a trabajar y aprenden de los técnicos en autopsia y con suerte aprueban una pasantía de dos semanas en Santiago y luego ya están haciendo pericias y firmando como peritos. Por tanto es un medio malo en general. ${ }^{112}$

Analiza también la situación externa al SML describiendo que "En general si uno hace un análisis a nivel de todo el país, se trata de un nivel mediocre". ${ }^{113}$ Otro perito señala sobre el punto: “... los que nos dedicamos a esto (la medicina legal) somos pocos y muchos no están especializados. Muchos llegan a un área a la que recién se están abriendo y no se quedan dentro de ella". ${ }^{114}$ Finalmente, un tercer perito, concordando con lo anterior, ofrece algunos datos para graficar el problema: "Los especialistas formados en medina legal en Chile somos 23. De estos están 10 activos y de ellos sólo 4 están en el SML. Por ende si hay 300 médicos en el SML, 296 no tienen formación en medicina legal, aunque sean especialistas en ciertas áreas y se dediquen a cuestiones médico legales, como un traumatólogo". ${ }^{115}$

Estas opiniones son corroboradas con otra información que fue recopilada en el desarrollo de esta investigación. Así, se obtuvo a modo ejemplar la composición de la unidad de sexología forense del SML en la Región Metropolitana. Se escogió este ejemplo ya que se trata de un peritaje de mucha importancia y frecuencia tratándose de delitos sexuales. En el estudio empírico de sentencias TOP en delitos sexuales fue la segunda categoría con mayor frecuencia, correspondiendo al 20,3\% del total de peritajes presentados a juicio. ${ }^{116} \mathrm{Al}$ mes de abril de 2016, la unidad estaba compuesta por 11 integrantes, siete de los cuáles no tenían ninguna especialidad, dos poseían la de medicina forense y dos la de ginecólogos. ${ }^{117}$ Para que se tenga una magnitud del trabajo de esta unidad, durante el año 2015 informaron 3.389 casos de los 6.182 realizados por el SML a nivel nacional (tabla $\mathrm{n}^{\circ} 3$ ). En consecuencia, estamos frente a una unidad con una carga intensa de trabajo, que produce una prueba crítica para la acreditación de ciertos tipos de delitos sexuales y en la cual sólo un $18 \%$ de quienes trabajan tiene especialidad en medicina legal y otro $18 \%$ en un área de relacionada. ${ }^{118}$

\footnotetext{
${ }^{112}$ Entrevista Perito ${ }^{\circ}$ 6, 8 de noviembre de 2016.

${ }^{113}$ Entrevista Perito ${ }^{\circ}$ 6, 8 de noviembre de 2016.

${ }^{114}$ Entrevista Perito ${ }^{\circ}$ 7, 18 de noviembre de 2016.

115 Entrevista Perito ${ }^{\circ}$ 3, 20 de julio de 2016.

116 SANTIBAÑEZ, Uso de la Prueba Pericial, cit. nota ${ }^{\circ} 4$, p. 35.

117 Información otorgada por el Servicio Médico Legal el día 20 de abril de 2016 (documento en formato electrónico en poder del autor).

${ }^{118}$ Impresiones muy similares a las descritas fueron entregadas por un fiscal entrevistado con alta experiencia en la persecución penal de delitos sexuales. Éste señaló: “...no tenemos como resolver este problema, peritos sexólogos forenses que no son forenses y no son ginecólogos, entonces tienen un entrenamiento mínimo que les dan en el servicio, usan el colposcopio, pero en el fondo lo que están haciendo es con un estándar muy débil y eso para nosotros es muy delicado, porque nosotros somos los que exponemos el caso y exponemos a un niño sentarse ahí a explicar estas cuestiones. En algunos casos los jueces lo perciben porque es evidente." Entrevista Fiscal n ${ }^{\circ}$ 6, 1 de septiembre de 2015.
} 
DUCE, Mauricio. “Una aproximación empírica al uso y prácticas de la prueba pericial en el proceso penal Chileno a la luz de su impacto en los errores del sistema".

A esto debe agregarse otro número de peritajes sexológicos (cuya cifra es desconocida) realizados por médicos que trabajan en servicios de salud pública. Se trata de personas que en su mayoría no tienen especialización formal en la materia. Así, en un reportaje reciente (de julio 2016) focalizado en el análisis de cómo se lleva adelante la investigación por los delitos de violación en nuestro país, se describe cómo en estos servicios se recibe habitualmente a víctimas de estos delitos por médicos sin ninguna capacitación sobre elaboración de peritajes sexológicos. Según el reportaje, sólo el año 2014 se habría realizado una primera capacitación en estas materias organizada por el Ministerio de Salud en la cual se graduaron 48 médicos (34 del Servicio de Salud y 14 del SML). ${ }^{119}$ Consultado sobre la calidad de esta a uno de los peritos entrevistados su respuesta fue:

Mi impresión de este curso es que es malo. No prepara a nadie ya que aparte que el tiempo de preparación era muy corto, las evaluaciones sexológicas son muy interpretables, hay que hacerse un criterio con tiempo para poder hacer un buen peritaje, analizando casos, imágenes, lo que requiere un tiempo que no había. ${ }^{120}$

Se trata de un punto muy importante a tener presente, ya como el mismo perito señala en esta área los peritajes son muy interpretables y la subjetividad de quien los practica tiene mucha incidencia, por lo que resulta crucial se trate de un experto calificado.

Volviendo al análisis general del área de la medicina legal, las causas que generan el escenario descrito difieren algo de las identificadas para la psicología forense. Los tres entrevistados concuerdan que una parte central del problema está en el poco prestigio que tiene la especialidad en Chile y los bajos incentivos económicos que ofrece en comparación a otras especialidades de su profesión. Se señala, por ejemplo, que un ginecólogo podría ganar hasta tres veces más en la atención privada que lo que podría obtener en el SML. Algo similar ocurriría con especialistas patólogos y todos ellos con mejores condiciones de trabajo y horarias. Desde el punto de vista de la formación especializada, sólo existiría un programa a nivel nacional ofrecido por la Universidad de Chile y el cual no se presentarían postulantes todos los años.

Muy brevemente me refiero al área de la auditoría forense, ya que en ella fue entrevistado un solo perito. La opinión es similar a las de las otras disciplinas, se sostiene que hay problemas de experiencia y formación, concluyendo que "Se venden como peritos forenses pero somos muy pocos los que en realidad lo somos. Aparecen colegas que no tienen formación de forense pero se vende así pues no saben la distinción entre experto y forense. No hay filtro de estándar que permita el escrutinio". ${ }^{121}$

El análisis de las tres áreas muestra que estamos en presencia de un problema bastante complejo y que no parece depender simplemente de la voluntad de las instituciones de tener más y mejores especialistas, sino también de elementos de diseño institucional y política

\footnotetext{
${ }^{119}$ DOMEYKO, “La Denuncia”, cit. nota n 4, p. 40.

${ }^{120}$ Entrevista Perito ${ }^{\circ} 7,18$ de noviembre de 2016.

${ }^{121}$ Entrevista perito ${ }^{\circ}$ 5, 15 de septiembre de 2016.
} 
Polít. crim. Vol. 13, № 25 (Julio 2018) Art. 2, pp. 42-103.

[http://www.politicacriminal.cl/Vol_13/n_25/Vol13N25A2.pdf]

pública un poco más sofisticados. Volveré sobre este punto en el próximo capítulo cuando aborde algunas sugerencias para el trabajo futuro.

2.2.3. El rol de la Audiencia de Preparación de Juicio Oral en la admisibilidad de la prueba pericial

En un escenario en el que, como se ha revisado previamente, existen importantes aprehensiones respecto a la calidad de los peritajes que habitualmente se producen en ciertas materias y cuestionamientos serios sobre los niveles de experiencia y formación de los peritos, se esperaría que el sistema intentara filtrar los casos de prueba pericial de menor calidad o elaborados por peritos sin las competencias básicas, para evitar que sean utilizados en juicio oral y lleven al sistema a cometer un error.

El momento institucional que nuestro proceso penal prevé debiera ocurrir este trabajo de depuración de la prueba que se presentará a juicio es la denominada Audiencia de Preparación de Juicio Oral (en adelante la APJO). Así, desde hace algún tiempo un sector de la doctrina y la jurisprudencia nacional ha venido sosteniendo que, junto con los requisitos generales de admisibilidad de todo medio probatorio, los peritajes tienen algunas reglas adicionales especiales dentro de las cuáles se incluyen la idoneidad del perito y la confiabilidad del peritaje. ${ }^{122}$ En el contexto descrito, la investigación intentó determinar si la APJO está cumpliendo o no en la práctica el rol de filtrar la prueba pericial que se intenta introducir a juicio, especialmente considerando razones vinculadas a los problemas de idoneidad y confiabilidad que aparentemente existirían en nuestro medio.

Se trata de un tema que fue especialmente indagado respecto de fiscales, defensores, abogados privados y jueces de garantía. En cambio, tratándose de jueces orales y peritos, por la naturaleza de sus funciones, no pareció pertinente ahondar en este tema. En este marco, el consenso compartido entre las cuatro categorías de entrevistados sobre el punto es que los debates de exclusión de la prueba pericial en la APJO son pocos. En algunos casos

\footnotetext{
${ }^{122}$ En la doctrina nacional véase: DUCE, Mauricio, “Admisibilidad de la Prueba Pericial en Juicios Orales: un Modelo para Armar en la Jurisprudencia Nacional”, en: ACCATINO, Daniela (coord.), Formación y Valoración de la Prueba en el Proceso Penal, Santiago, AbeledoPerrot, 2010, pp. 45-86. Debo señalar que más allá del debate local, la exigencia de mayores filtros para la admisibilidad de la prueba pericial es una tendencia muy significativa en el ámbito comparado, tanto en países de la tradición anglosajona y crecientemente en los de la tradición europeo continental. FRECKELTON et al., Expert Evidence, cit. nota $n^{\circ}$ 15, pp. 19-46; JACKSON, John D.; SUMMERS, Sarah J., The Internationalisation of Criminal Evidence: Beyond the Common Law and Civil Law Traditions, Cambridge: Cambridge University Press, 2012, pp. 7476; VÁZQUEZ, Carmen, Estándares de Prueba y Prueba Científica. Ensayos de Epistemología Jurídica, Madrid: Marcial Pons, 2013. En materia de la jurisprudencia local hay algunas decisiones de Cortes de Apelaciones del país que han validado la exclusión por falta de acreditación de idoneidad de los peritos, por ejemplo, Corte de Apelaciones de San Miguel, Sentencia de 12 de octubre de 2007, rol n ${ }^{\circ}$ 1392-2007, y, Corte de Apelaciones de Valparaíso, Sentencia de 29 de abril de 2016, rol n 644-2016. Como también otras en donde el problema es que se ha tratado de una pericia de poca confiabilidad, por ejemplo, Corte de Apelaciones de Rancagua, Sentencia de 23 de mayo de 2013, rol n ${ }^{\circ} 199-2013$. Se trata, con todo, de una tendencia jurisprudencial que no pareciera ser la dominante como volveré a mencionar.
} 
DUCE, Mauricio. “Una aproximación empírica al uso y prácticas de la prueba pericial en el proceso penal Chileno a la luz de su impacto en los errores del sistema".

se plantea que estos debates serían incluso inexistentes, ${ }^{123}$ pero la gran mayoría los describe más bien como de carácter excepcional. ${ }^{124}$ Un fiscal que se incluye dentro de la primera categoría señala: "No hay debate de admisibilidad y eso es pésimo. Quizás nos puede favorecer en algunos casos, pero hasta ahí no más ya que en el fondo es una ganancia a corto plazo, ya que si el perito es malo no te sirve tampoco. Yo echo de menos que haya debate de admisibilidad". ${ }^{25}$ Otro que, en cambio se ubica dentro del segundo grupo, indica "Hay muy poco debate en relación al que debiera existir, lo que se traduce en juicios de duración excesiva con peritos malos". ${ }^{126}$ Me pareció interesante reproducir estas declaraciones ya que muestran consciencia en los actores del sistema que se está frente a una práctica deficitaria desde distintos puntos de vista: la calidad de la prueba y la eficiencia del sistema.

Resulta interesante intentar explicar la situación descrita. Son varias hipótesis posibles, por ejemplo, se podría señalar que el problema surge como consecuencia del desconocimiento que en general fiscales y defensores tienen de las reglas de admisibilidad especiales de la prueba pericial o de los mecanismos idóneos para su discusión. ${ }^{127}$ Más adelante entregaré información sobre la capacitación recibida por estos actores para lidiar con la prueba pericial. Como se verá, la información que consistentemente entregan indicaría que efectivamente hay carencias en esta materia.

El comportamiento poco proactivo de fiscales y defensores para generar estos debates también podría explicarse como consecuencia de una actitud derrotista frente a los resultados que obtienen regularmente en las APJO. Al final del día, si la probabilidad de éxito es baja, una tendencia natural es no hacer un esfuerzo que no traerá resultados positivos. ${ }^{128}$ Varias opiniones dan cuenta que éste podría ser un factor. Por ejemplo,

\footnotetext{
${ }^{123}$ Entrevista Fiscal $n^{\circ}$ 3, 10 de julio de 2015; Entrevista Fiscal $n^{\circ}$ 6, 11 de septiembre de 2015, Entrevista Fiscal $n^{\circ}$ 13, 29 de enero de 2016; Entrevista Abogado ${ }^{\circ}$ 3, 2 de julio de 2015; y, Entrevista Abogado $n^{\circ} 4$, 22 de julio de 2015.

${ }^{124}$ Entrevista Fiscal $n^{\circ}$ 1, 7 de mayo de 2015; Entrevista Fiscal $n^{\circ} 2,9$ de junio de 2015; Entrevista Fiscal ${ }^{\circ}$ 4, 28 de julio de 2015; Entrevista Fiscal $n^{\circ}$ 5, 4 de septiembre de 2015; Entrevista Fiscal $n^{\circ}$ 7, 2 de octubre de 2015; Entrevista Fiscal $n^{\circ}$ 8, 28 de diciembre de 2015; Entrevista Fiscal $n^{\circ}$ 9, 4 de enero de 2016; Entrevista Fiscal $n^{\circ} 11,7$ de enero de 2016; Entrevista Fiscal ${ }^{\circ}$ 12, 12 de enero de 2016; Entrevista Juez de Garantía ${ }^{\circ}$ 1, 7 de mayo de 2015; Entrevista Juez de Garantía n 3, 26 de junio de 2015; Entrevista Juez de Garantía $n^{\circ} 4$, 8 de julio de 2015; Entrevista Juez de Garantía n ${ }^{\circ}$ 5, 15 de julio de 2015; Entrevista Juez de Garantía $n^{\circ} 6,3$ de septiembre de 2015; Entrevista Juez de Garantía ${ }^{\circ}$ 7, 14 de septiembre de 2015; Entrevista Juez de

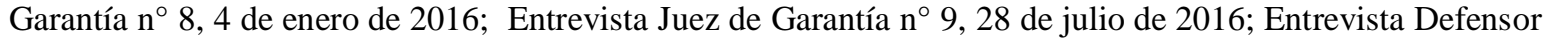
$\mathrm{n}^{\circ} 1,11$ de junio de 2015; Entrevista Defensor $\mathrm{n}^{\circ} 5$, 4 de septiembre de 2015; Entrevista Defensor $\mathrm{n}^{\circ} 6,1$ de abril de 2016; Entrevista Defensor n ${ }^{\circ}$ 7, 19 de abril de 2016; Entrevista Defensor $n^{\circ}$ 8, 11 de mayo de 2016; Entrevista Abogado ${ }^{\circ}$ 1, 4 de mayo de 2015; Entrevista Abogado $n^{\circ} 2,2$ de junio de 2015; Entrevista Abogado n ${ }^{\circ}$ 5, 25 de agosto de 2016; y, Entrevista Abogado n 6, 25 de agosto de 2016.

125 Entrevista Fiscal n ${ }^{\circ} 6,11$ de septiembre de 2015.

${ }^{126}$ Entrevista Fiscal $n^{\circ} 12,12$ de enero de 2016.

127 Se plantean problemas en ambas direcciones. Véase: DUCE, Mauricio, "Los Informes en Derecho Nacional y su Admisibilidad como Prueba a Juicio en el Proceso Penal Chileno", Revista de Derecho (Valdivia), vol. 29, n 1 (2016), pp. 297-327.

128 Esta es una de las explicaciones que en los Estados Unidos se dan respecto al pobre desempeño de los defensores en un tema análogo como es la exclusión de los reconocimientos oculares producidos en condiciones que no aseguran su confiabilidad mínima. WELLS, Gary L.; GREATHOUSE, Sarah M.;
} 
algunos entrevistados manifestaron que, para los jueces de garantía, los problemas potenciales que podrían impedir la admisibilidad de una prueba pericial son más bien temas de fondo y por eso esta prueba pasa sin problemas a juicio oral ya que allí debieran ser discutidas. ${ }^{129}$ Otros, en cambio, señalan que incluso respecto de jueces de garantía dispuestos a excluir prueba pericial en la APJO, el problema se presenta ya que las Cortes de Apelaciones regularmente revierten ese tipo de decisiones. ${ }^{130}$ Cómo se podrá apreciar, estos ejemplos dan cuenta que se ha instalado una cultura en el sistema según la cual no se debe hacer un escrutinio muy estricto tratándose de esta prueba. Todo ello podría explicar el bajo nivel de discusión en esta materia.

La excepción principal a la situación descrita se produciría en debates sobre la falta de idoneidad del perito que las partes presentan. Con todo, estos debates se basarían no en una discusión de fondo sobre el tema sino que en la no presentación de antecedentes formales que la acrediten, por ejemplo, las copias de los títulos profesionales o el curriculum vitae. ${ }^{131}$ Se trata de un debate surgido al amparo de la regla contenida en el artículo 314 inciso primero del Código Procesal Penal (en adelante el CPP) que señala que los intervinientes pueden solicitar en la APJO sea admitida su prueba pericial "acompañando los comprobantes que acreditaren la idoneidad profesional del perito". Sobre este tema es posible encontrar variada jurisprudencia en nuestros tribunales superiores de justicia y que ratificaría la opinión de los entrevistados que ésta sería la principal área de debate en la materia. ${ }^{132}$ Con menor frecuencia se mencionan debates de exclusión de la prueba pericial

SMALARZ, Laura, Why do Motions to Suppress Suggestive Eyewitness Identifications Fail?, Washington D.C.: American Psychological Association, 2012, p. 179.

${ }^{129}$ Por ejemplo, un defensor explicando la excepcionalidad de los debates de admisibilidad señaló que "Las pericias que se debaten también son pocas y los jueces no son receptivos de esto. Pesa el criterio de valoración del peritaje y no de admisibilidad" Entrevista Defensor $n^{\circ} 1$, 11 de junio de 2015 . En una línea similar Entrevista Defensor $n^{\circ}$ 5, 4 de septiembre de 2015; y, Entrevista Abogado $\mathrm{n}^{\circ}$ 1, 4 de mayo de 2015. De una forma algo más genérica un fiscal parece estar de acuerdo con el punto al señalar que "Siempre pasa la prueba porque para el juez de garantía es más fácil pasarlo y que lo vea el tribunal oral..." Entrevista Fiscal $\mathrm{n}^{\circ} 11,7$ de enero de 2016. Finalmente, un juez de garantía ratificaría estas apreciaciones al reconocer que los jueces son en general bastante laxos en materia de admisibilidad de la prueba pericial lo que hace que "pase todo" a juicio oral. Entrevista Juez de Garantía n 9, 28 de julio de 2016.

${ }^{130}$ Entrevista Fiscal n ${ }^{\circ}$ 5,4 de septiembre de 2015; Entrevista Defensor n ${ }^{\circ} 3,2$ de julio de 2015; Entrevista Defensor $n^{\circ}$ 4, 2 de julio de 2015; Entrevista Juez de Garantía $n^{\circ}$ 4, 8 de julio de 2015; y, Entrevista Juez de Garantía $\mathrm{n}^{\circ} 7,14$ de septiembre de 2015.

${ }^{131}$ Entrevista Fiscal $n^{\circ}$ 2, 9 de junio de 2015; Entrevista Fiscal $n^{\circ} 4,28$ de julio de 2015; Entrevista Fiscal $n^{\circ}$ 5, 4 de septiembre de 2015; Entrevista Fiscal $n^{\circ}$ 7, 2 de octubre de 2015, Entrevista Fiscal $n^{\circ} 8,28$ de $^{\circ}$ diciembre de 2015; Entrevista Fiscal n 9, 4 de enero de 2016, Entrevista Fiscal $n^{\circ} 11,7$ de enero de 2016; Entrevista Fiscal $n^{\circ}$ 12, 12 de enero de 2016; Entrevista Juez de Garantía $n^{\circ} 2$ 2, 25 de junio de 2015; Entrevista Juez de Garantía n ${ }^{\circ}$ 4, 8 de julio de 2015; Entrevista Juez de Garantía n 5, 15 de julio de 2015; Entrevista Juez de Garantía n ${ }^{\circ}$ 6, 3 de septiembre de 2015; Entrevista Juez de Garantía n ${ }^{\circ}$ 7, 14 de septiembre de 2015; Entrevista Juez de Garantía n 8, 4 de enero de 2016; Entrevista Defensor n 6, 1 de abril de 2016; Entrevista Defensor $n^{\circ}$ 8, 11 de mayo de 2016; y, Entrevista Abogado n ${ }^{\circ}$, 25 de agosto de 2016.

${ }^{132}$ Buena parte de esta jurisprudencia está destinada a resolver el problema de si la exigencia de acompañar los antecedentes de los peritos a la APJO se extiende a los funcionarios que trabajan en instituciones auxiliares del Ministerio Público o ellos quedan excluidos de tal deber por una excepción que establecería el artículo 321 del Código Procesal Penal. A pesar que, en mi opinión, el tenor literal y el fin de dicha regla no permiten concluir la existencia de una excepción, la jurisprudencia mayoritaria se ha pronunciado en contrario, sosteniendo que en esos casos no se requiere acompañar comprobantes y, por lo mismo, ha 
DUCE, Mauricio. “Una aproximación empírica al uso y prácticas de la prueba pericial en el proceso penal Chileno a la luz de su impacto en los errores del sistema".

por falta de pertinencia de la misma ${ }^{133}$, por haber sido obtenida con infracción de garantías $^{134}$ y por intentar que el informe escrito ingrese a juicio oral como prueba. ${ }^{135}$

Para cerrar esta sección, la información disponible indica claramente que no hay debates relevantes sobre la admisibilidad de la prueba pericial basados en los problemas que más intensamente podrían generar errores del sistema.

\subsubsection{Prácticas problemáticas en la producción de la prueba pericial en juicio oral}

Como se determinó en la sección previa, la regla general es que la prueba pericial presentada por los intervinientes sea admitida a juicio oral aún cuando pudiera tener algunos problemas de confiabilidad en su elaboración o de especialidad de quien la realizó. Siendo esto así, un punto central a indagar fue analizar las prácticas de los intervinientes para examinar si en el contexto de la audiencia hacían un esfuerzo por presentar la información que aportan los peritos de manera clara y, especialmente, si desarrollaban una práctica de confrontación intensa de manera de presentar cuestionamientos acerca de su calidad al tribunal de juicio oral. Como ya he revisado, la evidencia comparada muestra que esta es un área problemática y que explica en parte los errores del sistema de justicia penal al evaluar la prueba pericial.

Sobre el primer punto, la presentación de la prueba, las entrevistas entregaron alguna información de interés. Lo que se aprecia es una visión crítica a la forma en que se rinde esta prueba en el juicio. Así, pudo percibirse que los jueces de juicio oral entrevistados manifestaban un cierto nivel de insatisfacción acerca del trabajo realizado por los litigantes en la materia. Uno de ellos señaló:

[...] muchos fiscales y defensores se quedan con la palabra del perito y no son capaces de explicarle al tribunal cual es la importancia de la información. Ahora yo creo que en esto influye también cómo se ha interpretado la norma de rendición de la prueba pericial. Esto ya que en general los tribunales lo que hacen es cumplirla a raja tabla y dejar que el perito hable. Entonces el perito se aprende un discurso de memoria antes de entrar a la sala de audiencias, da un largo discurso y luego así no te queda un

revocado decisiones de exclusión adoptadas por jueces de garantía. A modo ilustrativo puede verse: Corte Suprema, Sentencia de 21 de julio 2014, rol n 11.115-2014; Corte de Apelaciones de Santiago, Sentencia de de 2 de septiembre de 2011, rol n' 1756-2011; Corte de Apelaciones de Antofagasta, Sentencia de 3 de septiembre de 2010, rol n ${ }^{\circ}$ 276-2010; Corte de Apelaciones de Arica, Sentencia de 7 de julio de 2010, rol $n^{\circ}$ 145-2010; Corte de Apelaciones de Santiago, Sentencia de 21 de octubre de 2009, rol no 2130-2009; Corte de Apelaciones de San Miguel, Sentencia de 5 de junio de 2007, rol n 802-2007; y, Corte de Apelaciones de San Miguel, Sentencia de 12 octubre de 2007, rol n 815-2007.

${ }_{133}$ Entrevista Fiscal $\mathrm{n}^{\circ}$ 4, 28 de julio de 2015; Entrevista Fiscal $\mathrm{n}^{\circ}$ 10, 6 de enero de 2016; Entrevista Defensor $^{\circ}$ 3, 2 de julio de 2015; Entrevista Defensor $n^{\circ} 4,2$ de julio de 2015; Entrevista Defensor $n^{\circ} 6,1$ de abril de 2016; Entrevista Juez de Garantía n ${ }^{\circ}$ 9, 28 de julio de 2016; Entrevista Abogado $n^{\circ} 5,25$ de agosto de 2016; y, Entrevista Abogado n 6, 25 de agosto de 2016.

${ }^{134}$ Entrevista Fiscal $n^{\circ}$ 10, 6 de enero de 2016; Entrevista Defensor 3, 2 de julio de 2015; Entrevista Defensor $\mathrm{n}^{\circ}$ 4, 2 de julio de 2015; y, Entrevista Juez de Garantía n ${ }^{\circ}$ 2, 25 de junio de 2015.

135 Entrevista Juez de Garantía n ${ }^{\circ}$ 3, 26 de junio de 2016 y Entrevista Juez de Garantía n 6,3 de septiembre de 2015 . 


\section{Polít. crim. Vol. 13, No 25 (Julio 2018) Art. 2, pp. 42-103. \\ [http://www.politicacriminal.cl/Vol_13/n_25/Vol13N25A2.pdf]}

espacio para preguntas. Lo que nos impide saber de acreditación, metodología y si las conclusiones se apegan al método. ${ }^{136}$

Otro juez oral en la misma dirección describe lo siguiente: "De partida, cuando llega el perito parte exponiendo el peritaje de la página uno hasta el pie de firma final, o sea, se trata de un relato súper estructurado. Como aporte, la forma de incorporarlo, da una soberana lata. Uno no los logra seguir, se pierde en el bosque, porque empiezan a hablar de una cantidad de información...y uno termina mareado". ${ }^{137}$

Estas opiniones darían cuenta de un muy bajo aporte de los litigantes en la producción de la prueba pericial y ello tendría impacto en la calidad de la información que los jueces tendrían para resolver sobre la misma. Los peritos entrevistados también comparten que el trabajo de los litigantes en esta materia es pobre. Así, por ejemplo uno señala que “....en el $90 \%$ de los casos me piden relate el informe completo, que repita todo". ${ }^{138}$ Otro describe su declaración de la siguiente forma: "Mi experiencia es la siguiente: uno expone todo lo que fue su autopsia, la causa de la muerte, los detalles y luego el fiscal muestra las fotos y me hace preguntas. La mayor parte de las veces me hacen una o dos preguntas". ${ }^{139}$ Otro perito pone acento en el trabajo de los defensores públicos dando cuenta de que "Tienen un conocimiento pobre del peritaje.....llegan a la audiencia preguntando cosas que yo tendría que validar, pero que se las tengo que negar, lo que indica que hay mala preparación, no saben lo que va a decir uno como perito". ${ }^{140}$

Este hallazgo se complementa con información recabada en el estudio se sentencias TOP delitos sexuales en tres tribunales de la Región Metropolitana. Dicha investigación arroja algunos datos preocupantes en relación a la calidad de la información que se aporta en el juicio. Así, la investigación da cuenta que sólo en un $13 \%$ de los casos los peritos son interrogados o mencionan su formación o experiencia en juicio, ${ }^{141}$ lo que daría cuenta que la acreditación del perito es entendida en la práctica como una cuestión sin mucha relevancia o, en el mejor de los casos, formal. A ello se suma que en un $32 \%$ de los casos no se presentó o explicó la metodología utilizada en el peritaje sino que sólo se expusieron las conclusiones del mismo. ${ }^{142}$ A lo anterior se debe sumar que si bien en todos los casos analizados los peritos expusieron sus conclusiones, en un 63,2\% ello fue realizado de manera incompleta. ${ }^{143}$ Como se podrá apreciar, elementos esenciales para la valoración de la prueba pericial no serían aportados con la intensidad requerida, lo que daría cuenta de un

\footnotetext{
${ }^{136}$ Entrevista Juez TOP n ${ }^{\circ} 6,14$ de junio de 2015.

${ }^{137}$ Entrevista Juez TOP n ${ }^{\circ} 7,5$ de octubre de 2015.

${ }^{138}$ Entrevista Perito ${ }^{\circ}$ 7, 18 de noviembre de 2016.

${ }^{139}$ Entrevista Perito ${ }^{\circ}$ 6, 8 de noviembre de 2016.

${ }^{140}$ Entrevista Perito ${ }^{\circ} 1,18$ de julio de 2016.

${ }^{141}$ SANTIBAÑEZ, Uso de la Prueba Pericial, cit. nota ${ }^{\circ} 4$, p. 46.

142 SANTIBAÑEZ, Uso de la Prueba Pericial, cit. nota $\mathrm{n}^{\circ} 4$, p. 51. La investigación realiza también un análisis de corte cualitativo en los casos en dónde hubo exposición de la metodología, concluyendo que en $73 \%$ de ese universo ella fue incompleta (p. 52).

${ }^{143}$ La autora del estudio consideró como una conclusión incompleta "aquella observada en la sentencia como una enumeración de hallazgos, sin explicar en qué consisten cada uno de ellos". SANTIBAÑEZ, Uso de la Prueba Pericial, cit. nota ${ }^{\circ}$ 4, p. 59.
} 
DUCE, Mauricio. “Una aproximación empírica al uso y prácticas de la prueba pericial en el proceso penal Chileno a la luz de su impacto en los errores del sistema".

trabajo de baja calidad de los litigantes. Algo similar ocurre con los datos aportados por la base de datos sentencias TOP delitos CVIF ya que en ella sólo en un 5,88\% de los casos los peritos son interrogados o mencionan su formación o experiencia en juicio. A ello se suma que sólo en un 16,18\% de los casos los peritos expusieron la metodología empleada para arribar a sus conclusiones.

Respecto a la capacidad de las partes para confrontar la información aportada por peritos presentados por la contraparte, las opiniones de todos los actores entrevistados son bastantes coincidentes: el control de la calidad de la información que se realiza en los contraexámenes es bajo o incluso prácticamente nulo. ${ }^{144}$ Esto quiere decir que las partes regularmente no cuestionan la prueba pericial presentada o si lo intentan hacer, normalmente ello no la controvierte mínimamente. Se trata de uno de los hallazgos más problemáticos de esta investigación ya que daría cuenta que los controles de calidad de la información que el sistema ha diseñado no se cumplen en la práctica y ello nos expone a la posibilidad que errores importantes sean cometidos al momento de evaluar esta prueba. Se trata, además, de un hallazgo coincidente con lo que el estudio sobre sentencias en delitos sexuales encontró en la materia. Así, según dicho estudio, sólo en un $23 \%$ de los casos analizados hubo algún tipo de cuestionamiento de los intervinientes a la calidad de la metodología, las conclusiones u otros elementos de la prueba pericial presentada por la contraparte. ${ }^{145}$ Resultados peores son arrojados de acuerdo a la base de datos sentencias TOP delitos CVIF, ya que en ella sólo el $11,03 \%$ de los peritajes fueron objeto de cuestionamientos en juicio por alguno de los intervinientes.

\footnotetext{
${ }^{144}$ Entrevista Fiscal n ${ }^{\circ}$ 1, 7 de mayo de 2015; Entrevista Fiscal $n^{\circ} 2,9$ de junio de 2015; Entrevista Fiscal ${ }^{\circ}$ 3, 10 de julio de 2015; Entrevista Fiscal ${ }^{\circ}$ 4, 28 de julio de 2015; Entrevista Fiscal $n^{\circ}$ 7, 2 de octubre de 2015; Entrevista Fiscal n ${ }^{\circ}$ 9, 4 de enero de 2016; Entrevista Fiscal ${ }^{\circ} 10,6$ de enero de 2016; Entrevista Fiscal ${ }^{\circ} 12,12$ de enero de 2016; Entrevista Juez TOP n ${ }^{\circ}$ 1, 9 de junio de 2015; Entrevista Juez TOP ${ }^{\circ}{ }^{\circ} 3,2$ de julio de 2015; Entrevista Juez TOP n ${ }^{\circ}$ 4, 6 de julio de 2015; Entrevista Juez TOP n ${ }^{\circ}$, 8 de julio de 2015; Entrevista Juez TOP $\mathrm{n}^{\circ}$ 6, 14 de julio de 2015; Entrevista Juez TOP $\mathrm{n}^{\circ}$ 7, 5 de octubre de 2015; Entrevista Juez TOP $n^{\circ}$ 8, 22 de diciembre de 2015; Entrevista Juez TOP n ${ }^{\circ}$ 9, 19 de agosto de 2016; Entrevista Juez de Garantía n $^{\circ}$ 1, 7 de mayo de 2015; Entrevista Juez de Garantía n ${ }^{\circ}$ 2, 25 de junio de 2015; Entrevista Juez de Garantía n $^{\circ}$ 3, 26 de junio de 2015; Entrevista Juez de Garantía n ${ }^{\circ}$ 7, 14 de septiembre de 2015; Entrevista Juez de Garantía n ${ }^{\circ}$ 8, 4 de enero de 2016; Entrevista Juez de Garantía n 9, 28 de julio de 2016; Entrevista Defensor $^{\circ}{ }^{\circ}$ 1, 11 de junio de 2015; Entrevista Defensor n ${ }^{\circ} 2,17$ de junio de 2015; Entrevista Defensor $n^{\circ} 3$, 2 de julio de 2015; Entrevista Defensor n ${ }^{\circ}$ 4, 2 de julio de 2015; Entrevista Defensor $n^{\circ} 5$, 4 de septiembre de 2015; Entrevista Defensor $n^{\circ}$ 6, 1 de abril de 2016; Entrevista Defensor $n^{\circ}$ 7, 19 de abril de 2016; Entrevista Defensor $^{\circ}{ }^{\circ}$ 8, 11 de mayo de 2016; Entrevista Abogado ${ }^{\circ}$ 1, 4 de mayo de 2015; Entrevista Abogado $n^{\circ} 3,2$ de julio de 2015; Entrevista Abogado ${ }^{\circ}$ 5, 25 de agosto de 2016; Entrevista Abogado ${ }^{\circ}$ 6, 25 de agosto de 2016; Entrevista Perito n ${ }^{\circ} 1,18$ de julio 2016; Entrevista Perito $n^{\circ} 2,19$ de julio de 2016; Entrevista Perito ${ }^{\circ}$ 3, 20 de julio de 2016; Entrevista Perito n ${ }^{\circ}$ 4, 4 de agosto de 2016; Entrevista Perito n ${ }^{\circ}$ 5, 15 de septiembre de 2016; Entrevista Perito n ${ }^{\circ}$ 6, 8 de noviembre de 2016; y, Entrevista Perito ${ }^{\circ}$ 7, 18 de noviembre de 2016.

145 SANTIBAÑEZ, Uso de la Prueba Pericial, cit. nota $n^{\circ} 4$, p. 63. A este dato debiera sumársele otro adicional. Alguien podría sostener que una estrategia diferente de controvertir la prueba pericial es por vía de presentar a otro perito del área que contradiga al presentado por el otro interviniente, de manera tal que la falta de contraexamen no sería tan grave. El mismo estudio identifica que la defensa presenta prueba pericial sólo en un $22,6 \%$ de los casos y que de ellos $2 / 3$ son metapericias, es decir, peritajes que analizan a otros peritajes presentados en juicio. Esto mostraría que tampoco esta vía parece ser una estrategia frecuente para el control de la calidad de la información. SANTIBAÑEZ, Uso de la Prueba Pericial, cit. nota ${ }^{\circ}$ 4, p. 30. Esto es también coincidente con las opiniones obtenidas en las entrevistas en donde por regla general se señaló que la presentación de metapericias de parte de defensores sólo era común en delitos sexuales.
} 
Polít. crim. Vol. 13, № 25 (Julio 2018) Art. 2, pp. 42-103.

[http://www.politicacriminal.cl/Vol_13/n_25/Vol13N25A2.pdf]

Los entrevistados ofrecen algunas razones que explicarían el escenario descrito. Una de las que más reiteradas tiene que ver con la falta de formación y destrezas específicas de los litigantes para lidiar con los expertos, ${ }^{146}$ lo que en palabras de un juez de garantía hace que los peritos se les "vayan en collera" a los litigantes. ${ }^{147}$ Como ya dije, volveré sobre este punto en el capítulo final de este trabajo, por lo que no me detengo en detalles ahora. Una segunda explicación es la poca preparación con la que llegan a litigar los casos a las audiencias de juicio, lo cual estaría vinculado a la falta de tiempo para poder hacerlo o, desde otro punto de vista, con la excesiva carga de trabajo que estarían teniendo fiscales y defensores. ${ }^{148}$ Una tercera y última causa que aparece mencionada en las entrevistas, aún cuando con menos frecuencia, es que varios actores identifican un proceso de deterioro en el funcionamiento del sistema o derechamente de "pérdida de calidad" en el trabajo de los litigantes, en la medida que los años han pasado desde la puesta en marcha inicial del sistema. $^{149}$

La excepción a este escenario general negativo se daría en dos hipótesis. La primera es que varios entrevistados concuerdan que en la medida que el litigante tenga una mayor especialidad en un tema específico (por ejemplo lleve casos preferentemente de una categoría de delitos), eso se traduce en una mayor capacidad de cuestionamientos a la prueba pericial. ${ }^{150}$ Vinculado a esta misma lógica estaría la segunda hipótesis, ya que algunos actores sostienen que en donde en general se daría mayor cuestionamiento a la

146 Entrevista Fiscal $n^{\circ} 2$, 9 de junio de 2015; Entrevista Defensor $n^{\circ} 1,11$ de junio de 2015; Entrevista

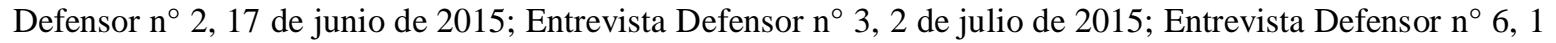
de abril de 2016; Entrevista Defensor $n^{\circ}$ 8, 11 de mayo de 2016; Entrevista Juez de Garantía $n^{\circ} 2,25$ de junio de 2015; Entrevista Juez de Garantía n ${ }^{\circ}$ 7, 14 de septiembre de 2015; Entrevista Juez de Garantía n ${ }^{\circ}$ 9, 28 de julio de 2016 ; Entrevista Juez TOP n ${ }^{\circ} 4,6$ de julio de 2015; Entrevista Juez TOP n 5, 8 de julio de 2015; Entrevista Juez TOP $\mathrm{n}^{\circ}$ 7, 5 de octubre de 2015; Entrevista Juez TOP $\mathrm{n}^{\circ}$ 8, 22 de diciembre de 2015; Entrevista Abogado $n^{\circ}$ 5, 25 de agosto de 2016; Entrevista Perito $n^{\circ}$ 3, 20 de julio de 2016; Entrevista Perito $\mathrm{n}^{\circ}$ 4, 4 de agosto de 2016; Entrevista Perito $\mathrm{n}^{\circ}$ 5, 15 de septiembre de 2016; y, Entrevista Perito $\mathrm{n}^{\circ} 6,8$ de noviembre de 2016.

${ }^{147}$ Entrevista Juez de Garantía ${ }^{\circ}$ 7, 14 de septiembre de 2015.

${ }^{148}$ Entrevista Defensor ${ }^{\circ} 7,19$ de abril de 2016; Entrevista Juez TOP n ${ }^{\circ} 2,15$ de junio de 2015 (quien pone énfasis en el análisis señalando que "los fiscales están colapsados"), Entrevista Juez TOP n 3, 2 de julio de 2015; Entrevista Juez TOP n 5, 8 de julio de 2015; Entrevista Juez TOP n ${ }^{\circ}$ 9, 19 de agosto de 2016; Entrevista Abogado $n^{\circ}$ 1, 4 de mayo de 2015; Entrevista Abogado n ${ }^{\circ}$ 5, 25 de agosto de 2016; Entrevista Abogado $n^{\circ}$ 6, 25 de agosto de 2016; Entrevista Perito $n^{\circ} 4,4$ de agosto de 2016; Entrevista Perito $n^{\circ} 5,15$ de septiembre de 2016; y, Entrevista Perito n ${ }^{\circ}$ 7, 18 de noviembre de 2016 (quien señala se da cuenta que los litigantes "no logran un estudio del peritaje con profundidad").

${ }^{149}$ En esta dirección un juez de garantía describe el escenario señalando que los litigantes "se han achanchado". Entrevista Juez d Garantía n 3, 26 de junio de 2015. Un abogado, en cambio, atribuye este fenómeno derechamente a la "falta de interés" por hacer bien el trabajo. Entrevista Abogado n ${ }^{\circ} 6,25$ de agosto de 2016. En una línea similar un perito considera que este fenómeno se explica por la "desidia" y la "lata" que tendrían algunos actores en realizar bien su trabajo. Entrevista Perito $\mathrm{n}^{\circ}$ 5, 15 de septiembre de 2016. En cambio, otro considera que este deterioro podría estar vinculado al recambio que ha habido con el transcurso del tiempo al constatar que fiscales más nuevos tendrían peor calidad que los originales. Entrevista Perito $\mathrm{n}^{\circ}$ 6, 8 de noviembre de 2016. Sin pronunciarse sobre una razón específica, pero constatando el mismo fenómeno, Entrevista Perito n ${ }^{\circ} 1,18$ de julio de 2016.

${ }^{150}$ Entrevista Fiscal $n^{\circ}$ 2, 9 de junio de 2015; Entrevista Fiscal $n^{\circ} 5$, 4 de septiembre de 2015; Entrevista

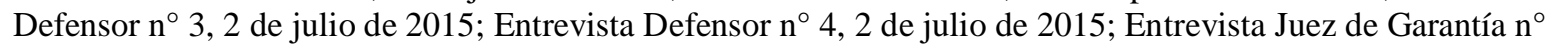
8, 4 de enero de 2016; y, Entrevista Perito ${ }^{\circ}$ 7, 18 de noviembre de 2016. 
DUCE, Mauricio. “Una aproximación empírica al uso y prácticas de la prueba pericial en el proceso penal Chileno a la luz de su impacto en los errores del sistema".

prueba pericial en juicio sería tratándose de los peritajes presentados en materia de delitos sexuales. En este sentido, ambos se relacionan ya que, en parte, esta mayor capacidad estaría asociada en algunos casos a que se trata de un tipo de delitos en dónde ha existido mayor especialización en el sistema. ${ }^{151}$ Con todo, esta última opinión podría morigerarse a la luz de los resultados del estudio empírico de sentencias que ya he citado, según el cual sólo en un $23 \%$ de los casos de delitos sexuales incluidos en la muestra habría cuestionamiento de la prueba pericial. ${ }^{152}$

Más allá de estas excepciones, el cuadro general que muestra la investigación es preocupante. Los testimonios indicarían que de manera regular la prueba pericial presentada a juicio no sería objeto de un escrutinio estricto de parte de los litigantes.

Un último tema que se indagó, en materia de presentación de la prueba pericial en juicio, tuvo que ver con la extensión de un fenómeno que se puede describir como el de "peritos que hablan más de lo que escriben". Bajo este rótulo identifico las hipótesis en que en la audiencia de juicio estos incluyen en su testimonio aspectos relevantes para el caso que no han sido objeto de mención en el informe escrito previo. Me interesó indagar este punto ya que cuando las diferencias van más allá de detalles o elementos accesorios, que naturalmente una declaración en juicio incorporará y que es difícil que esté contenida con exactitud en el informe escrito previo, su admisión genera riesgos importantes al sistema. Esto, ya que dificulta en extremo someter estos nuevos contenidos a un examen serio de verosimilitud y seriedad, al no entregar un espacio real a la contraparte para hacerse cargo de ellos. Por lo mismo, se trata de una forma indirecta de debilitar los controles de la calidad de la información. ${ }^{153}$

Se trata de un tema que especialmente fue indagado con los litigantes y jueces de juicio oral. En los fiscales existe una posición dividida sobre este punto a pesar que un grupo reconoce se trata de una práctica común. ${ }^{154}$ Los defensores, en cambio, manifestaron un mucho mayor nivel de acuerdo que se trataría de un fenómeno habitual y que recaería sobre aspectos relevantes de las declaraciones. ${ }^{155}$ En los abogados particulares también hay una

${ }^{151}$ Entrevista Fiscal $n^{\circ}$ 6, 11 de septiembre de 2015; Entrevista Fiscal $n^{\circ}$ 7, 2 de octubre de 2015; Entrevista Fiscal $n^{\circ} 11,7$ de enero de 2016; Entrevista Fiscal n ${ }^{\circ} 12,12$ de enero de 2016; y, Entrevista Juez de Garantía $\mathrm{n}^{\circ} 7,14$ de septiembre de 2015 .

152 SANTIBAÑEZ, Uso de la Prueba Pericial, cit. nota ${ }^{\circ} 4$, p. 63.

${ }^{153}$ La jurisprudencia de la Corte Suprema se ha ido consolidando en términos de estimar que situaciones de este tipo afectan el derecho a defensa y ha declarado la nulidad de audiencias de juicio en donde ello ha ocurrido. Por ejemplo, véase: Corte Suprema, Sentencia de 17 de junio de 2013, rol n ${ }^{\circ}$ 2866-2012, y Corte Suprema, Sentencia de 11 de marzo de 2015, rol n 448-2015. Esto revierte alguna jurisprudencia previa de cortes de apelaciones en sentido diverso. Por ejemplo, Corte de Apelaciones de Puerto Montt, Sentencia de 8 febrero de 2010, rol no 267-2009.

${ }^{154}$ En esta dirección Entrevista Fiscal n 6, 11 de septiembre de 2015 (quien atribuye este comportamiento a peritos de la defensa) ; Entrevista Fiscal n 10, 6 de enero de 2016; y, Entrevista Fiscal n ${ }^{\circ} 13,29$ de enero de 2016 (quien destaca que además es una práctica frecuente y aceptada por los tribunales). En contra, en cambio, Entrevista Fiscal n ${ }^{\circ}$ 3, 10 de julio de 2015 y Entrevista Fiscal n ${ }^{\circ}$ 8, 28 de diciembre de 2015. En una posición intermedia están los fiscales que reconocen la práctica pero que ella sólo se referiría a temas accesorios. Por ejemplo, Entrevista Fiscal n 4, 28 de julio de 2015.

155 Entrevista Defensor $n^{\circ} 1,11$ de junio de 2015 8quien señala se trata de una cuestión que intentan "pelear" en la audiencia); Entrevista Defensor n 3, 2 de julio de 2015; Entrevista Defensor n 4, 2 de julio de 2015; 
Polít. crim. Vol. 13, № 25 (Julio 2018) Art. 2, pp. 42-103.

\section{[http://www.politicacriminal.cl/Vol_13/n_25/Vol13N25A2.pdf]}

tendencia mayoritaria a describir esto como una práctica problemática, ${ }^{156}$ aún cuando algunos señalan sólo se refieren a cosas accesorias o no trascendentales. ${ }^{157}$ En este contexto de cierta dispersión de opiniones resulta interesante detenerse en la percepción de los jueces orales en este punto. La tendencia en este grupo de entrevistados es clara en identificar que sí se trataría de un fenómeno común en el desarrollo de las audiencias y que recaería en materias importantes. ${ }^{158}$ Es interesante constatar que algunos jueces no obstante lo extensivo de la práctica no la consideran problemática, lo cual podría explicar el porqué se sigue produciendo a pesar de que tensiona la vigencia del derecho de defensa y la posibilidad real de confrontar la prueba. Así, por ejemplo, uno señala que "Casi siempre ocurre eso. Con lo cual el informe escrito ha pasado a ser en una buena medida una formalidad que constituye, a lo sumo, un resumen ejecutivo. Es bastante razonable, porque como el peritaje es lo que dice el perito en juicio, se reduce a eso". ${ }^{159}$ Con algún matiz otro juez relata que "La fiscalía sobretodo hace extender al perito a nuevos puntos, a nuevas hipótesis, pretenden ir más allá. ¿Cómo se resuelve? Depende de cada sala del tribunal, algunos colegas dan lugar, otros como yo no". ${ }^{160}$ Esto sería coincidente con la opinión expresada por algunos defensores que indican que trata de evitar los peritos hagan esto, pero en general pierden tal litigio. ${ }^{161}$

Para cerrar esta sección es posible señalar que en lo referido a la producción de la prueba pericial en juicio, la investigación permite identificar varios riesgos que podrían aumentar la probabilidad de decisiones erróneas. El primero está en la presentación de la prueba que dificultaría a los jueces captar toda la información relevante aportada por los peritos. En segundo lugar, se produciría luego un bajo cuestionamiento que permite depurar la calidad de la información producida. Finalmente, habría un cierto nivel de laxitud en el control de la información que aportan los peritos a juicio.

\subsubsection{Problemas en la valoración de la prueba pericial en juicio}

Una última etapa en la que la prueba pericial puede tener incidencia en la producción de errores del sistema se genera al momento en que debe ser valorada por los jueces. Mi objetivo en las entrevistas fue indagar cómo los distintos actores del sistema de justicia penal perciben el trabajo que realizan nuestros jueces al momento de valorar la prueba

Entrevista Defensor $n^{\circ}$ 6, 1 de abril de 2016; Entrevista Defensor $n^{\circ}$ 7, 19 de abril de 2016(quien señala que a pesar que cuestiona la práctica en la audiencia los jueces lo permiten); Entrevista Defensor $n^{\circ} 8,11$ de mayo de 2016.

${ }^{156}$ Entrevista Abogado n ${ }^{\circ}$ 3, 2 de julio de 2015; Entrevista Abogado n ${ }^{\circ} 5,25$ de agosto de 2016; y, Entrevista Abogado $n^{\circ} 6,25$ de agosto de 2016.

${ }^{157}$ Entrevista Abogado n ${ }^{\circ} 1,4$ de mayo de 2015 y Entrevista Abogado n 2, 2 de junio de 2015.

${ }_{158}$ Entrevista Juez TOP n ${ }^{\circ}$ 2, 15 de junio de 2015; Entrevista Juez TOP n ${ }^{\circ} 3,2$ de julio de 2015; Entrevista Juez TOP n 4, 6 de julio de 2015 (aún cuando con algunos matices); Entrevista Juez TOP n ${ }^{\circ} 5,8$ de julio de 2015; Entrevista Juez TOP $\mathrm{n}^{\circ}$ 6, 14 de julio de 2015; Entrevista Juez TOP $\mathrm{n}^{\circ}$ 7, 5 de octubre de 2015; Entrevista Juez TOP $n^{\circ}$ 8, 22 de diciembre de 2015; Entrevista Juez TOP n ${ }^{\circ}$ 9, 19 de agosto de 2016 (aún cuando en este caso se señala estos adicionales tendrían que ver generalmente con aspectos generales de la disciplina).

${ }^{159}$ Entrevista Juez TOP n ${ }^{\circ} 5,8$ de julio de 2015.

${ }^{160}$ Entrevista Juez TOP ${ }^{\circ} 7,5$ de octubre de 2015.

${ }^{161}$ Entrevista Defensor $^{\circ} 1,11$ de junio de 2015 y Entrevista Defensor n ${ }^{\circ} 7,19$ de abril de 2016. 
DUCE, Mauricio. “Una aproximación empírica al uso y prácticas de la prueba pericial en el proceso penal Chileno a la luz de su impacto en los errores del sistema".

pericial que es presentada a juicio. Para presentar los resultados obtenidos divido el análisis en dos categorías: opiniones de los litigantes y peritos y la de los propios jueces (de garantía y de tribunal oral en lo penal).

La tendencia general dentro de los litigantes y peritos es la de una visión crítica del trabajo judicial en la materia. Por cierto, se trata de una opinión que no es unánime y que se formula con diversos matices, por ejemplo, haciendo distinciones por tipos de jueces y tipos de pericias. ${ }^{162}$ Con todo, consideradas las opiniones en su conjunto, el consenso de los entrevistados litigantes coincide se trata de un área problemática. ¿Cuáles serían estos principales problemas? Pude identificar tres. Un primer problema estaría en que los entrevistados estiman que hay una falta de comprensión de los jueces de los contenidos de los peritajes que se presentan a juicio. ${ }^{163}$ Este surgiría como consecuencia de la poca formación en las materias sobre las que recaen muchas pericias y también por la falta de especialización de los jueces en categorías específicas de delitos en los que normalmente se presentan peritajes del mismo tipo. Un segundo problema se produciría por la escasa calidad en el análisis realizado en las sentencias respecto a la prueba pericial. ${ }^{164}$ Un fiscal lo plantea así: "Creo que el sistema está bien achanchado en ciertas categorías de delito...cada vez que hay que meterse en un tema que es efectivamente muy complicado en la calidad del informe y profundizar ciertos temas, a los jueces le queda grande. Para el caso que sale de la norma general, que requiere un análisis más fino, los jueces quedan desbordados". ${ }^{165}$ Esto sería consistente con los hallazgos de la investigación sobre sentencias TOP en delitos sexuales. Por ejemplo, en el total de sentencias analizadas en donde se produjo prueba pericial por las partes, sólo en un $13 \%$ el tribunal se hace cargo de manera explícita de la metodología utilizada en el peritaje para fundar su valoración en el mismo. ${ }^{166}$

En algunos casos extremos el problema de la calidad del análisis identificado, según la percepción de los actores entrevistados, es que los jueces deciden más por sus propios prejuicios o pre concepciones que haciéndose cargo de la información aportada por la

\footnotetext{
162 Por ejemplo, Entrevista Fiscal $n^{\circ} 5,4$ de septiembre de 2015 (quien reconoce ha habido un avance en la materia y los jueces están más especializados que antes); Entrevista Fiscal n ${ }^{\circ} 8,28$ de diciembre de 2015 (quien considera que la mitad de los jueces hace bien su trabajo, cuestión que coincide con Entrevista Abogado $n^{\circ}$ 1, 4 de mayo de 2015); Entrevista Fiscal $n^{\circ} 12,12$ de enero de 2016 (quien en cambio considera que en la mayoría de los casos los jueces lo hacen bien); Entrevista Defensor n ${ }^{\circ} 1,11$ de junio de 2015 (que sostiene que en los casos grandes o importantes hay buen análisis, pero no en los comunes y corrientes); y, Entrevista Perito $n^{\circ}$ 1, 18 de julio de 2016 (quien identifica que los jueces jóvenes, de 40 años o menos, en general lo hacen bien).

${ }^{163}$ Entrevista Fiscal $n^{\circ} 2,9$ de junio de 2015; Entrevista Fiscal $n^{\circ} 3,10$ de julio de 2015; Entrevista Fiscal $n^{\circ}$ 7, 2 de octubre de 2015; Entrevista Fiscal n ${ }^{\circ}$ 8, 28 de diciembre de 2015; Entrevista Fiscal $n^{\circ} 9,4$ de enero de 2016; Entrevista Defensor $n^{\circ}$ 3, 2 de julio de 2015; Entrevista Defensor $n^{\circ} 4,2$ de julio de 2015; Entrevista Abogado $n^{\circ}$ 1, 4 de mayo de 2015; Entrevista Abogado ${ }^{\circ}$ 3, 2 de julio de 2015; Entrevista Abogado $n^{\circ} 5,25$ de agosto de 2016; Entrevista Abogado ${ }^{\circ}$ 6, 25 de agosto de 2016; Entrevista Perito ${ }^{\circ} 2,19$ de julio de 2016; Entrevista Perito $\mathrm{n}^{\circ}$ 3, 20 de julio de 2016; Entrevista Perito $\mathrm{n}^{\circ}$ 5, 15 de septiembre de 2016; y, Entrevista Perito ${ }^{\circ} 7,18$ de noviembre de 2016.

${ }^{164}$ Entrevista Fiscal ${ }^{\circ}$ 1, 7 de mayo de 2015; Entrevista Defensor n ${ }^{\circ} 1,11$ de junio de 2015; y, Entrevista Defensor $n^{\circ} 8,11$ de mayo de 2016 .

${ }^{165}$ Entrevista Fiscal $n^{\circ} 1,7$ de mayo de 2015.

166 SANTIBAÑEZ, Uso de la Prueba Pericial, cit. nota n ${ }^{\circ}$ 4, pp. 66-69.
} 
Polít. crim. Vol. 13, No 25 (Julio 2018) Art. 2, pp. 42-103.
[http://www.politicacriminal.cl/Vol_13/n_25/Vol13N25A2.pdf]

prueba pericial. ${ }^{167}$ En esta dirección un perito aporta una explicación que vincula los dos problemas identificados hasta el momento señalando: "Creo que esto se debe a que los jueces no han tenido ningún tipo formación en estos temas. Entonces, a menos que el perito pueda ilustrar perfectamente al tribunal del fenómeno que están observando, seguirán fallando conforme al sentido común o los prejuicios". ${ }^{168}$ Los datos que arroja la base de datos sentencias TOP delitos CVIF apoyarían esta percepción ya que indican que sólo en un $8,09 \%$ del total de las pericias los jueces las valoran expresamente en la sentencia para fundar su decisión.

Finalmente, un tercer problema identificado estaría en los razonamientos judiciales para asignarle peso a la prueba pericial. Así, según algunos, el problema estaría en la concesión de un peso excesivo a esta prueba sin justificación adecuada ${ }^{169}$ y en otros casos lo que se critica es que en la asignación de peso probatorio habría un sesgo de los jueces a favor de la prueba del Ministerio Público o de los peritos de organismos auxiliares. ${ }^{170}$ Un aspecto más general que explicaría las críticas descritas estaría asociado según varios entrevistados a una incapacidad de los jueces para cuestionar los contenidos de la prueba pericial, lo que les impediría apartarse de las conclusiones que se presentan y tener verdadera autonomía o libertad para asignarlo peso a esta prueba. ${ }^{171}$

En este contexto crítico, resulta interesante conocer la percepción de los propios jueces acerca de cómo realizan la labor de valoración de la prueba pericial. Lo que se puede apreciar como una tendencia general, tanto en jueces de garantía como juicio oral, es una preocupación por cómo efectivamente valoran a esta prueba, reconociendo se trata de un tema complejo y que genera riesgos potenciales para el sistema. Un juez de garantía señala que "Los peritajes siempre van a ser complicados porque si es una ciencia que no conoce una va a tender a dar un valor superior, un valor adicional justamente por la experticia del profesional, por eso creo que hay que tener harto cuidado al momento de analizar los peritajes". ${ }^{172}$ Otro juez de garantía, respondiendo a si piensa que los jueces se equivocan al valorar la prueba pericial, señala "Hay ciertos delitos donde es clave esta prueba y, por lo tanto, es necesario reforzar la idea de que se necesita especialización....Es necesario que se

${ }^{167}$ Entrevista Fiscal n ${ }^{\circ}$ 2, 9 de junio de 2015; Entrevista Fiscal $n^{\circ}$ 6, 11 de septiembre de 2015; Entrevista Perito ${ }^{\circ} 1,18$ de julio de 2016; y, Entrevista Perito ${ }^{\circ}{ }^{4}$, 4 de agosto de 2016.

${ }^{168}$ Entrevista Perito ${ }^{\circ}$ 4, 4 de agosto de 2016.

${ }^{169}$ Entrevista Fiscal n ${ }^{\circ}$ 7, 2 de octubre de 2015 (quien excluyendo a los peritajes en el ámbito sexual señala "Pero en el resto del ámbito de las pericias, lo que dijo el perito casi que se da por sentado.") Entrevista Fiscal $\mathrm{n}^{\circ} 11,7$ de enero de 2016 ("Lo que he visto es que la pericia para el juez es muy creíble, el perito expone y explica todo y al tribunal no le cabe más duda”); Entrevista Defensor $\mathrm{n}^{\circ} 5$ (“...por lo general los jueces le creen a los peritos"); y, Entrevista Defensor n 7, 19 de abril de 2016 ("La regla general es que se de alto valor a los peritajes, sobre todo en delitos sexuales.")

${ }^{170}$ Entrevista Defensor $n^{\circ} 1,11$ de junio de 2015 ("Respecto a pericias que vienen de instituciones como el SML se mantiene ese prejuicio de que como viene de esa institución se le tiende a dar más valor, no tanto como al inicio de la reforma, pero aún pasa.”); y, Entrevista Perito n 3, 20 de julio de 2016 (“...hay jueces que aún creen que la prueba oficial es la única que existe...").

${ }^{171}$ Entrevista Fiscal $n^{\circ}$ 7, 2 de octubre de 2015; Entrevista Fiscal $n^{\circ}$ 9, 4 de enero de 2016; Entrevista Defensor n $^{\circ}$ 3, 2 de julio de 2015; Entrevista Defensor n 4, 2 de julio de 2015; y, Entrevista Defensor ${ }^{\circ} 7$, 19 de abril de 2016.

${ }^{172}$ Entrevista Juez de Garantía nº 5, 15 de julio de 2015. 
DUCE, Mauricio. “Una aproximación empírica al uso y prácticas de la prueba pericial en el proceso penal Chileno a la luz de su impacto en los errores del sistema".

tenga herramientas en esto. Los jueces estamos preocupados por esto, es un tema". ${ }^{173}$ Respondiendo la misma pregunta un juez oral sostuvo "Se cometen errores. Falta el que los jueces tengan claro cuánto pueden entrar a cuestionar la calidad". ${ }^{174}$ En la misma dirección otro juez oral, luego de señalar que se está en presencia de un área de riesgo en el sistema, indica: "Es que nosotros no sabemos ponderar un peritaje. Yo diría que no tenemos una metodología para hacer un escrutinio del peritaje, por ejemplo, los jueces nunca piden que se exponga la metodología". ${ }^{175}$ Como se puede apreciar de estos ejemplos, en general pareciera estar instalada una visión con un nivel de autocrítica relevante respecto a su propio quehacer.

Analizadas en detalle el contenido de las respuestas, se puede apreciar que existen varias coincidencias entre las justificaciones que entregan los jueces para explicar este diagnóstico con las formuladas por los demás actores del sistema entrevistados. Nuevamente, el punto que es mencionado con mayor frecuencia es la falta de capacitación y especialización de los jueces en materia de valoración de la prueba pericial. ${ }^{176}$ Varios entrevistados también se refieren al mayor peso que asignan a la prueba pericial y la dificultad que tienen para cuestionarla. ${ }^{177}$ También se puede leer en algunas respuestas la existencia de un sesgo valorativo a favor de los peritajes provenientes de los organismos auxiliares del sistema sin justificar mucho la razón de aquello. ${ }^{178}$

Los jueces, eso sí, agregan como un tema relevante a considerar el impacto que tendría el mal o buen trabajo de los litigantes en sus capacidades para valorar la prueba pericial. En palabras de un juez de garantía: "El problema de valoración de un peritaje, en mi experiencia, es tributario a la calidad de cómo llevan adelante el interrogatorio y contrainterrogatorio los abogados. Es difícil pensar en que uno puede autárquicamente razonar la información de alguien que la está vertiendo si no es contextualizada por quien tiene el rol institucional de hacerlo...". ${ }^{179}$ Un juez oral destaca que para mejorar en sus procesos de valoración debieran contar con más información crítica sobre los peritajes, indicando que "Mucha de esta información debe ser entregada por las partes". ${ }^{180} \mathrm{El}$

\footnotetext{
${ }^{173}$ Entrevista Juez de Garantía n ${ }^{\circ}$ 6, 3 de septiembre de 2015.

${ }^{174}$ Entrevista Juez TOP $n^{\circ} 8,22$ de diciembre de 2015.

${ }^{175}$ Entrevista Juez TOP n ${ }^{\circ} 3,2$ de julio de 2015.

${ }^{176}$ Entrevista Juez de Garantía n ${ }^{\circ}$ 2, 25 de junio de 2015; Entrevista Juez de Garantía n ${ }^{\circ}$ 6, 3 de septiembre de 2015; Entrevista Juez TOP n¹ 9 de junio de 2015; Entrevista Juez TOP $\mathrm{n}^{\circ} 3,2$ de julio de 2015; Entrevista Juez TOP n ${ }^{\circ}$ 4, 6 de julio de 2015 (quien eso sí pone énfasis en la experiencia del juez); Entrevista Juez TOP n ${ }^{\circ}$ 7,5 de octubre de 2015; y, Entrevista Juez TOP n ${ }^{\circ} 8,22$ de diciembre de 2015.

${ }^{177}$ Entrevista Juez Garantía n ${ }^{\circ}$ 5, 15 de julio de 2015; Entrevista Juez TOP n ${ }^{\circ} 1,9$ de junio de 2015; Entrevista Juez TOP n 2, 15 de junio de 2015; y, Entrevista Juez TOP n ${ }^{\circ}$ 5, 8 de julio de 2015. Cabe señalar eso sí que en opinión de varios litigantes y jueces, se señala que tratándose de las pericias psicológicas y psiquiátricas que se presentan habitualmente en materia de delitos sexuales existiría cada vez una mayor distancia crítica de los jueces al momento de valorarlas. Por ejemplo, Entrevista Juez TOP n 9, 19 de agosto de 2016 (quien poco foco en cómo ha evolucionado la evaluación de los peritajes de credibilidad).

${ }^{178}$ Entrevista Juez de Garantía n ${ }^{\circ}$ 9, 28 de julio de 2016; Entrevista Juez TOP n 6, 14 de julio de 2015; y, Entrevista Juez TOP $\mathrm{n}^{\circ}$ 9, 19 de agosto de 2016.

${ }^{179}$ Entrevista Juez de Garantía ${ }^{\circ} 2,25$ de junio de 2015.

${ }^{180}$ Entrevista Juez TOP n 1,9 de junio de 2015.
} 
Polít. crim. Vol. 13, No 25 (Julio 2018) Art. 2, pp. 42-103.

[http://www.politicacriminal.cl/Vol_13/n_25/Vol13N25A2.pdf]

problema estaría precisamente en que según los jueces el trabajo de los litigantes no sería por regla general de mucha calidad, como ya he tenido oportunidad de revisar. ${ }^{181}$

En definitiva, pareciera existir un cierto nivel de consenso que en materia de valoración de la prueba pericial el sistema se expone a riesgos de decisiones erradas producto de algunas debilidades no sólo del trabajo judicial, sino también del aporte que los intervinientes realizan. Hay una cierta discrepancia en las causas, especialmente en el rol de los abogados en esto. Con todo, el hallazgo central parece bastante sólido, especialmente cuando son los propios jueces que reconocen sus debilidades en la materia.

\subsubsection{Demoras significativas en producción de informes}

Un último aspecto que fue espontáneamente mencionado como problemático por una cantidad importante de entrevistados en las distintas categorías fue las demoras significativas que se están generando en la producción de la prueba pericial, al menos respecto de algunos tipos de peritajes. Se trata de un problema muy importante para el sistema desde distintos puntos de vista. Por ejemplo, para la persecución penal genera dificultades enormes de gestión de los casos y el requerir un peritaje en ciertas áreas pasa a constituirse en uno de los principales cuellos de botella del sistema. También se trata de un fenómeno con un enorme impacto en la vigencia de garantías de los imputados, por ejemplo, para permitir que se cumpla el derecho que tienen a ser juzgados en un plazo razonable. Finalmente, también tiene incidencia en el problema que da origen a esta investigación vinculado a los errores del sistema como ya tuve oportunidad de revisar en el primer capítulo.

El problema de la demora es mencionado por fiscales ${ }^{182}$, jueces de garantía ${ }^{183}$, jueces de juicio oral ${ }^{184}$, abogados privados ${ }^{185}$ y por los propios peritos. ${ }^{186}$ Ahora bien, me parece que no es casualidad que en las categorías en donde esta opinión se presenta con mucho más frecuencia sea tratándose de fiscales y jueces de garantía. Los primeros ya que son ellos los principales requirentes de esta prueba ante distintos organismos públicos $\mathrm{y}$, los segundos, ya que las demoras en su producción normalmente se traducen luego en audiencias de ampliación de plazo de la investigación.

\footnotetext{
${ }^{181}$ En esta misma lógica ver también Entrevista Juez TOP n ${ }^{\circ}$ 6, 14 de julio de 2015 y Entrevista Juez TOP ${ }^{\circ}$ 8,22 de diciembre de 2015.

${ }^{182}$ Entrevista Fiscal $n^{\circ} 1,7$ de mayo de 2015; Entrevista Fiscal $n^{\circ} 3,10$ de julio de 2015; Entrevista Fiscal $n^{\circ}$ 4, 28 de julio de 2015; Entrevista Fiscal $n^{\circ} 5,4$ de septiembre de 2015; Entrevista Fiscal $n^{\circ} 6,11$ de septiembre de 2015; y, Entrevista Fiscal n 13,29 de enero de 2016.

${ }^{183}$ Entrevista Juez de Garantía n ${ }^{\circ}$ 1, 7 de mayo de 2015; Entrevista Juez de Garantía n ${ }^{\circ} 2,25$ de junio de 2015; Entrevista Juez de Garantía $n^{\circ}$ 3, 26 de junio de 2015; Entrevista Juez de Garantía $n^{\circ} 4,8$ de julio de 2015; Entrevista Juez de Garantía n ${ }^{\circ}$ 6, 3 de septiembre de 2015; Entrevista Juez de Garantía $n^{\circ} 7,14$ de septiembre de 2015; Entrevista Juez de Garantía n 8, 4 de enero de 2016; y, Entrevista Juez de Garantía $n^{\circ} 9$, 28 de julio de 2016.

${ }^{184}$ Entrevista Juez TOP n ${ }^{\circ} 5,8$ de julio de 2015.

185 Entrevista Abogado n $^{\circ}$ 2, 2 de junio de 2015; Entrevista Abogado n ${ }^{\circ}$ 3, 2 de junio de 2015; y, Entrevista Abogado $\mathrm{n}^{\circ}$ 4, 22 de julio de 2015.

${ }^{186}$ Entrevista Perito ${ }^{\circ} 1,18$ de julio de 2016.
} 
DUCE, Mauricio. “Una aproximación empírica al uso y prácticas de la prueba pericial en el proceso penal Chileno a la luz de su impacto en los errores del sistema".

Peritajes que son mencionados reiteradamente como aquellos que generan más demoras incluyen los que se practican sobre drogas (cuyos resultados se obtendrían en plazos que varían entre 90 y 120 días como mínimo), alcoholemias (también con plazos entre 90 y 120 días), informes mentales (psiquiátricos), peritajes de credibilidad, sobre negligencias médicas, lesiones, entre otros. A estos patrones generales se agregan relatos de casos extremos en donde los plazos han sido de mucha extensión. Por ejemplo, un fiscal relata que se ha demorado años en recibir peritajes sobre negligencias médicas ${ }^{187}$, otro indica que ha recibido informes sobre drogas luego de diez meses de haberlos requerido ${ }^{188}$, un juez de garantía cuenta que le ha tocado ver informes de lesiones realizados por el SML que han demorado más de un año o informes preparados por el CAVAS de la PDI que se han entregado en plazos entre uno y dos años. ${ }^{189}$ Un juez oral relata que le ha tocado conocer peritajes psicológicos realizados sobre niños que han tardado cerca de dos años en ser elaborados. ${ }^{190}$

Más allá de estos casos extremos, pareciera existir una opinión bastante consistente en demoras significativas en el funcionamiento regular del sistema. Eso coincide con algunas cifras oficiales que me fueron proporcionadas por distintas instituciones por medio de requerimientos de transparencia. Así, Carabineros informó que el promedio en días a nivel nacional que tomó la elaboración de peritajes de informática forense el año 2015 fue de 115 días, los médico criminalísticos y de incendio tardaron 97 días cada uno y los de genética forense y biología 95 días cada uno. ${ }^{191}$ Por su parte, la PDI informó que el promedio en días en la Región Metropolitana que tomaron la elaboración de peritajes en el año 2015 incluyeron 155 días para los de info-ingeniería, 126 días para los de bioquímica y biología, 94 días para los de paisajismo y urbanismo, 74 días para los de dibujo y planimetría. ${ }^{192}$

No obstante la consistencia de estos tiempos con las opiniones recogidas en las entrevistas, otras instituciones informaron resultados un tanto disonantes. Por ejemplo, el ISP señaló que el año 2015 los promedios para informar muestras fueron de 4,9 días en las muestras priorizadas y 31,8 días en las no priorizadas. ${ }^{193}$ El SML, por su parte, envió información sobre cumplimiento de indicadores de gestión que darían cuenta del porcentaje de casos que cumple con los plazos establecidos como meta por la propia institución. Dentro de ellos tomo tres ejemplos de peritajes mencionados como problemáticos por los entrevistados. De acuerdo a este indicador, el 98,92\% de los informes de alcoholemia se habrían producido en

\footnotetext{
${ }^{187}$ Entrevista Fiscal $n^{\circ} 13,29$ de enero de 2016.

${ }^{188}$ Entrevista Fiscal ${ }^{\circ} 4,28$ de julio de 2015.

${ }^{189}$ Entrevista Juez de Garantía n ${ }^{\circ}$ 9, 28 de julio de 2016. Un abogado privado que ejerce en materia de delitos sexuales indica que las pericias del CAVAS de la PDI en su experiencia tienen retrasos superiores a los seis meses. Entrevista Abogado ${ }^{\circ}$ 3, 2 de julio de 2015.

${ }^{190}$ Entrevista Juez TOP n ${ }^{\circ} 5,8$ de julio de 2016.

191 Información entregada por comunicación electrónica gracias a requerimientos de acceso a información pública disponibles en formato digital en poder del autor. La información de Carabineros de Chile fue enviada el 6 de septiembre de 2016.

192 Información entregada por comunicación electrónica gracias a requerimientos de acceso a información pública disponibles en formato digital en poder del autor. La información de la PDI fue enviada con fecha 11 de agosto de 2016.

193 Información entregada por comunicación electrónica el 20 de julio de 2016 gracias a requerimientos de acceso a información pública disponibles en formato digital en poder del autor. La información registra el número como "muestras informadas" no como peritajes.
} 
Polít. crim. Vol. 13, № 25 (Julio 2018) Art. 2, pp. 42-103.

[http://www.politicacriminal.cl/Vol_13/n_25/Vol13N25A2.pdf]

el plazo de 15 días en la Región Metropolitana durante el año 2015, el 95,97\% de los informes psiquiátrico forenses se habrían elaborado dentro de 35 días en la misma región y año y el 86,14\% de los informes psiquiátricos infantiles también dentro de 35 días. ${ }^{194}$ La explicación de esta potencial discrepancia entre los testimonios obtenidos y esta información oficial tiene que ver con la forma de contar los plazos. Así, el SML ellos no se inician desde el momento en que existe un requerimiento por parte de un fiscal, sino desde los propios plazos que la institución determina (normalmente cuando inicia la ejecución del peritaje respectivo). Esto llevaría a que en el indicador que formalmente comunican se produzca un acortamiento significativo de las demoras que perciben, por ejemplo, los propios fiscales. 195

Para finalizar con este tema, menciono que varios entrevistados ofrecieron sus explicaciones a las demoras en la producción de la prueba pericial. El consenso entre quienes se pronunciaron sobre este punto fue la falta o escases de recursos tanto materiales como humanos en las instituciones respectivas. ${ }^{196}$ Llama la atención que no aparezca con la misma fuerza una mirada autocrítica de los actores legales del sistema, especialmente de los fiscales, en términos de examinar su propia práctica en materia de requerimientos de prueba pericial. Si las instituciones presentan un cierto nivel de colapso, en parte este podría también explicarse por una demanda excesiva de los mismos en algunas categorías. ${ }^{197}$

\section{A modo de conclusión: algunas recomendaciones preliminares}

Los hallazgos de esta investigación dan cuenta de la existencia en nuestro sistema de justica penal de un conjunto de prácticas descritas en la experiencia comparada que podrían traducirse en decisiones de persecución penal o judiciales erróneas. Así, se ha podido observar que existen cuestionamientos importantes respecto a la calidad y confiabilidad de algunas pericias que se presentan frecuentemente en juicios orales. También existen problemas en relación a la real especialización y experticia de quienes comparecen habitualmente en calidad de peritos. En ese contexto, un hallazgo significativo ha sido el

194 Información entregada el 24 de agosto de 2016 por vía de comunicación electrónica gracias a requerimientos de acceso a información pública disponibles en formato digital en poder del autor.

${ }^{195}$ Se trata de una explicación entregada por una persona que tiene un cargo directivo en una de las unidades del SML y que me fue explicada al finalizar una presentación que realicé en un seminario en el que expuse este problema (Segundas Jornadas de Medicina Forense del Sur, 6 de octubre de 2016). No se trata de una entrevista formal realizada en el contexto de la ejecución de este proyecto y, por lo tanto, no la cito como las anteriores.

196 Entrevista Fiscal n ${ }^{\circ} 1,7$ de mayo de 2015; Entrevista Fiscal n ${ }^{\circ} 2,9$ de junio de 2015; Entrevista Fiscal $n^{\circ}$ 8, 28 de diciembre de 2015; Entrevista Fiscal n 13, 29 de enero de 2016; Entrevista Juez de Garantía ${ }^{\circ} 1,7$ de mayo de 2015; Entrevista Juez de Garantía n ${ }^{\circ} 4,8$ de julio de 2015; Entrevista Juez TOP nº 5,8 de julio de 2015; y, Entrevista Abogado n 4, 22 de julio de 2015.

197 Indirectamente algunos fiscales indican que se ha generado un cierto abuso tratándose de la solicitud de elaboración de peritajes de credibilidad en delitos sexuales en casos que no era necesario y esto ha tenido el impacto de transformar dichos peritajes en una cuestión casi obligatoria en ese tipo de juicios a pesar de su falta de necesidad en casos concretos. Entrevista Fiscal n ${ }^{\circ} 12,12$ de enero de 2016 y Entrevista Fiscal $n^{\circ} 13$, 29 de enero de 2016. Desde otro punto de vista juez oral estima que a juicio ingresa mucho peritaje que no es tal, dando cuenta de una cierta desprolijidad en lo que llega como evidencia a esa instancia. Entrevista Juez TOP $\mathrm{n}^{\circ} 1,9$ de junio de 2015 . 
DUCE, Mauricio. “Una aproximación empírica al uso y prácticas de la prueba pericial en el proceso penal Chileno a la luz de su impacto en los errores del sistema".

constatar el escaso o nulo control que se está realizando de esta prueba en la APJO y luego un trabajo de baja calidad en la presentación y confrontación de la misma en juicio. Todo esto reforzado finalmente por las dificultades que tienen los jueces para encarar adecuadamente su valoración. A ello se agrega una opinión bastante uniforme en relación a las demoras con las cuáles se están produciendo una cantidad importante de los peritajes en el sistema. La combinación de estos factores es en extremo problemática y debiera llevarnos a discutir algunas medidas para aminorar los riesgos de error que genera. Se trata de un complejo entramado de políticas públicas y reformas legales posibles de encarar. El desarrollo en profundidad de estas excede los alcances de un trabajo de esta naturaleza, pero me parece indispensable avanzar al menos en delinear algunos caminos de acción para iniciar un debate sobre el punto. En lo que sigue me detengo brevemente en tres aspectos.

\subsection{Capacitación de los actores del sistema legal}

He sugerido a lo largo del texto que un factor que explicaría varias de las prácticas problemáticas identificadas es la falta de capacitación de los actores legales en la materia. En efecto, esta hipótesis justificaría, al menos en parte, el poco trabajo de debate sobre la admisibilidad de esta prueba en las APJO, luego de la falta de calidad en la presentación y confrontación de la misma en juicio y, finalmente, los problemas que enfrentan los jueces para su valoración. Estas percepciones se ven reforzadas por otro hallazgo obtenido en las entrevistas en las cuáles específicamente se les preguntó sobre la materia. La gran mayoría de los actores legales entrevistados que trabajan en instituciones del sistema reconoció que en el área de los peritajes no ha recibido del todo o sólo ha recibido muy poca capacitación específica y que, por lo mismo, tienen la percepción de no contar con todas las herramientas necesarias para lidiar con esta prueba en las distintas etapas procesales que les corresponde. ${ }^{198}$ Las excepciones estarían focalizadas en algunas capacitaciones en delitos específicos o en unidades especializadas. ${ }^{199}$

Se trata de un espacio de trabajo del sistema en donde es necesario realizar cambios profundos. Me parece que el desarrollo de programas de capacitación y perfeccionamiento debiera cubrir al menos tres áreas para tener impacto en la mejora del sistema. Una primera tiene que ver con proveer de conocimientos sobre los principios básicos de cómo opera la

\footnotetext{
198 Entrevista Fiscal $n^{\circ}$ 1, 7 de mayo de 2015; Entrevista Fiscal $n^{\circ} 2,9$ de junio de 2015; Entrevista Fiscal $n^{\circ}$ 3, 10 de julio de 2015; Entrevista Fiscal n 5, 4 de septiembre de 2015; Entrevista Fiscal n ${ }^{\circ}$ 8, 28 de diciembre de 2015; Entrevista Fiscal $n^{\circ}$ 9, 4 de enero de 2016; Entrevista Fiscal $n^{\circ} 10,6$ de enero de 2016 (quien eso si señala los fiscales especializados en delitos sexuales si tendrían buena capacitación); Entrevista Juez TOP $\mathrm{n}^{\circ}$ 1, 9 de junio de 2015; Entrevista Juez TOP n ${ }^{\circ}$ 2, 15 de junio de 2015; Entrevista Juez TOP n ${ }^{\circ} 3,2$ de julio de 2015; Entrevista Juez TOP n ${ }^{\circ}$ 4, 6 de julio de 2015; Entrevista Juez TOP n ${ }^{\circ} 5,8$ de julio de 2015; Entrevista Juez TOP $n^{\circ}$ 6, 14 de julio de 2015; Entrevista Juez TOP $n^{\circ} 7,5$ de octubre de 2015; Entrevista Juez TOP ${ }^{\circ}$ 8, 22 de diciembre de 2015; Entrevista Juez TOP $n^{\circ}$ 9, 19 de agosto de 2016; Entrevista Juez de Garantía $\mathrm{n}^{\circ} 1$, 7 de mayo de 2015; Entrevista Juez de Garantía n 2, 25 de junio de 2015; Entrevista Juez de Garantía $n^{\circ} 3$, 26 de junio de 2015; Entrevista Juez de Garantía n 6, 3 de septiembre de 2015; Entrevista Juez de Garantía $\mathrm{n}^{\circ}$ 7, 14 de septiembre de 2015; Entrevista Juez de Garantía n ${ }^{\circ} 8,4$ de enero de 2016; Entrevista Juez de Garantía $n^{\circ}$ 9, 28 de julio de 2016; Entrevista Defensor $n^{\circ} 1,11$ de junio de 2015; Entrevista Defensor $n^{\circ} 3,2$ de julio de 2015; Entrevista Defensor n ${ }^{\circ} 4,2$ de julio de 2015; Entrevista Defensor $n^{\circ} 6$, 1 de abril de 2016; Entrevista Defensor ${ }^{\circ}$ 7, 19 de abril de 2016; y, Entrevista Defensor n ${ }^{\circ}$ 8, 11 de mayo de 2016.

${ }^{199}$ Por ejemplo, un fiscal señala que hay buena capacitación en estos temas para los fiscales especializados en delitos sexuales, aún cuando no para el resto. Entrevista Fiscal n 10, 6 de enero de 2016.
} 
Polít. crim. Vol. 13, № 25 (Julio 2018) Art. 2, pp. 42-103.

[http://www.politicacriminal.cl/Vol_13/n_25/Vol13N25A2.pdf]

ciencia y las disciplinas forenses. Sin esto es difícil pensar que los actores del sistema legal estén en condiciones de comprender adecuadamente la prueba sobre la cual deben trabajar. Una segunda área debiera incorporar el conocimiento general de las principales disciplinas que producen evidencia experta en el país. ${ }^{200}$ Finalmente, los programas debieran incorporar el desarrollo de destrezas y habilidades propias de la función que cumple cada actor del sistema. Por ejemplo, tratándose de fiscales y defensores debiera fortalecerse su capacidad de litigar en sede de admisibilidad y juicio a este prueba, en el caso de los jueces la valoración y toma de decisiones basadas en la información proveniente de este medio probatorio, etc.

Por otra parte, estos programas de capacitación debieran también desarrollarse en dos niveles. En un primer término, algunos componentes de ellos debieran formar parte del "paquete de formación básica" que se recibe al ingresar a las respectivas instituciones. Además, debiera luego formar parte de programas especializados de perfeccionamiento continúo que permitan acceder a un conocimiento que en la materia se ha ido incrementando y evolucionando.

Una de las ventajas de identificar la capacitación y perfeccionamiento como un área clave de trabajo tiene que ver con que todas las instituciones del sistema tienen hoy día un enorme espacio en el que dichos programas pudieran ser desarrollados. En efecto, instituciones como el Poder Judicial ofrece un programa de capacitación inicial a sus integrantes antes de que asuman sus funciones y todas cuentan luego con una oferta de perfeccionamiento en el tiempo. En los dos ámbitos los recursos destinados son significativos, independiente que siempre pueda haber algunas necesidades insatisfechas. Lo que ocurre con el Poder Judicial es un ejemplo claro de lo que he dicho. Hoy día cualquier persona que quiera ser un juez de la república debe ser aceptado y aprobar el programa de formación que ofrece la Academia Judicial de cerca de diez meses de duración en el cual se entregarían las herramientas necesarias para cumplir su labor frente a "... las insuficiencias que presenta la formación universitaria para el ejercicio de la función judicial". ${ }^{201}$ Una vez en posesión de sus cargos, los jueces tendrán la posibilidad de tomar cursos de perfeccionamiento destinados a "...promover la adquisición de nuevos conocimientos y desarrollar habilidades para desempeñar de mejor forma su función”. ${ }^{202} \mathrm{En}$

\footnotetext{
200 En esta dirección se pronuncia también la recomendación número 9 del NAS Report. Explícitamente señala: "Adicionalmente, abogados y jueces usualmente tienen insuficiente entrenamiento y conocimiento en metodología científica y frecuentemente fallan en comprender a cabalidad las aproximaciones empleadas por las diferentes disciplinas forenses y la fiabilidad de la evidencia científica forense que es ofrecida a juicio. Esta capacitación es esencial...". National Research Council, Identifying the Culprit: Assessing Eyewitness Identification, Washington D.C.: The National Academies of Sciences, Engineering, and Medicine, 2014. pp. 26-27. (la traducción es del autor).

${ }^{201}$ Información obtenida del sitio web de la Academia Judicial, disponible en: http://www.academiajudicial.cl/Programas.aspx?id_menu=24 [Visitado el 02.02.2017].

${ }^{202}$ Información obtenida del sitio web de la Academia Judicial, disponible en: http://www.academiajudicial.cl/Programas.aspx?id_menu=23 [Visitado el 02.02.2017]. Según describe la propia página "Anualmente la Academia presenta una variada oferta de cursos de perfeccionamiento, abordando contenidos de diversa índole, que van tanto desde temas propios de la teoría del derecho, como otros relativos al derecho vigente, hasta tópicos dirigidos a mejorar los aspectos cotidianos de las tareas en tribunales."
} 
DUCE, Mauricio. “Una aproximación empírica al uso y prácticas de la prueba pericial en el proceso penal Chileno a la luz de su impacto en los errores del sistema".

definitiva, los jueces cuentan con un sistema que ofrece enormes espacios para el perfeccionamiento en materias como las que planteo. Algo similar ocurre tratándose de fiscales y defensores.

Las instituciones de nuestro sistema de justicia penal ofrecen un espacio importante de capacitación que podría aprovecharse para mejorar la situación en esta materia. Si como he visto en secciones previas se trata de una prueba de suma importancia en la resolución de casos y, además, que produce un riesgo importante de tomar decisiones equivocadas, debiera claramente formar parte de las prioridades de capacitación.

\subsection{Fortalecimiento de especialidades forenses $y$ del trabajo de las comunidades de profesionales expertos}

Una segunda línea de acción en la que me parece indispensable avanzar es en el fortalecimiento de la comunidad de profesionales que aportan conocimiento experto al sistema de justicia criminal. En buena medida, los riesgos que he detectado se producen por la baja capacidad del sistema de producir peritajes de calidad en ciertas áreas. Mejorar esto supone un trabajo en diversas dimensiones. ${ }^{203}$

Una primera pasa por fortalecer a los organismos auxiliares que, como se mostró, son los principales productores de prueba pericial para el sistema. Se trata de una necesidad que se viene planteando desde hace tiempo en nuestro país y en la que se ha avanzado sólo en forma parcial. ${ }^{204}$ Resulta indispensable fortalecer las capacidades existentes y para ello se requiere un estudio más acabado de la conveniencia de pensar un diseño institucional diverso a los que tenemos en la actualidad. ${ }^{205}$

En un segundo plano, parece indispensable establecer incentivos y mecanismos para promover los estudios e investigación en las especialidades disciplinares asociadas a la

\footnotetext{
${ }^{203}$ Sugiero en esta materia revisar las recomendaciones número 1 a 10 del NAS Report que desarrolla con propuestas más específicas varios de los temas que abordaré a continuación. Research Council, Identifying the Culprit, cit. nota $\mathrm{n}^{\circ} 203$, pp. 19-29.

204 Así, por ejemplo, en el contexto de las campañas presidenciales del año 2013, la necesidad de avanzar en esta dirección fue planteada explícitamente en el programa de gobierno de la Presidenta Bachelet. Este señaló sobre el punto: "Desde el inicio del nuevo sistema procesal penal, un cuello de botella para su funcionamiento ha sido la capacidad de los organismos auxiliares (Servicio Médico Legal, Instituto de Salud Pública, Laboratorios Policiales, etc.). Realizaremos una modernización y fortalecimiento de los servicios auxiliares que tienen por función producir evidencia científica para el sistema." Chile de Todos. Programa de gobierno Michelle Bachelet 2014-2018, p. 104, en: http://michellebachelet.cl/programa/ [Visitado el 02.02.2017].

205 Por ejemplo, debiéramos preguntarnos si es una buena idea que existan laboratorios realizando peritajes similares repartidos en distintas instituciones, con recursos y capacidades institucionales diversas. Tal vez valdría la pena pensar en la creación de un servicio que concentrara dichos recursos y pudiera establecer un estándar equivalente para todos los peritajes que se le encarguen. También habría que preguntarse cuál es la mejor ubicación institucional más adecuada para servicios de este tipo ¿debieran ser más bien organismos autónomos de fuerte perfil científico más que pertenecer a instituciones con un rol claro en el sistema como los laboratorios de las policías? Una recomendación que ha ido generando consenso en el ámbito comparado es precisamente la de darle autonomía a las instituciones forenses respecto a las de persecución penal. Por ejemplo véase COLLEY, Craig; TURVEY, Brent, "Forensic reform", en TURVEY, Brent y COLLEY, Craig, Miscarriages of justice, Oxford: Elsevier Academic Press, 2014, pp. 339-357, p. 353. En fin, son muchos los temas que se debiera tener en la materia y que en Chile no hemos discutido sino sólo de manera marginal.
} 
producción de prueba pericial. Como se vio en el desarrollo del texto, hay áreas -como por ejemplo la medicina legal- en donde los incentivos existentes promueven que no se estudie la especialidad y que el ejercicio en el área sea más bien visto como un trabajo de paso en el desarrollo de una carrera con proyecciones diferentes. A ello hay que agregar la necesidad de contar con programas de formación al día en el desarrollo de la ciencia que produce prueba pericial. Por lo mismo, es clave buscar fórmulas y mecanismos que permitan a corto plazo aumentar la investigación nacional en estas materias y a mediano y largo constituir comunidades académica de especialistas que se transformen en actores relevantes en el diseño, uso y debate de la prueba pericial. En esta línea me parece que el Estado dispone de varias herramientas que podrían incentivar este desarrollo sin grandes cambios a políticas públicas que hoy se encuentran vigentes. ${ }^{206}$ Todo ello, además, en el contexto actual de discusión del nuevo estatuto y financiamiento de la educación superior en Chile, en el que se podría también considerar parte de los fondos basales de investigación fueran asignados a instituciones de educación superior que desarrollen líneas de trabajo o constituyan de equipos en la materia de fortalecimiento de ciertas áreas de experticia forense. En fin, me parece que en el actual esquema de promoción de capital humano, investigación científica y fortalecimiento institucional de las universidades que promueve el Estado existen espacios importantes para el desarrollo de una comunidad especializada en materia de prueba pericial.

Una última dimensión que quisiera sugerir, sin pretender agotar otras posibles, se vincula al rol central que en mi opinión debieran jugar los colegios y asociaciones profesionales en las distintas áreas para mejorar la calidad de la prueba pericial. Hay tres formas centrales en donde veo ellas podrían hacer importantes contribuciones. La primera es por medio de la promoción y desarrollo de investigación en su disciplina que nutra el trabajo de los expertos. ${ }^{207}$ La segunda, es por medio del desarrollo de protocolos o guías de acción que establezcan los mínimos aceptables en sus respectivas disciplinas que permitan, por una parte, orientar a los profesionales de las mismas y, por otra, entregar herramientas a otros actores para controlar que se han cumplido con las exigencias disciplinares en la

206 Para la formación de capital humano avanzado, por ejemplo, se dispone del programa conocido como Becas Chile que tiene por propósito explícito la formación de "investigadores y profesionales de excelencia con alta preparación en todas las áreas del conocimiento para el desarrollo de Chile." Mayores antecedentes en: http://www.conicyt.cl/becas-conicyt/sobre-becas-conicyt/que-es-becas-conicyt/ [Visitado el 02.02.2017]. A nivel de investigación y formación de equipos académicos una fórmula que permitiría avanzar en esta dirección es la de orientar una porción de los fondos concursables que entrega la Comisión Nacional de Investigación Científica y Tecnológica (Conicyt) en sus diversos tipos de proyectos de investigación (Fondecyt, Anillos en Ciencias, etc.) Mayores antecedentes en: http://www.conicyt.cl/ [Visitado el 02.02.2017].

${ }^{207}$ Un ejemplo notable en esta dirección es el trabajo que realiza la American Psychological Asociation (APA), que ha desarrollado una línea intensa de publicaciones de manuales y textos en diversas materias vinculadas a la psicología forense. Información general de la institución puede verse en http://www.apa.org/about/index.aspx [Visitado el 02.02.2017]. Como ejemplo concreto de su trabajo de investigación y publicaciones sugiero revisar el extraordinario trabajo en dos tomos: CUTLER, Brian; ZAPF, Patricia (ed.), APA Handbook of Forensic Psychology, Vol.1. Individual and Situational Influences in Criminal and Civil Contexts, Washington: American Psychological Association, 2014; CUTLER, Brian; ZAPF, Patricia (ed.), APA Handbook of Forensic Psychology, Vol. 2. Criminal investigation, adjudication, and sentencing outcomes, Washington: American Psychological Association, 2015. 
DUCE, Mauricio. “Una aproximación empírica al uso y prácticas de la prueba pericial en el proceso penal Chileno a la luz de su impacto en los errores del sistema".

elaboración de los peritajes. ${ }^{208}$ Finalmente, se esperaría que las asociaciones profesionales pudieran cumplir un rol de control ético de sus integrantes y de esa manera contribuir a elevar estándares de trabajo profesional. El gran desafío en esta materia es que desde el año 1981 en nuestro país (Decreto Ley n ${ }^{\circ} 3621$ de 3 de febrero), la colegiatura a los mismos es voluntaria, por lo que la capacidad de estas organizaciones de disciplinar a los profesionales de su disciplina es baja.

La opinión de los expertos entrevistados es coincidente en identificar que se trata de una dimensión en la que existe muy escaso trabajo de los colegios profesionales o asociaciones afines. ${ }^{209}$ Esto refuerza la necesidad de explorar vías para superar el escenario descrito. Como señalaba al inicio, sin un trabajo de la propia disciplina es difícil pensar en un mejoramiento sistemático de la calidad profesional de los peritos.

\subsection{Algunas reformas legales orientadas a potenciar el control sobre la prueba pericial}

He dejado para el final esta tercera línea de acción. En principio me parece que los principales problemas que he detectado en esta investigación no se deben centralmente a problemas de diseño legal. Es decir, que aún cuando no perfectas, las reglas del CPP permitirían desarrollar una práctica de mejor calidad que la que se ha identificado en la investigación. Por otra parte, a esta altura debiera ser relativamente obvio que poner todas las expectativas que un cambio legal mejore por si sólo las cosas es, por decir lo menos, iluso. Como bien es sabido, las normas legales por sí mismas no tienen la capacidad de cambiar la realidad y las prácticas si no va acompañada de otros aspectos, como por ejemplo, una implementación adecuada que incluya medios y capacitación. Con todo, en el estado actual que ha sido descrito en esta investigación, una reforma legislativa podría constituir una señal política fuerte para que las distintas instituciones del sistema de justicia penal se hagan cargo de manera más intensa de los problemas que se enfrentan en la materia y, especialmente, de la posibilidad de aumentar los controles de calidad respecto a la prueba pericial que se incorpora y valora en los procedimientos. Pareciera que una señal de ese tipo es necesaria en la actualidad.

En este contexto, estimo que hay tres áreas específicas en dónde podrían realizarse perfeccionamientos al CPP en materia de prueba pericial con el propósito de reforzar los controles a su uso, tanto en sede de admisibilidad como luego en juicio oral. A continuación las identifico sin entrar al detalle concreto del contenido específico de las

\footnotetext{
${ }^{208}$ Siguiendo con el ejemplo de la APA, pueden revisárselas guías especiales para el ejercicio de la psicología forense en: http://www.apa.org/pubs/journals/features/forensic-psychology.pdf [Visitado el 02.02.2017].

${ }^{209}$ Entrevista Perito $\mathrm{n}^{\circ}$ 1, 18 de julio de 2016 (quien identifica que en su área la postura de ha sido más orientada a defensa de las críticas que destinada a elevar la calidad profesional); Entrevista Perito $\mathrm{n}^{\circ} 2,19$ de julio de 2016 (quien señala que no se hace mucho); Entrevista Perito n ${ }^{\circ} 3,20$ de julio de 2016 (señala que en su área no hay trabajo de este tipo); Entrevista Perito $n^{\circ}$ 4, 4 de agosto de 2016 (quien identifica eso si un creciente rol de universidades); Entrevista Perito $n^{\circ} 5,15$ de septiembre de 2016 (quien nota un trabajo incipiente en su área); Entrevista Perito $\mathrm{n}^{\circ}$ 6, 8 de noviembre de 2016 (que destaca que en su área las sociedades profesionales no tienen la labor de mejoras estándares); y, Entrevista Perito $\mathrm{n}^{\circ} 7,18$ de noviembre de 2016 (que identifica que los grandes esfuerzos en las dimensiones descritas se da por personas individuales de la profesión de alto reconocimiento más que por instituciones).
} 
Polít. crim. Vol. 13, № 25 (Julio 2018) Art. 2, pp. 42-103.

[http://www.politicacriminal.cl/Vol_13/n_25/Vol13N25A2.pdf]

modificaciones que podrían introducirse ya que ello supondría un análisis que excede el objetivo que busco en este trabajo.

La primera tiene que ver con introducir reglas que permitan reforzar el control de admisibilidad de la prueba pericial en la APJO. Como ya mencioné previamente, se trata de un tema en el que ha existido un enorme desarrollo en el ámbito comparado desde hace algunas décadas. ${ }^{210}$ En nuestro país un sector de la doctrina y alguna jurisprudencia han venido planteando que nuestro CPP contempla reglas especiales de admisibilidad en la materia. ${ }^{211}$ Con todo, esto no se ha traducido, como vimos, en una práctica fuerte de control en el sistema.

En el escenario descrito, me parece que mejorar la posibilidad de controlar la admisibilidad de la prueba pericial en la APJO supone introducir dos modificaciones legales. Por una parte, que se regule una regla específica que establezca exigencias de admisibilidad especiales a este tipo de prueba ${ }^{212}$ y que se contemple otra que de manera directa le permita al juez excluir o no admitir la prueba pericial presentada en la APJO que no cumpla con estos requisitos especiales. $^{213}$

Una segunda materia de perfeccionamiento legal podría darse tratándose de reglas que regulan el descubrimiento o de acceso a información sobre la prueba pericial que se pretende introducir a juicio. Esto supone regular un momento claro para el acceso de todos los intervinientes al informe pericial de manera previa a la APJO para poder facilitar su

\footnotetext{
${ }^{210}$ Recomiendo revisar la bibliografía citada en nota 125 que da cuenta de este desarrollo tanto en países de tradición anglosajona como europeo continentales. Aclaro también que esta tendencia se da tratándose de sistemas que cuentan con jurados y otros de jueces profesionales. Por ejemplo, en Canadá no existe en materia penal el derecho a que todos los casos sea juzgados por un jurado como en los Estados Unidos, pero igualmente se ha desarrollado una fuerte tendencia a elevar criterios de admisibilidad de la prueba pericial. También en muchos de los países de tradición anglosajona estas reglas especiales de admisibilidad se aplican a procesos civiles que son conocidos y resueltos por jueces profesionales. Es por estas razones que identificar barreras adicionales de admisibilidad con juicios por jurados es en la actualidad del derecho comparado un error.

${ }^{211}$ Se plantea que el CPP contempla al menos tres requisitos específicos de admisibilidad especiales: necesidad del peritaje, idoneidad del experto, confiabilidad de la prueba. Véase: DUCE, "Admisibilidad de la Prueba Pericial", cit. nota ${ }^{\circ} 125$, pp.58-86.

${ }^{212}$ Una nueva regla podría más explícitamente plantear lo que la doctrina ha venido sosteniendo son requisitos de admisibilidad previstos en nuestro CPP (necesidad, idoneidad y confiabilidad) y, eventualmente, incorporar otros nuevos, por ejemplo, el de imparcialidad del experto que se ha empezado a discutir recientemente en el ámbito comparado. En general sobre el tema de la imparcialidad en el ámbito comparado, véase: APPAZOV, Expert Evidence, cit. nota n ${ }^{\circ} 28$, pp. 63-84.

${ }^{213}$ El problema en este punto ha sido la comprensión que ha tenido nuestra doctrina y jurisprudencia de los alcances de la libertad probatoria, ya que se ha entendido que ella flexibiliza a tal punto la introducción de prueba que permite el ingreso de todo tipo de fuente de información de cualquier manera, lo que impediría a los jueces de garantía rechazar prueba por fuera de los casos de exclusión contemplados en el artículo 276 del CPP. Como en dicha regla no hay una causal de exclusión asociada a los requisitos especiales de admisibilidad de la prueba pericial, muchos jueces consideran que no pueden sino admitir esta evidencia, aún cuando sea claro el incumplimiento de estas exigencias especiales. Un argumento en contra de esta comprensión, sosteniendo que el artículo 295 del CPP le permite a los jueces no admitir prueba pericial que no cumpla con los requisitos de admisibilidad especiales exigidos por el CPP puede verse en: DUCE, "Los Informes en Derecho", cit. nota $\mathrm{n}^{\circ} 130$, p. 324-325.
} 
DUCE, Mauricio. “Una aproximación empírica al uso y prácticas de la prueba pericial en el proceso penal Chileno a la luz de su impacto en los errores del sistema".

estudio, debatir sobre su admisibilidad en la misma ${ }^{214}$ y eventualmente para luego preparar su confrontación en juicio. Además, se hace necesario mejorar los contenidos de los informes, es decir, los aspectos que debiera incluir. En mi opinión, el artículo 315 del CPP que regula esta materia contiene exigencias bastante razonables, pero podría ser mejorado en dos órdenes de cuestiones. Por una parte, exigir la inclusión en los informes de mayor información en aspectos curriculares de los peritos. Por ejemplo, se podría incluir un listado de casos judiciales en los últimos años que han comparecido como peritos, identificando la parte que los convocó, y también una lista de publicaciones en el área si las tienen. Además, se podría agregar la exigencia de incluir la especificación de las remuneraciones obtenidas por efectuar el peritaje (en caso de quienes la reciban). ${ }^{215}$

Otra mejora posible en relación al descubrimiento de la prueba pericial debiera estar en la regulación de lo que podría identificarse como los anexos de los informes escritos. Muchos de las opiniones de los expertos se construyen a partir de entrevistas con las víctimas (las que son registradas), fotografías tomadas a lugares, prácticas de test de diversa índole al periciado, etc. Como se vio en el capítulo previo, lo normal es que dicho material no esté disponible ni sea acompañado junto con el informe. Esto dificulta el análisis en profundidad de la calidad del trabajo pericial. En esta dirección, una norma podría fijar un estándar más claro que el vigente en términos de la necesidad de incluir estos materiales como anexos del informe escrito o, en el peor de los casos, una regla que obligue a su custodia permitiendo su acceso a la contraparte.

Finalmente, una tercera área de perfeccionamiento legal podría darse tratándose de las reglas que regulan la presentación de la prueba pericial en el juicio de manera de mejorar el escenario de su producción y control. Una primera cuestión se refiere a la regla del artículo 329 inciso tercero del CPP que regula la declaración del perito en juicio de una manera distinta a la de los testigos señalando que los peritos deben iniciar su declaración exponiendo brevemente el contenido y conclusiones de su informe. Como se vio en el capítulo anterior, esta regla ha generado una práctica bastante formalista en la producción de la prueba pericial, afectando la calidad de la información que los jueces reciben para valorarla. Lo lógico sería eliminar esta regulación especial y someter al perito a las mismas reglas que rigen para testigos, es decir, la declaración por vía de las preguntas que formula el interviniente que lo trae. ${ }^{216}$

En el ámbito de incrementar los controles y confrontación de esta prueba en juicio, un avance potencial podría ser regular una regla que, de manera explícita, impida al perito en juicio abordar temas relevantes no considerados en su informe pericial, de manera de evitar

\footnotetext{
214 En este punto el principal problema en nuestra legislación se da tratándose de la prueba pericial que intenten presentar defensores y potencialmente querellantes. Tratándose de la del Ministerio Público, por aplicación del artículo 260 del CPP, los informes escritos debieran estar disponibles en el peor de los casos en la carpeta investigativa que se ha puesto a disposición junto con la acusación.

215 Se trata de aspectos que son recogidos en la legislación comparada, por ejemplo, en las Reglas Federales de Proceso Civil de los Estados Unidos, regla 26 a) 2.B. http://www.law.cornell.edu/rules/frcp/rule 26 [Visitado el 02.02.2017].

${ }^{216}$ Se trata de una recomendación que desde hace tiempo viene planteada desde la lógica de la litigación en nuestro país. Véase: BAYTELMAN, Andrés; DUCE, Mauricio, Litigación Penal. Juicio Oral y Prueba, Santiago: Ediciones Universidad Diego Portales, 2004, pp. 306-308.
} 
Polít. crim. Vol. 13, No 25 (Julio 2018) Art. 2, pp. 42-103.

[http://www.politicacriminal.cl/Vol_13/n_25/Vol13N25A2.pdf]

la práctica que fue identificada en el capítulo anterior de "peritos que hablan más de lo que escriben" que, como vi, todavía pareciera ser tolerada por un grupo importante de jueces. Además, me parece que habría que pensar la posibilidad de introducir algunos mecanismos de confrontación directa entre peritos en casos de disputas de opiniones expertas en juego difíciles de resolver. En esta línea Vázquez, tomando como base la regla 35.12 de la Reglas de Procedimiento Civil de Reino Unido, ha argumentado la posibilidad de generar confrontaciones directas entre expertos. Así, ha sostenido que "Este tipo de mecanismos adecuadamente concebidos podrían ayudar a la mejor comprensión de parte del juez, a que las partes se aseguren precisamente de dicha comprensión y, por supuesto, para una adecuada valoración de la prueba". 217

Como señalé, no es el objetivo de este trabajo perfilar todas y de manera específica las reformas legales posibles, sino más bien indicar que a partir de los problemas identificados en esta investigación surgen desafíos a nuestro sistema de justicia penal en diversos niveles que debiéramos comenzar a discutir antes de darnos cuenta que puede ser un poco tarde.

${ }^{217}$ VÁZQUEZ, Carmen, De la Prueba Científica a la Prueba Pericial, Madrid: Marcial Pons, 2015, p. 263. 
DUCE, Mauricio. “Una aproximación empírica al uso y prácticas de la prueba pericial en el proceso penal Chileno a la luz de su impacto en los errores del sistema".

\section{Bibliografía}

APPAZOV, Artur, Expert Evidence and International Criminal Justice, Suiza: Springer, 2016.

BAYTELMAN, Andrés; DUCE, Mauricio, Litigación Penal. Juicio Oral y Prueba, Santiago: Ediciones Universidad Diego Portales, 2004.

CAROCCA, Alex, El Nuevo Sistema Procesal Penal Chileno, 4ta Edición, Santiago: Thomson Reuters, 2008.

COLLEY, Craig; TURVEY, Brent, "Forensic reform", en TURVEY, Brent y COLLEY, Craig, Miscarriages of justice, Oxford: Elsevier Academic Press, 2014, pp. 339357.

CONDEMARÍN, Patricia; MACURÁN, Greter, Peritajes Psicológicos sobre los Delitos Sexuales, Santiago: Editorial Jurídica de Chile, 2005.

CUTLER, Brian; ZAPF, Patricia (ed.), APA Handbook of Forensic Psychology, Vol.1. Individual and Situational Influences in Criminal and Civil Contexts, Washington: American Psychological Association, 2014.

CUTLER, Brian; ZAPF, Patricia (ed.), APA Handbook of Forensic Psychology, Vol. 2. Criminal investigation, adjudication, and sentencing outcomes, Washington: American Psychological Association, 2015.

Defensoría Penal Pública, Memoria 2013, Santiago: Defensoría Penal Pública, 2013, en: http://www.dpp.cl/resources/upload/files/documento/3a11ed0c600a87c84d4b07eaff c937c3.pdf [Visitado el 02.02.2017].

Defensoría Penal Pública, Memoria 2014, Santiago: Defensoría Penal Pública, 2014, pp. 72-74, 235, en:

http://www.dpp.cl/resources/upload/files/documento/3a11ed0c600a87c84d4b07eaffc937c3. pdf [Visitado el 02.02.2017].

Defensoría Penal Pública, Memoria 2015, Santiago: Defensoría Penal Pública, 2015, pp. 68-70, 258, en:

http://www.dpp.cl/resources/upload/files/documento/c3b8389eb0ae9ec02148e4225368f58b .pdf [Visitado el 02.02.2017]. 
Polít. crim. Vol. 13, $\mathrm{N}^{\circ} 25$ (Julio 2018) Art. 2, pp. 42-103.

[http://www.politicacriminal.cl/Vol_13/n_25/Vol13N25A2.pdf]

DOMEYKO, Antonia, “La Denuncia: el Duro Camino de una Violación”, en: Revista Ya, $\mathrm{n}^{\circ} 1714,2016$, pp. 38-41.

DUCE, Mauricio, La Prueba Pericial, Buenos Aires: Ediciones Didot, 2013.

DUCE, Mauricio, "Los Informes en Derecho Nacional y su Admisibilidad como Prueba a Juicio en el Proceso Penal Chileno", Revista de Derecho (Valdivia), vol. 29, $\mathrm{n}^{\circ} 1$ (2016), pp. 297-327.

DUCE, Mauricio, “Admisibilidad de la Prueba Pericial en Juicios Orales: un Modelo para Armar en la Jurisprudencia Nacional", en: ACCATINO, Daniela (coord.), Formación y Valoración de la Prueba en el Proceso Penal, Santiago, AbeledoPerrot, 2010, pp. 45-86.

EDMOND, Gary, "Actual Innocents? Legal Limitations and Their Implications for Forensic Science and Medicine", Australian Journal of Forensic Sciences, vol. 43, $\mathrm{n}^{\circ}$ 2-3 (2011), pp. 177-212.

EDMOND, Gary, "Expert Evidence in Report and Courts", Australian Journal of Forensic Sciences, vol. 45, $\mathrm{n}^{\circ} 3$ (2013), pp. 248-262.

FORST, Brian, "Wrongful Convictions in a World of Miscarriages of Justice", en: HUFF, Ronald; KILLIAS, Martin (Eds.), Wrongful Conviction and Miscarriages of Justice: Causes and Remedies in North American and European Criminal Justice Systems, New York: Routledge, 2013, pp. 15-43.

FPT Heads of Prosecutions Committee Working Group, Report on the Prevention of Miscarriages of Justice, Canadá: Department of Justice, 2004.

FPT Heads of Prosecutions Committee, The Path to Justice: Preventing Wrongful Convictions, Canadá: FPT Heads Of Prosecutions Committee, 2011.

FRECKELTON, Ian; GOODMAN-DELAHUNTY, Jane; HORAN, Jacqueline, y McKIMMIE, Blake, Expert Evidence and Criminal Jury Trials, Oxford: Oxford University Press, 2016.

GARRET, Brandon, Convicting the Innocent: Where Criminal Prosecutions Go Wrong, United States: Harvard University Press, 2011.

GARRET, Brandon; NAUFELD, Peter, "Invalid Forensic Testimony and Wrongful Convictions", Virginia Law Review, vol. 95, nº 1 (2009), pp. 1-97.

HARRIS, David, Failed Evidence: Why Law Enforcement Resists Science, New York: New York University Press, 2012. 
DUCE, Mauricio. “Una aproximación empírica al uso y prácticas de la prueba pericial en el proceso penal Chileno a la luz de su impacto en los errores del sistema".

HIRSCHBERG, Max, La Sentencia Errónea en el Proceso Penal, Trad.: BANZHAF, Tomas A., Buenos Aires: Ediciones Jurídicas Europa-América, 1969.

JACKSON, John D.; SUMMERS, Sarah J., The Internationalisation of Criminal Evidence: Beyond the Common Law and Civil Law Traditions, Cambridge: Cambridge University Press, 2012.

JARA, Matías; ALBERT, Carolina, "Tribunales de Familia: las Graves Deficiencias del Sistema de Peritos, en: CIPER Chile, 2016, en: http://ciperchile.cl/2016/08/30/tribunales-de-familia-las-graves-deficiencias-delsistema-de-peritos/ [Visitado el 02.02.2017].

JIAHONG, He, Back from the Dead: Criminal Justice and Wrongful Convictions in China, Honolulu: University of Hawai'i Press, 2016.

KOEN, Wendy y BOWERS, Michael, Forensic science reform: protecting the innocent, London: Elsevier, 2017.

MACURÁN, Greter, La Prueba Pericial Psicológica en los Delitos de Abuso Sexual Infantil, Santiago: Editorial Jurídica de Chile, 2011.

MAIER, Julio, Derecho Procesal Penal, Tomo III Parte General. Actos Procesales, Buenos Aires: Editores del Puerto, 2011.

MAFFIOLETTI, Francisco (ed.) et al, "Evaluación Pericial Psicológica de Credibilidad de Testimonio: Documento de Trabajo Insterinstitucional”, en: Revista Jurídica del Ministerio Público, no 34, 2008, pp. 215-253.

MATURANA, Cristián; MONTERO, Raúl, Derecho Procesal Penal, Tomo II, Santiago: AbeledoPerrot, 2010.

Ministerio Público de Chile, Boletín Estadístico Anual 2013, Santiago: Ministerio Público de Chile, 2014, en: http://www.fiscaliadechile.cl/Fiscalia/estadisticas/index.do?d1=0 [Visitado el 02.02.2017].

Ministerio Público de Chile, Boletín Estadístico Anual Enero-Diciembre 2015, Santiago: Ministerio Público de Chile, 2016, en:

http://www.fiscaliadechile.cl/Fiscalia/estadisticas/index.do?d1=0 [Visitado el 02.02.2017].

National Research Council, Strengthening Forensic Science in the United States: A Path Forward, Washington: The National Academies Press, 2009, pp. 1-33. Disponible en:

https://www.ncjrs.gov/pdffiles1/nij/grants/228091.pdf [Visitado el 2 de febrero de 2017]. 
Polít. crim. Vol. 13, No 25 (Julio 2018) Art. 2, pp. 42-103.

[http://www.politicacriminal.cl/Vol_13/n_25/Vol13N25A2.pdf]

National Research Council, Identifying the Culprit: Assessing Eyewitness Identification, Washington D.C.: The National Academies of Sciences, Engineering, and Medicine, 2014.

NAUGHTON, Michael, The Innocent and the Criminal Justice System. A Sociological Analysis of Miscarriages of Justice, United Kingdom: Palgrave Macmillan, 2013.

QUIJADA, Diego, “Aportes al Debido Proceso Penal en Evaluación Pericial Psicológica y Psiquiátrica a Imputados en Delitos Sexuales: ¿Existe Eelación de Coherencia entre Solicitud y Respuesta Pericial?”, en: FUENTES, Claudio (Comp.), Diez Años de la Reforma Procesal Penal en Chile, Santiago: Ediciones Universidad Diego Portales, 2011, pp. 457-499.

ROXIN, Claus, Derecho Procesal Penal, 25 Edición, Trad.: CÓRDOBA, Gabriela; PASTOR, Daniel, Buenos Aires: Editores del Puerto, 2003.

ROACH, Kent, "Wrongful Convictions: Adversarial and Inquisitorial Themes", North Carolina Journal of International Law and Commercial Regulation, vol. 35, $\mathrm{n}^{\circ} 2$ (2010), pp. 387-446.

SAKS, Michael; SPELLMAN, Barbara, The Psychological Foundations of Evidence Law, New York: New York University Press, 2016.

SANTIBANEZZ, Martina, Uso de la prueba pericial en juicio oral de connotación sexual, Santiago: Trabajo final para titulación del Magíster en Derecho Penal y Procesal Penal, Universidad Diego Portales, 2016.

The Law Commission, Expert Evidence in Criminal Proceedings in England and Wales, London: Stationary Office, Law Com. $\mathrm{N}^{\circ} 325,2011$, p.1. Disponible en:

https://www.gov.uk/government/uploads/system/uploads/attachment_data/file/229043/082

9.pdf [Visitado el 2 de febrero de 2017].

THOMAS, Sabra, “Addressing Wrongful Convictions: An Examination of Texas's New Junk Science Writ and other Measures for Protecting the Innocent", Houston Law Review, n ${ }^{\circ} 22$ (2015), pp. 1037- 1068.

VÁZQUEZ, Carmen, Estándares de Prueba y Prueba Científica. Ensayos de Epistemología Jurídica, Madrid: Marcial Pons, 2013.

VÁZQUEZ, Carmen, De la Prueba Científica a la Prueba Pericial, Madrid: Marcial Pons, 2015.

VILLARRUBIA, Gustavo: FIGUEROA, Juan Pablo, "La Dolorosa Ruta Judicial que Recorren los Niños Abusados Sexualmente", en: CIPER Chile, 2010, en: 
DUCE, Mauricio. "Una aproximación empírica al uso y prácticas de la prueba pericial en el proceso penal Chileno a la luz de su impacto en los errores del sistema".

http://ciperchile.cl/2013/10/28/la-dolorosa-ruta-judicial-que-recorren-los-ninosabusados-sexualmente/

VRIJ, Aldert, Detecting Lies and Deceit, West Sussex: Wiley, 2008.

WELLS, Gary L.; GREATHOUSE, Sarah M.; SMALARZ, Laura, Why do Motions to Suppress Suggestive Eyewitness Identifications Fail?, Washington D.C.: American Psychological Association, 2012.

\section{Jurisprudencia}

Corte de Apelaciones de Antofagasta, Sentencia de 3 de septiembre de 2010, rol n ${ }^{\circ} 276-$ 2010

Corte de Apelaciones de Arica, Sentencia de 7 de julio de 2010, rol nº 145-2010.

Corte de Apelaciones de Puerto Montt, Sentencia de 8 febrero de 2010, rol nº 267-2009.

Corte de Apelaciones de Rancagua, Sentencia de 23 de mayo de 2013, rol n 199-2013.

Corte de Apelaciones de Santiago Sentencia de 21 de octubre de 2009, rol nº 2130-2009.

Corte de Apelaciones de Santiago Sentencia de 2 de septiembre de 2011, rol no 1756-2011

Corte de Apelaciones de San Miguel, Sentencia de 5 de junio de 2007, rol nº 802-2007.

Corte de Apelaciones de San Miguel, Sentencia de 12 octubre de 2007, rol nº 815-2007.

Corte de Apelaciones de San Miguel, Sentencia de 12 de octubre de 2007, rol n ${ }^{\circ} 1392-$ 2007.

Corte de Apelaciones de Valparaíso, Sentencia de 29 de abril de 2016, rol n 644-2016.

Corte Suprema, Sentencia de 17 de junio de 2013, rol n 2866-2012.

Corte Suprema, Sentencia de 21 de julio de 2014, rol n 11.115-2014.

Corte Suprema, Sentencia de 11 de marzo de 2015, rol n 448-2015. 
Polít. crim. Vol. 13, № 25 (Julio 2018) Art. 2, pp. 42-103.

[http://www.politicacriminal.cl/Vol_13/n_25/Vol13N25A2.pdf]

\section{Anexo Metodológico}

Este anexo tiene por objeto proveer información más detallada sobre la metodología de esta investigación y, en particular, sobre su componente de entrevistas. Se trató de entrevistas semi-estructuradas elaboradas sobre una matriz común de preguntas generales, pero que incluyeron componentes diferenciados por rol. Estas entrevistas se caracterizan por estructurarse sobre una pauta que se define en forma previa de acuerdo a los objetivos perseguidos por la investigación, pero que sólo sirve de base ya que incluye temas generales sin entrar en preguntas sobre los detalles específicos. Esto permite que el entrevistador indague con un margen de libertad a partir de las respuestas obtenidas y pueda profundizar sobre aspectos de interés o incluir cuestiones nuevas no previstas originalmente.

Todas las pautas cubrieron cinco áreas temáticas principales: calidad y rigurosidad peritajes y de los peritos; imparcialidad de los peritos; calidad del litigio; valoración de la prueba pericial; y, otros aspectos relevantes. Las pautas utilizadas por cada categoría de entrevistados están disponible en los archivos del proyecto que guarda el investigador responsable, pero se reproduce a manera ejemplar la pauta diseñada para jueces de garantía en la parte final de este anexo.

Las entrevistas fueron ejecutadas en el período del mes de mayo de 2015 y noviembre de 2016. Su duración fue en promedio de una hora. En cada una de ellas los entrevistaron fueron informados de sus derechos y prestaron su consentimiento. Copia de dichos consentimientos informados se encuentran en poder del autor de este trabajo de acuerdo a las pautas que exige Fondecyt.

Las entrevistas fueron grabadas digitalmente y transcritas en forma completa por un equipo de colaboradores técnicos del proyecto, todos estudiantes de derecho de cursos avanzados de la carrera. Como se ha señalado en la introducción, se trató de 52 entrevistas que incluyeron a 13 fiscales, 8 defensores, 9 jueces de garantía, 9 jueces de tribunales de juicio oral, 6 abogados particulares y 7 peritos. En el caso de los jueces, se tomaron los listados disponibles en la página web del Poder Judicial y se escogieron nombres de tribunales diversos que fueron contactados luego por correo electrónico programándose la entrevista de acuerdo a las respuestas recibidas. En el caso de fiscales y defensores se recurrió, en primer lugar, a personas conocidas por el investigador responsable en las distintas oficinas regionales y luego se pudo acceder a otros por medio de referencias. En el caso de los abogados, se buscó identificar abogados de distintos perfiles de ejercicio profesional conocidos por el investigador principal. Procedimiento similar se utilizó tratándose de los peritos, pero focalizándome centralmente en dos áreas de prueba pericial en dónde se investigó información complementaria que permitiera tener un cuadro más completo de las mismas (psicología forense y medicina legal).

Las entrevistas fueron realizadas individualmente por el investigador responsable (31 entrevistas, 59,6\% del total) o los ayudantes del proyecto (21, 40,3\% del total). Los actores involucrados son todos funcionarios de sus respectivas instituciones que se desempeñaban a 
DUCE, Mauricio. “Una aproximación empírica al uso y prácticas de la prueba pericial en el proceso penal Chileno a la luz de su impacto en los errores del sistema".

la fecha de la entrevista en la Región Metropolitana, aún cuando varios tenían experiencia previa en otras regiones del país. En el caso de los peritos casi todos tenían experiencia también en regiones.

La selección de los entrevistados se hizo intentando buscar diversidad de experiencias en atención a las diferenciase en las prácticas que se pueden observar en distintas zonas de la Región Metropolitana. Para ello entonces se intentó cubrir distintas jurisdicciones en cada rol y diversidad de género. Tratándose de los fiscales, los entrevistados pertenecen a tres de las cuatro fiscalías regionales metropolitanas (cuatro de la Centro Norte, seis de la Oriente y tres de la Sur). En el caso de los defensores ellos forman parte de las dos unidades regionales de la Región Metropolitana (cinco de la Norte y tres de la Sur). Los jueces de garantía y de juicio oral corresponden a ocho y nueve juzgados diferentes de la Región Metropolitana respectivamente. Respecto a los abogados entrevistados, cuatro llevan adelante ejercicio libre en el área penal y dos trabajan en una institución privada que presta asesorías en la materia. Tratándose de peritos, dos desarrollan su actividad en un organismo auxiliar y cinco de manera privada, pero dos de ellos habían trabajado en períodos previos en dichas instituciones.

En cuanto a las características de género de los entrevistados, 22 de ellos, es decir, un $42,3 \%$, correspondió a mujeres y $30(57,7 \%)$ hombres. Por categorías, la menor presencia de mujeres se dio en los abogados privados en donde ellas fueron un 30,8\%. En cambio, tratándose de jueces de juicio oral, ellas representaron el 55,5\% de los entrevistados.

\section{EJEMPLO: PAUTA DE ENTREVISTA SEMI-ESTRUCTURADA FORMATO JUECES DE GARANTÍA}

\section{Uso de prueba pericial}

(Versión 11 de junio 2015)

- ¿Qué opinión tiene sobre la rigurosidad de los peritajes y de los peritos en el medio nacional? Distinción por principales áreas e instituciones

- ¿Cómo evalúa la capacidad técnica y logística de los organismos auxiliares para producir peritajes de calidad y confiables? Distinguir por instituciones:

- SML (físicos y psiquiátricos)

- Laboratorios policías

- Instituto de salud Pública

- Otros

- ¿Estima que puede haber problemas con la falta de imparcialidad, producto del rol que cumplen, de las instituciones que producen pericias en nuestro medio?

- ¿Qué opinión tiene sobre la calidad y completitud de los informes escritos de los peritajes? ¿qué problemas enfrenta respecto a ellos?

- ¿Existen debates sobre admisibilidad de peritajes en la APJO? ¿qué argumento y causal? ¿Con qué frecuencia? intentar categorizar: habitualmente, algunas veces, en casos excepcionales ¿qué resultados?

- ¿Con qué frecuencia se presentan cuestionamientos a la prueba pericial en juicio simplificado? intentar categorizar: habitualmente, algunas veces, en casos excepcionales ise trata de cuestionamientos pertinentes y eficaces? 
Polít. crim. Vol. 13, No 25 (Julio 2018) Art. 2, pp. 42-103.

[http://www.politicacriminal.cl/Vol_13/n_25/Vol13N25A2.pdf]

- ¿Es común que los peritos declaren en juicio simplificado elementos adicionales a los contenidos en sus informes? intentar categorizar: habitualmente, algunas veces, en casos excepcionales ¿de qué magnitud?

- ¿Cree usted que los jueces cometen errores o evalúan de manera correcta de la prueba pericial? ¿Qué errores? ¿Por qué?

- ¿Los fiscales y defensores cuentan con capacitación y destrezas adecuadas para lidiar con peritos en disciplinas técnicas?

- ¿Ha recibido capacitación institucional en la materia? SI / NO ¿En qué consistió?

- ¿Es frecuente el uso de "metapericias" en juicio simplificado? intentar categorizar: habitualmente, algunas veces, en casos excepcionales ¿Qué opina usted de ellas? ¿debieran ser admitidas? ¿Son valoradas por los jueces en su experiencia?

- ¿En dónde ve usted los principales problemas en el uso de prueba pericial? ¿Qué recomendaría para superar esos problemas? 